\title{
QUEERING GAY MALE BODY DISSATISFACTION
}

\author{
by
}

Alexander T. Vasilovsky, H.B.Sc. (University of Toronto, June 2009)

\author{
A thesis \\ presented to Ryerson University \\ in partial fulfillment of \\ Master of Arts \\ in the Program of \\ Clinical Psychology \\ Ryerson University
}

Toronto, Ontario, Canada, 2012

(C)Alexander T. Vasilovsky 2012 


\section{Author's Declaration}

I hereby declare that I am the sole author of this thesis. This is a true copy of the thesis, including any required final revisions, as accepted by my examiners.

I authorize Ryerson University to lend this thesis to other institutions or individuals for the purpose of scholarly research

I further authorize Ryerson University to reproduce this thesis by photocopying or by other means, in total or in part, at the request of other institutions or individuals for the purpose of scholarly research.

I understand that my thesis may be made electronically available to the public. 


\section{Abstract}

Queering Gay Male Body Dissatisfaction

Master of Arts, November 2012

Alexander T. Vasilovsky

Clinical Psychology

Ryerson University

A sizable body of psychological research suggests that gay men exhibit greater body dissatisfaction than heterosexual men. However, much of this research has been critiqued for presenting explanatory models that pathologize homosexuality by suggesting that it is the cause of gay male body dissatisfaction. This thesis relied on the voices of 19 gay/queer men/genderqueers to problematize the explanatory models' characterization of gay identities, communities, and body ideals as monolithic. The participants expressed ideas that were antithetical to the explanatory models' restrictive formulations of homosexuality. Additionally, this thesis developed a theory of gay/queer embodiment based on the Foucauldian concept of subjection. How the participants negotiated embodied gay and queer identities was explored in relation to larger discursive regimes of power, like heterosexism, hegemonic masculinity, and neo-liberalism. Specific attention was given to queer forms of embodied resistance. 


\section{Acknowledgements}

This thesis was financially supported by the Social Sciences and Humanities Research Council of Canada. I want to thank my supervisor, Dr. Maria Gurevich, for her support, guidance, and invaluable input throughout all stages of my thesis' construction. I have been initiated into a world of academic inquiry that has proven to be revelatory, personally, politically and otherwise. Additionally, I want to thank my thesis committee - Drs. Kelly McShane and Stephanie Cassin - for their thoughtful, insightful reviews of my thesis, Nataliya Uzerina for her painstakingly detailed, accurate transcription work, and the gay/queer men/genderqueers whom I interviewed, because my thesis would not exist without them. Lastly, I want to thank Ryerson University's Gender, Sexuality, and Critical Psychology Laboratory for fostering such a lovely intellectual environment that continually challenges my world view. 


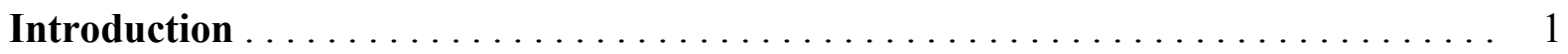

Queering gay male body dissatisfaction $\ldots \ldots \ldots \ldots \ldots \ldots \ldots \ldots \ldots \ldots \ldots \ldots$

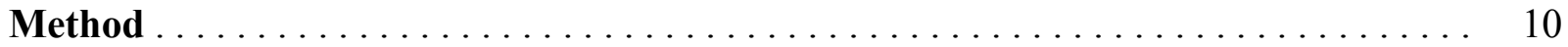

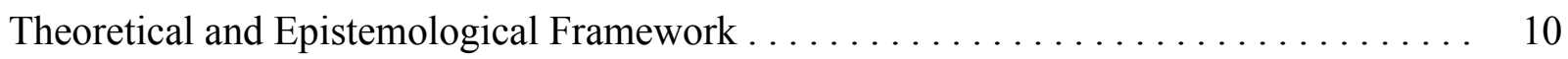

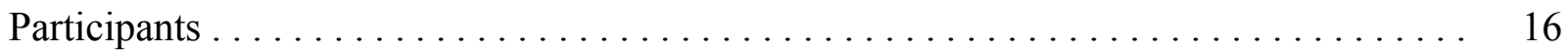

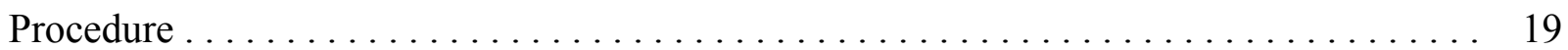

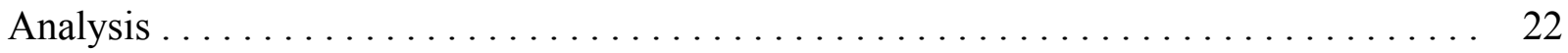

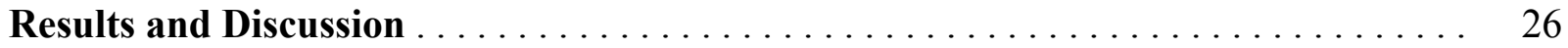

The gay male body dissatisfaction imperative $\ldots \ldots \ldots \ldots \ldots \ldots \ldots$

Gay identities, communities, and body ideals . . . . . . . . 37

Heterosexism, hegemonic masculinity, neo-liberalism, and queer epistemology . . . . . 58

Heterosexism, hegemonic masculinity, and neo-liberalism . . . . 63

Shame/masculine compensation . . . . . 84

Neo-liberalism and gay equality . . . . . 97

Embodied queer resistances . . . . . . . . . . . . . . 108

Conclusions and Future Directions $\ldots \ldots \ldots \ldots \ldots \ldots \ldots \ldots \ldots \ldots \ldots \ldots$

References .............................. 124

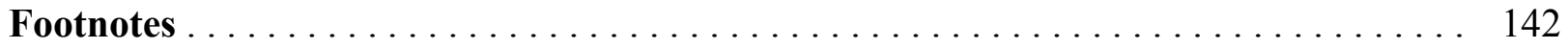

Table $1 \ldots \ldots \ldots \ldots \ldots \ldots \ldots \ldots \ldots \ldots \ldots \ldots \ldots \ldots \ldots \ldots \ldots \ldots \ldots$

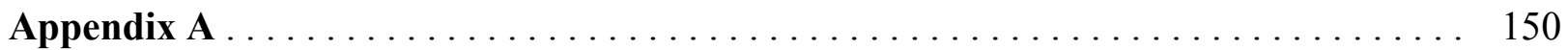

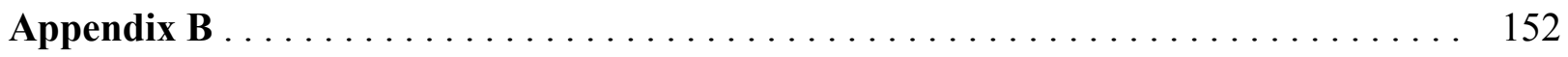

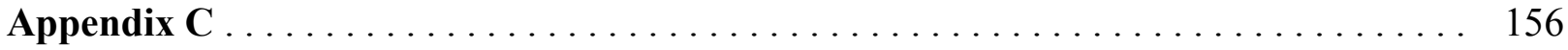




\section{Queering Gay Male Body Dissatisfaction}

How is the gay/queer male body fashioned through and by psychology? Almost invariably, it is positioned within discourses about body dissatisfaction (Duncan, 2010a; Kane, 2009, 2010). Body image is the experience of embodiment, a composite of our attitudes about (i.e., body satisfaction) and perceptions of our bodies (Cash \& Smolak, 2011). While certainly not unequivocal, a large body of psychological research implies that gay men exhibit greater body image disturbance, body dissatisfaction and disordered eating, and lower body esteem than heterosexual men (e.g., Lakkis, Ricciardelli, \& Williams 1999; Schneider, O’Leary, \& Jenkins, 1995). Most quantitative studies are cross-sectional and involve comparing gay men to heterosexual men (as well as lesbians to heterosexual women) on a battery of measures to ascertain who is most dissatisfied. Measures typically include: Likert-type rating scales that evaluate satisfaction with one's overall appearance; single-item measures and checklists that assess satisfaction with different parts of the body; and body size drawings that provide self-ideal discrepancy appraisals (Morrison, Morrison, \& Sager, 2004). A recent meta-analysis (Morrison et al., 2004) synthesized the results of 27 studies - 20 published and seven unpublished conducted between 1983 and 2003 that compared the difference in body satisfaction between 1,397 heterosexual men and 984 homosexual men. The studies produced an average weighted effect size of 0.24, a small effect (Cohen, 1992), which nonetheless permitted Morrison et al. (2004) to conclude that gay men are most unhappy with their physical appearance.

A close reading of the literature reveals that the results of studies purporting to reveal greater body dissatisfaction among gay men are also not always straightforward. For instance, Martins, Tiggemann, and Kirkbride (2007) compared 98 gay men to 103 heterosexual men and concluded that gay men demonstrated higher levels of self-objectification, body surveillance, 
body shame, drive for thinness, and upper and lower body dissatisfaction, though "further analyses" (p. 639) revealed that some of the authors' results were non-significant (moreover, effects sizes were not reported). These results that seem less supported by their statistical analyses than by the belief that "physical attractiveness" (p. 636) is necessarily of "increased importance" (p. 636) to all gay men. Gil (2007) wrote that the gay men in his study reported both lowers levels of ideal body image and ideal-actual body image difference, as well as less selfacceptance than heterosexual men for which he censured "gay male subculture" (p. 241) and gay men's need "to establish their sense of personal and narcissistic worth based on their physical appearance" (p. 242). Gay men did report lower levels of "ideal" body size as measured by a contour drawing rating scale, but they also reported lower levels of "actual" body size; thus, their low ideal-actual body image difference simply indicated that there was a smaller discrepancy between their ideal and actual body sizes. Furthermore, on the same inventory Gil (2007) used to establish gay men's lower self-acceptance, heterosexual men scored significantly lower on "autonomy" (and lower, but not significantly so, on "personal growth" and "positive relation with other"). Duggan and McCreary (2004) likewise summarized their study by declaring that gay men possessed "poorer eating attitudes and a greater desire to be thin" (p. 55). This declaration does not seem wholly demonstrative of the researchers' discovery that two out of three measures of body dissatisfaction revealed no significant differences between gay and heterosexual men. Williamson and Spence (2001) found that the most powerful predictor of eating disturbance among gay men was internalized cultural beliefs about the importance of slimness, which was based on a measure not validated for use with men. The authors created a series of leading items designed to ascertain the participants' "gay developmental histories" (p. 220 ) - such as, "Most people on the gay scene are particularly body conscious," which $65.9 \%$ of 
the participants endorsed. This led them to summarize their results as follows: "Gay men generally perceived that attractive appearance was highly valued by other members of the gay community" (p. 223). Such an abridgment belies their finding that a sense of alienation from the "gay scene" actually predicted increased body dissatisfaction. Chaney (2008) supported "the idea that gay and bisexual men may be more susceptible to [muscle dysmorphia] compared to heterosexual men" (p. 166) based on "the findings reported [in his study]" (p. 166) though he did not actually perform such a comparison. Countless other examples exist of researchers evaluating gay men against a heterosexual norm and "discovering" a lack or deficiency while discounting or dissembling repudiating evidence.

Kane (2009) has also noted that several authors have found no difference or few, often trivial, differences between gay and heterosexual men (e.g., Brand, Rothblum, \& Solomon, 1992; Olivardia, Pope, \& Hudson, 2000; Olivardia, Pope, Mangweth, \& Hudson, 1995; Pope, Hudson, \& Jonas, 1986). Boroughs and Thompson (2002) administered five body image and eatingrelated measures to 134 gay and heterosexual participants; they found some marginally significant effects for sexual orientation, but, mainly, no difference. Pope, Phillips, and Olivardia (2000) analyzed 49 gay men's attitudes toward body image and determined that both gay and heterosexual men desired a more muscular body; the only dissimilarity was a smaller discrepancy between the gay men's ideal body and their actual muscularity. Likewise, Hausmann, Mangweth, Walch, Rupp, and Pope (2004) found that gay men were indistinguishable from a comparison group of heterosexual men on measures of body ideal and body image distortion. Even the results of a study (Yelland \& Tiggemann, 2003) oft-cited as a conspicuous illustration of gay men's greater desire to embody a lean, but muscular mesomorphic body ideal are quite equivocal: though gay men did exhibit a significantly greater 
"desired muscularity" than heterosexual men, the researchers found no difference on measures of body esteem, satisfaction with overall body shape and weight, and desired thinness.

Given these results, Pope et al. (2000) suggested that body dissatisfaction "may just be more announced in [gay men], not necessarily more pronounced" (p. 217). That is, both groups of men are similarly worried about the appearance of their bodies, but there exists a cultural injunction that deters heterosexual men from voicing their concerns. Through their clinical work, the authors found that their heterosexual male clients often lacked "body consciousness" and concealed their body dissatisfaction for fear of being viewed as vain, less masculine, or gay. For instance, Silberstein, Mishkind, Striegel-Moore, Timko, and Rodin (1989) concluded that gay men are at greater risk for developing eating disorders based on evidence demonstrating that they tended to emphasize "weight control," "mood," "attractiveness," and "body tone" when asked why they exercise as opposed to heterosexual men who highlighted the importance of "fitness" and "health." This methodological bias - which also includes recruitment strategies that overrepresent heterosexual undergraduates and gay men from clinical populations - led Pope et al. (2000) to caution against any straightforward interpretation of the literature, which has also been critiqued for flaws in its instrumentation and procedures, data analysis, and theoretical formulation. Filiault and Drummond (2009) inspected the methods of 45 peer-reviewed articles concerning body image among gay men from Westernized cultures and similarly discovered a myriad of limitations including, "the need for improved recruitment methods, the precarious role of the Internet in body image research, a need for clarity regarding the definition of homosexuality and bisexuality, a lack of longitudinal data, [and] the need for psychometric standardization" (p. 307). It should be noted, however, that the authors found a number of 
strengths in the literature, such as its inclusion of men at various points in the life cycle in addition to international and transnational perspectives.

The aim of this thesis is to question the manner in which gay men have been "studied" in psychology and demystify the scientific expertise that has established a "specific tenant that gay men are more dissatisfied with their bodies than heterosexual men" (Kane, 2009, p. 31) - what may be referred to as psychology's gay male body dissatisfaction imperative. This thesis does not argue that gay men do not experience body dissatisfaction. Undeniable pressures exist for Western males as a whole to strive for muscular, athletic physiques, typically devoid of fat (Pope, et al., 2000), just as there are, undoubtedly, social hierarchies based on physical appearance in a multitude of gay or queer environments (e.g., Berry, 2007; Drummond, 2005a, 2005b, 2010; Filiault \& Drummond, 2007; Westhaver, 2006; Wood, 2004). Furthermore, this thesis does not delineate all of the quantitative literature's methodological flaws; indeed, others, like Filiault (2010), Filiault and Drummond (2010) and Kane (2009, 2010), have already written excellent critiques. Rather, this thesis documents how psychology's insistence that gay denotes a unitary, transhistorical (i.e., not historically-contingent) meaning (re)produces a dominant mode of identity politics that constructs a circumscribed characterization of homosexuality. Psychology has done more than simply "find" that gay men are more dissatisfied with their bodies than heterosexual men. The theoretical or explanatory models developed by psychologists to "explain" the aforementioned finding are involved in the discursive construction of a particular gay identity: one that is pathologized and exclusively implicated in its own dissatisfaction. The theoretical models, which include "atypical" gender-role behaviour, internalized homophobia/homonegativity, childhood gender non-conformity, minority stress, and objectification, all foreground one's (homo)sexuality as the best explanation of gay male body 
dissatisfaction (Filiault, 2010). Allegedly, something inherent to a gay identity causes gay men to desire to look a certain way, "thereby resulting in greater concern about issues pertinent to the body" (Morrison et al., 2004, p. 130). These theories all present an essentialist understanding of homosexuality, which uncritically buttresses the notion that gay men completely immerse themselves in a narcissistic, body-obsessed homogenous "gay community" where everyone receives a singular media message - that it is indispensable to be attractive and muscular - and is taught to emulate a very specific ideal of beauty. ${ }^{1}$

In order to more accurately theorize body image among gay men, one must operate from a position that acknowledges that (sexual, gender) identity is never fixed, that a gay identity does not connote a unified subject, unstratified "along the lines of class, age, physical fitness, gender, and so forth" (Kong, 2004). Certainly, the lives of gay and heterosexual men are dissimilar along certain axes of difference, but any dissimilarity in body satisfaction should not be attributed to only the purported superficiality of gay men and the "gay community." Focus must be placed on the "hierarchical organisation of masculinities and sexuality in modern social life" (Duncan, 2010b, p. 27) - the manner in which male homosexuality is always marked and subordinate to male heterosexuality. It is difficult to "understand" gay men's body dissatisfaction without exploring the notoriously complicated nexus of sexuality and gender (Sedgwick, 1990) with an awareness of how gay masculinities are positioned within discourses about heterosexism or heteronormativity and hegemonic masculinity. As the few qualitative studies on this matter have demonstrated, a number of social discourses and cultural institutions - like psychology's gay male body dissatisfaction imperative - shape and condition the gay male body. Kong (2004), for instance, appropriated Bourdieu's (1986) notion of class to establish a theory of embodied cultural capital: fit bodies, youthful bodies, wealthy bodies, able bodies - they all embody 
cultural capital. Kong's (2004) approach recognized the function of wider sociocultural influences: the ideal (gay) man is the quintessence of youth and masculinity, he is alternately White, able-bodied, "straight-acting," or all of the above. His embodied cultural capital is established not exclusively by a "gay community" that exists within a cultural vacuum but by the coercive powers of heterosexism and hegemonic masculinity, sexual and gender institutions that doubly subordinate gay male bodies (and identities). Given this discursive backdrop, Kong's (2004) study documented the efforts of several participants to subtly subvert numerous hegemonic ideals while feeling incongruously compelled to publicly adhere to sexual and gender norms. Similarly, Duncan (2010b) interviewed 16 gay men who had experienced and continued to experience dissatisfaction with their bodies, generally, but also within gay social life. Like Kong (2004), the author implicated the manner in which masculinity and sexuality are "organised in terms of heterosexuality" (Duncan, 2010b, p. 28). The participants were aware of the privilege ascribed to particular (toned, masculine) gay bodies, a cognizance that regulated the forms their bodies took, the movements their bodies made, and the adornment their bodies sported within various environments, including a range of mainstream gay and alternative queer communities. Contemporaneously, gay/queer communities and cultures provided sites of resistance to "the limitations placed on gay men in heteronormative society" (p. 27).

Furthermore, as Duncan (2007) argued, if researchers continue to leave under-theorized gay men's multiple positionings within and active embodiments of a heteronormative culture with rather definite ideas about what masculinity is (and what femininity and effeminacy are), the potentiality of gay male embodiment will be left dissembled:

Little attention has been paid to the way gay male identity is tied up with notions of the corporeal. The "doing" of gay identity by way of reflection upon one's body and 
appearance, in relation to discourses about gay male sexuality, gay identity and masculinity, have largely been overlooked. (pp. 333)

Examining gay male body dissatisfaction through a limited focus on narcissism or bodyobsession stifles the expressive, communicative (gay, male) body by failing to explain how it operates as an identity-producing device in its own right (Baerveldt \& Voestermans, 1998). Duncan (2007) noted that concentrating on "the subjectivities of gay men as they reflect upon, contest and live their bodies/identities" (p. 334) in a manner irreducible to dissatisfaction is uncharted theoretical territory. Little attention has been paid to the ways in which one's body plays a role is establishing or denoting one's sexual identity, whether in the context of one's subjection to or rejection of larger discursive regimes of power and ideological practice. In contrast, Duncan (2010a) proposed a focus on "self-reflexive practices" - an examination of gay men negotiating conceptions of the body and identity as a foundation for, or point of entry into, an engagement with "social and political visibility, self-perception, and relationships with other gay men" (p. 438).

The purpose of this thesis is to explore the gay/queer male/genderqueer body outside of the traditional discursive connections between homosexuality, superficiality/irrationality, and body-obsession (Duncan, 2010a). First, this thesis presents a queer, feminist reading of the state of the literature on body image among gay men, which is iteratively informed by the gay and queer participants who were interviewed for this thesis. This reading deconstructs psychology's dominant explanations of gay male body dissatisfaction and reveals how homosexuality is paradigmatically positioned as disordered while the unmarked term - heterosexuality - is allowed to remain unproblematized. Second, the participants' "talk" is organized into a cogent theoretical account of gay/queer male/genderqueer embodiment. Throughout this thesis, the term 
embodiment is used to refer to the body's broad role in social life; that is, "the values, perceptions and gestures that are inscribed in and through the body and how we live these experiences through our bodies" (Wearing, 1996, p. 68). In doing so, this thesis relies on feminist post-structuralist philosophy to explicate how the participants developed their individual understandings of sexual identity and embodiment while navigating discourses about heterosexism and hegemonic masculinity, in particular. Given the gay male body's yoking with dissatisfaction, attention is paid to the other options available to, primarily, the queer participants who challenged the aforementioned discourses through dense, intricate configurations of embodied queer resistances. This thesis is interested in how the body functions as a "producer" of sexual identity and - for the queer participants - queer anti-identity. Working with Drummond's (2005b) admonition that "it is crucial to understand the meaning of body image among gay men in a far more encompassing and broader perspective than the term body image has come to reflect" (Duncan, 2005, p. 287), this thesis asks: What can the body mean, say, or do, when detached from a regulative assignment as a site of dissatisfaction? Thus, concern rests with mitigating what Kane (2009) referred to as the "universal applications and populist assertions" (p. 21) of the literature by querying and queering the epistemological foundations of gay male body dissatisfaction - querying because this thesis problematizes and contextualizes the existing explanatory models through an engagement with queer persons (the first, to my knowledge, to do so), and queering because it develops new connections between sexual identity and embodiment among a diverse sample of gay and queer Canadian men and genderqueers. 


\section{Method}

\section{Theoretical and Epistemological Framework}

This thesis is situated within a critical psychology perspective that draws on poststructuralism, which is a heterogeneous postmodern critical theory that problematizes linguistic referentiality and authorial intent, rejects "reason" as universal or foundational, critiques humanism, and stresses difference. Critical psychology seeks to highlight the historical context, assumptions, and implications inherent in many of mainstream psychology’s "truths." Specifically, it acknowledges that the discipline is actively engaged in producing truths, social realities, and subjects - it does not simply study them. Psychology's production of knowledge is not a neutral, value-free enterprise conducted by scientists who are detached from particular sociopolitical circumstances; rather, it is a human, social venture influenced by differing interests and thorny power dynamics (Fox, Prilleltensky, \& Austin, 2009). According to Parker (1999), definitionally, critical psychology involves the systematic examination of how some modes of psychological knowledge production are privileged over others and of how dominant accounts or theoretical formulations operate ideologically and in the service of power. Thus, critical psychology provides an opportunity to self-reflexively examine and expose how knowledge or particular scientific findings are instantiated as truths and to formulate ideas that articulate alternatives to prevailing epistemologies (Slife, Yanchar, \& Reber, 2005).

Broadly, the epistemological framework of this thesis can be labelled materialdiscursive: discursive, because it appreciates the socially and linguistically mediated quality of human experience, and material, because it attends to the physical features of human lives, including our bodies and corporeal activities in addition to our environments, institutions, and artefacts (Yardley, 1997). A material-discursive approach is not analogous to systems theory or 
biopsychosocial models, which assimilate non-biological (i.e., cultural, psychic) variables into a biomedical, reductionist perspective, a manoeuvre that reifies psychosocial phenomena by rendering them as objective facts rather than as constructed by language and society (Henriques, Hollway, Urwin, Venn, \& Walkerdine, 1984). In accordance with critical psychology, a material-discursive approach critiques the assumptions fundamental to the positivist, empiricist tradition of mainstream psychology, such as its reliance on "value-free" research and hypothetico-deductivism, exaltation of objectivity, and disregard for ideology and power relations (Gavey, 1989). Power relations are embedded in systems of linguistic organization and symbolic signification, and are ceaselessly renewed in social interactions (Foucault, 1988). Consequently, one's identities, behaviours, beliefs are engendered by one's cultural history and social positionings (Shotter \& Gergen, 1989). The "cause," connotation, and effects of individual attitudes, personalities, cognitions, and actions must be understood in the broader, messier context of the socio-linguistic customs and constraints that produce - and are reproduced by the discourse and activities of individuals (Harré \& Gillett, 1994). Discursive theory carves out space for an exploration of the axes of gender (e.g., hegemonic masculinity), sexuality (e.g., heterosexism), age, class, race and ethnicity, of "macro-level social policies or micro-level patterns of social interaction" (Yardley, 1997, p. 7), of psychological and other "expert" discourses (e.g., the gay male body dissatisfaction imperative), and of casual conversation.

In particular, this thesis relies on what Fuss (1989) described as a Derridean understanding of identity as différance. According to a positivist or realist view of the world, words derive their meaning from their relationship with the "real" things they represent: the sign "chair" refers to an exact signified, to something with four legs, a seat, and a back. Such a representationalist theory of language proposes that the distinctions we make - between, for 
instance, a chair and a sofa, recliner, rocker, couch, chesterfield, etcetera - are "natural" and given by the world around us. Ostensibly, our ideas are the origin of the language we speak and determine what a chair is and what a chair is not. Post-structuralist philosophy is epistemologically antithetical to a representationalist account and proposes that our ideas are the effect of the meanings we learn and reproduce. In the Course in General Linguistics, Saussure (1986) noted that, in language, there are only differences without positive terms, which suggests that words do not refer nor "contain" meaning; they possess no positive content and owe their meaning to différance. Language, which seems to name units given in nature, does not in practice depend on reference to things, or even to our ideas of things. Definitions are differential as opposed to referential and words gain their meaning from the social context in which they are used and from their relationships to other words, from linguistic opposition. According to Derrida (1974), our use of language contains a performative dimension: instead of repeating or referring to pre-existing meanings in our "citation" of previously used words, we alter, if always within limits, the meaning of words. Each separate use of a word tweaks it in this or that direction in relation to a variety of pressures: the context, the audience, conscious or unconscious purposes. Languages are reproduced, are kept alive and functioning, through innumerable acts of use; but, those acts also constantly change the language. In a similar vein, Butler (1990) proposed that we understand sex, gender, and sexuality as citational repetitions. Various cultural discourses converge in a prevailing understanding of what "man" and "woman" or "heterosexual" and "homosexual" signify. Individual actions then "cite" these meanings, playing off them in various ways. The little boy learns that his crying is not masculine; he must grow into his masculinity by imitating the behaviour designated as "male" to the point that such behaviour becomes “second nature." In Butler's (1990) view, we feel our way into these roles, slowly 
establishing (under the watchful eyes of powerful social forces) the way we will occupy them. Given our prevailing categories, we experience this process as discovering our identity.

The body is thoroughly implicated in the discursive production of identity; it should not be considered as exclusively a material resource, because embodiment involves social worlds both "material and extant [and] ephemeral and possible" (Radley, 1998, p. 14). This thesis's understanding of gay/queer male/genderqueer embodiment is particularly informed by feminist post-structuralist Susan Bordo (1993), who theorized the body as a "text of culture" (p. 165) that serves as a blueprint for "the central rules, hierarchies, and even metaphysical commitments of a culture" (p. 165). Not merely about the social, the body is culture and a manifestation of a given culture's power. Bordo (1993) suggested that what women do with and to their bodies is determined by patriarchal ideology. She presented the notion of an "intelligible body" that comprises all "the scientific, philosophic, and aesthetic representations of the body" (p. 181) and forms a set of regulations through which the "living body" becomes a "socially adapted and 'useful body"' (p. 181). The useful body - or, practical body - is not a natural, biological entity; instead, it is culturally mediated and determined by dominant "norms of beauty [and] modes of health" (p. 181). Importantly, Bordo's (1993) position was opposed to feminist discourses that view the body as "a socially shaped and historically "colonized territory" (p. 167). Rather, her approach was invested in the reciprocal tension between cultural images and the "practical life of the body" (p. 181) via a focus on the discourses through which society not only produces but also interacts with the body. By examining "the realm of femininity...' from below"' (p. 167), Bordo (1993) underscored the way in which power operates through the "seemingly willing acceptance of various norms and practices" (p. 167) to which the body plays a central role. In her discussion of gendered, historically localized disorders - hysteria, agoraphobia, and anorexia 
nervosa - Bordo (1993) noted that the bodies of these "disordered" women are graphic texts that insist on being read as cultural statements about gender, presenting the "emaciated body of the anorectic" (p. 170) as a "caricature of the contemporary ideal of hyperslenderness for women" (p. 170). Bordo (1993) considered these exaggerated performances of femininity as parodic expressions of "protest and retreat in the same gesture" (p. 174); they mark the ways in which individual women both insert their bodies into the system of practices, institutions, and technologies within which bodies are produced and struggle against those very categories. Though these bodies have a critical relationship to dominant ideologies of the feminine, Bordo (1993) insisted that these performances fail; they voice critique but are unable to effect change. Instead of rebelling against the established order, these performances capitulate and replicate "precisely that which is being protested" (p. 177).

In another essay, however - this one investigating postmodern bodies - Bordo (1993) invoked both hooks (1990) and Flax (1990) to suggest that the decentred subject may possess transformative potential. According to post-structuralist thought, the decentred subject is an antihumanist belief that "any articulation of identity, of 'we,' is a totalizing fiction” (Bordo, 1993, p. 283). When explored less theoretically, the decentred subject may refer to the lived experience of individuals at the margins; for some, this has even meant "homelessness, dislocation from history, a sense of political and intellectual vertigo and paralysis" (p. 283). hooks (1990), for instance, recognized that "black identity has been specifically constituted in the experience of exile and struggle" (p. 29) without succumbing to any essentialist notions of race; however, she also acknowledged that the fragmentation of identity (i.e., the decentring of the subject) allows for "creating transformative subjectivities that express and exhibit the multiple aspects of identity" (Bordo, 1993, p. 284). In fact, when the elements of (female, black, gay) identity are 
embodied at the "margins" and brought to the "centre," the "hegemony of existing cultural styles of subjectivity [may] be challenged" (p. 284). Consequently, Bordo's (1993) account provides a space for this thesis to theorize the participants' ostensible acceptance of and resistance to particular discourses (i.e., embodied queer resistances).

Writers examining the gay male body are just as equivocal in their assessment of its resistant or subversive potential. "Gym bunnies," ${ }^{2}$ for instance, have alternately been thought of as perpetuating a gay caste system based on a "cult of masculinity" (Signorile, 1997) and of "forging a new association between masculinity and sexual receptivity...while detaching male homosexuality from its phobic association with "femininity" (Halperin, 1995, p. 90). Even identities further at the margins of mainstream gay identity politics, those represented through outsider bodies, like "bears,"3 have been theorized as celebrating body diversity (Gough \& Flanders, 2009), as redefining masculinity (Manley, Levitt, \& Mosher, 2007), and as adhering to "heteronormative and hegemonically masculine interpretations of sex" (Hennen, 2005, p. 25). In his discussion of queer bodies, Wood (2004) noted that "many theorists have interpreted camp, drag, and gay machismo as modes of cultural critique and resistance to the prevailing hetero/sexist gender system" (p. 51) - some argue that queer bodies engage in "semiotic guerrilla warfare" (Weeks, 1985, p. 191), while others are less optimistic (e.g., Bersani, 1988). Because "embodied ideological practices have penetrated and remain deeply secreted within us" (Sampson, 1998, p. 48), relations of domination certainly occur at the body, but so, too, do emancipatory practices. This thesis is interested in how and in what manner non-hegemonic masculinities - gay/queer masculinities in all their myriad constitutions - are discursively produced and embodied. It explores the material practices of gays and queers who alternately "accept" or resist discourses about heterosexism and hegemonic masculinity. In doing so, this 
thesis asks: How might the gay/queer body function as a site of identity disavowal or even play, while maintaining an awareness of material consequences?

\section{Participants}

Participants were recruited using a systematic, non-probabilistic theoretical sampling strategy, which allows the researcher to actively select participants with the largest potential for advancing understanding about a given topic, and, therefore, does not rely on randomization (Glaser \& Strauss, 1967). Sampling proceeds according to the relevance of cases and is not governed by representativeness or a quantitative commitment to large sample sizes and external validity. Rather, variable, "information-rich," contextualized data from a small number of individuals instead of "restricted" data from a large sample (Yardley, 1997) was sought for this thesis. In order to ensure that this small sample contained a relevant, diverse range of perspectives, recruitment targeted gay and/or queer men or genderqueers, between the ages of 18 and 32, who live in the Greater Toronto Area and speak English fluently, as these are the most relevant "knowledge-keepers" of the information pertaining to this thesis. Eligibility criteria were left deliberately open in order to attract a diverse array of men/genderqueers from a range of ethnic groups, socioeconomic and relationship statuses, and education levels. For instance, prospective participants did not need to be "out of the closet" or identify as an active member of one of Toronto's gay or queer communities.

Because a diverse sample was anticipated (e.g., those who identify as transgender, genderqueer, intersexual, and asexual), the age range was restricted to control for the differing experiences of various generations of gay/queer men/genderqueers. While it is erroneous to suggest that all gay men of a particular age share comparable life experiences or are identically affected by certain sociocultural or political factors, specific generational differences do exist: in 
particular, older gay men are confronted with a number of unique concerns with respect to their bodies, worries that do not typically affect younger gay men (Drummond, 2010). In fact, as many participants did differ along multiple axes, limiting the age range allowed for a more focused, nuanced study of issues pertinent to an already disparate group of gay/queer Millennials - those born in 1982 and into the 1990s (i.e., Generation Y). Over the course of the interviews, the younger age of the participants facilitated emerging reflections on their developing notions of identity, sexuality, gender, and embodiment, and how they came to be. Furthermore, the participants' joint membership in Generation Y rendered certain discursive connections more salient. In particular, Millennials, recently labelled "The Go-Nowhere Generation" by The New York Times (Buchholz \& Buchholz, 2012), have been pigeonholed as (and, at times, excoriated for ostensibly being) "hopeless homebodies eternally shuffling zombie-like through their parents' basements in footsie pajamas" (Barry, 2012, para. 4) and as navel-gazing hipsters infatuated with their own sense of individualism (Strauss \& Matson, 2000). This blanket characterization may give one pause, but a number of these similarly-aged participants endorsed a post ethos: many spoke casually about living in a post-race, post-gender Canadian society, and some viewed their sexual identities as post-gay. As will be demonstrated throughout this thesis, such proclamations of personal uniqueness are steeped in neo-liberal ideology and tied to heterosexist and masculinist discourses.

Nineteen participants, between the ages of 19 and 32 years $(M=26.4, S D=3.8)$, were interviewed. All participants were given pseudonyms to protect their confidentiality. Sociodemographic characteristics are listed in Table 1. Most participants' $(94.7 \%)$ self-identified ${ }^{4}$ gender was male; Skylar (31, queer) was the only participant who self-identified as genderqueer, a catchall neologism for gender identities other than man or woman preferred by those who 
reject the gender binary and cisnormativity. ${ }^{5}$ Genderqueers strategically and reflexively queer gender by expressing it non-normatively, as both man and woman (bigender, pangender), neither man nor woman (genderless, agender), moving between genders (genderfluid), or third- or othergendered. All participants were "assigned male at birth." In terms of sexual identity, one participant self-identified as "bisexual," one as "somewhere between bi and gay" (Jian, 25, bisexual/gay), four as gay and queer, four as queer, and almost half (47.4\%) as gay. In its noun form, this thesis uses queer in a deliberately broad manner. According to Warner (1999), queer self-identification should not be restricted to a constrained set of identities, as the term connotes an implicit understanding that "people suffer, often indiscriminately, from gender norms, objectorientation norms, norms of sexual practice, and norms of subjective identification" (p. 30). The participants who self-identified as gay/queer or queer did so in order to position themselves as anti-assimilationist and ideologically opposed to mainstream gay identity politics.

All participants were out of the closet and self-identified as a member of one of Toronto's gay or queer communities. In terms of ethno-cultural background, six participants (31.6\%) selfidentified as Canadian, four as European (Italian, Scottish, Western European, Scottish-BritishIrish-Italian), five as of European descent (English-Scottish-Irish-Canadian, German-American, Polish-Danish-Canadian, Scottish-Canadian, Sicilian-Canadian), two as of cross-national descent (Goan-Portuguese, New Zealander-Irish-French), one as Eurasian (Turkish), and one as Asian (Chinese). The participants' ethno-cultural backgrounds were difficult to categorize and often resisted simplistic national and ethnic identifications; indeed, they seemed somewhat ambivalent when asked to select an ethno-cultural background, indicating suspicion of "Canadianness" or "Europeanness," of unified national identity. Fourteen participants (73.7\%) labelled Canada their country of origin. The remainder were born in Hong Kong, Kuwait, New Zealand, Turkey, and 
the United States of America. Twelve participants (63.2\%) did not endorse religious affiliation; the remainder were agnostic (5.3\%), Anglican (10.5\%), Protestant (5.3\%), and "spiritual" (15.8\%). Many participants were single (52.6\%); out of the nine partnered participants, one described his relationship as monogamous, two as polyamorous, and two as polyamorous and long-distance. Lastly, this sample of gay/queer men/genderqueers was relatively well educated: the majority were completing or had completed a Bachelor's degree (63.2\%) in disciplines as diverse as dramatic arts/theatre, English, German, communication studies, fashion, philosophy, Celtic studies, advertising, marketing and management, psychology, math, and engineering science; six were completing or had completed a Master's degree, or had received some doctoral training (31.6\%) in either music performance, gender studies, geography, philosophy of medicine/science, divinity, theology, or counselling psychology; and one participant's highest level of education completed was high school. Given the number of students and transitioning students (e.g., from Master's to doctoral work) in this sample, 14 were unemployed (e.g., awaiting entry into Master's or doctoral programs), students, or students who worked part- or full-time (73.7\%); the remainder worked full-time (10.5\%) or part-time $(15.8 \%)$.

\section{Procedure}

The participants were recruited from three main sources. First, flyer advertisements were placed around the Ryerson University and University of Toronto campuses, Toronto's Gay Village (Church and Wellesley), and in the 519 (an LGBT community centre). In order to attract more queer participants, flyers were also placed outside the Queer West Arts and Culture Centre (this organization does not allow the placement of recruitment flyers for academic research purposes on their premises) and around what is colloquially known as Queer West Village, portions of Toronto that include Kensington Market, West Queen West, Ossington Avenue, 
Dundas West, Parkdale, and Roncesvalles. Less than 30\% of gay/queer men/genderqueers still call the Church St. Village home (Ledger, 2010), and Toronto's Queer West Village, a place "where anything goes" (para. 8) - with its numerous art galleries, queer burlesque cabarets, "homo hip-hop" nights, and trans spoken word poetry slams - has recently become an alternative scene praised by those who seek an antithesis to the Village's privileged, White gay malepopulated bars and clubs and derided by those who view it as a hipster enclave. Second, online advertisements were posted on the Gender, Sexuality, and Critical Psychology Laboratory's Facebook page, Craig's List, and Kijiji. Third, snowball sampling, a non-probabilistic sampling technique, was used to recruit participants from among my acquaintances (i.e., to recruit friends of friends who are queer), and queer participants were encouraged to solicit their like-minded friends' participation. Two types of flyers and online advertisements were used - one seeking gay men and one seeking queer men. ${ }^{6}$ Posters and online advertisements included a brief description of the study (including the purpose), incentives to participate, eligibility criteria, and contact information. All the interviews were conducted between March and August 2012, and recruitment ended once theoretical saturation - the point at which "no additional data are being found whereby the [researcher] can develop properties of the category" (Glaser \& Strauss, 1967, p. 61) - was met. According to Guest, Bunce, and Johnson (2006), theoretical saturation typically occurs within the first 12 interviews; after completing approximately 15 interviews (and having a few more already scheduled), common refrains and ideas were consistently heard and recruitment was discontinued.

During the recruitment period, prospective participants contacted me via email, at which point they were assessed, via telephone recruitment script (Appendix A), to gather whether they met the eligibility criteria. If so, prospective participants were provided with a fuller description 
of the study (including, potential risks/discomforts and benefits, confidentiality, incentives to participate, and the voluntary nature of participation) and subsequently scheduled for an interview. Once scheduled, the participants arrived at the Gender, Sexuality, and Critical Psychology Laboratory, located in Ryerson University’s Psychology Research \& Training Clinic, 105 Bond Street. Before beginning the interview, the participants were asked to carefully read and sign a consent form (Appendix B) In order to assess their understanding of the research, they were asked a question regarding the purpose of this thesis. In addition, the consent form indicated that the participants had an opportunity to ask any questions before beginning the interview, and they were debriefed post-interview. To thank the participants for their time and effort, their names were entered into a draw to win one of two cash prizes of $\$ 100.00$. All the interviews, lasting between one-and-a-half to two hours, were digitally recorded and later transcribed. Ryerson University’s Research Ethics Board approved this study.

In-depth, individual semi-structured interviews (Appendix C) were the most appropriate method for collecting verbal data for this thesis (as opposed to the group discussion, focus group, or joint narrative procedures), because they permitted an exploration of each participant's "subjective theories" about gay male body dissatisfaction, which included assumptions that were explicit, immediate, and expressed spontaneously in answering the interview questions.

Individual interviews allow for the co-construction of meaning with interviewees, whereas focus groups are more appropriate for examining group norms and social knowledge (Johnson, 2002; Jowett \& O'Toole, 2006). The interview schedule began with 12 demographic questions, then examined four interconnected topics of interest: the body, sexual identity, embodied identity, and oppression and resistance. With respect to the body, this thesis focused on the phenomenological- or felt-body and the bodies the participants viewed, delimited by exterior 
contours. Sexual identity referred to the participants' social identity (not sexual orientation), which includes sexual behaviours, erotic/romantic attractions, and/or broader socio-political affiliations. Embodied identity explored the ways in which gay/queer male/genderqueer identity is tied up with notions of the corporeal. Finally, oppression and resistance delved into the participants' beliefs about particular (gay/queer) embodied identities and whether or not they resist or submit to certain cultural discourses (e.g., dominant notions of male beauty and/or masculinity). The interview questions were deliberately broad to capture a range of responses: for instance, with respect to sexual identity, the first question asked was, "How would you describe your sexual identity?" That type of open question elicited ideas readily "at hand" for the participants, which was followed more theory-driven questions like, "How is your sexual identity manifested or expressed?" - posed to investigate this thesis's interest in how the body may function as a "producer" (of knowledge, or identity). Though not written into the interview schedule, probes (e.g., "What do you mean by ___?") were also used to further question the beliefs the participants presented in response to the theory-driven questions and to critically reexamine them, especially in light of competing alternatives.

\section{Analysis}

Once the interviews were completed and transcribed, they were analyzed using a Critical Discourse Analysis technique, which places emphasis upon power's material-discursive effects and fits with this thesis' feminist post-structuralist Foucauldian-influenced approach. This technique is concerned with elucidating the meanings and functions of discourses and their links with social relations and the exercise of power. Throughout this thesis, the term discourse is used to refer to symbolic systems of meaning that permeate and structure society and language (e.g., heterosexism, hegemonic masculinity, neo-liberalism). Discourses are not just words or 
language; they encompass organized bodies of knowledge and practitioners (including modern academic disciplines, like psychology) that are integral to the discursive ordering and physical management wielded by modern power (Yardley, 1997). As a structuring principle of society (Weedon, 1997), discourses are not only reproduced in social or political institutions; they brandish material bases of power at the level of individual subjectivity (Henriques et al., 1984). Knowledge/power is the term coined by Foucault to expose how the assembly of knowledge is wedded to productive power, an interconnection that individualizes and produces the modern subject in order to better control, like an all-seeing - or, panoptic - force that keeps its subject under relentless surveillance (Foucault, 1980). Prevailing regimes of knowledge and regulatory material practices "systematically form the objects of which they speak" (Foucault, 1972, p. 49) by intervening from day one to form, train, and normalize subjects. Because an identifiable, immutable sense of self is considered a fantasy, humans are conceptualized as subjects whose identities are organized within and against multiple, contradictory meaning systems, sociocultural forces, power structures, and linguistic practices - or, discourses (Widdicombe, 1995).

Critical Discourse Analysis posits that language and other symbolic systems and cultural practices, as constructive processes, are paramount to our understanding and expression of experience. In particular, feminist post-structuralism contests the notion that "people's ordinary discourse reflects real and often stable phenomena and processes such as attitudes, personalities or cognitions that exist within the individual, independent of language" (Malson, 1998, p. 38). Language is not a transparent medium, readily revealing core "truths" about an individual (Potts, 2002) or some objective reality that is deemed to lie "behind" the transcript (whether social, psychological, or material; Gill, 2009). Rather, discourses offer multiple, often-conflicting ways 
to strategically and reflexively talk about - or, make meaning of - one's experiences, one's world, one's self, one's body. Indeed, as Wetherell and Edley (1999) noted, identity is "best understood as the personal enactment of communal methods of self-accounting, vocabularies of motive, culturally recognizable emotional performances and available stories for making sense" (p. 338). Said talk highlights how individuals "take up" or occupy particular subject positions the various "roles" that exist within a discourse or institution (Gavey, 1989). However, Critical Discourse Analysis is not akin to "radical relativism," as the possibilities for constituting subjectivity vary in terms of authority and the power they afford individuals. Certain traditional discursive constructions of femininity, for instance, dominate patriarchies and "constitute the subjectivity of most people most of the time" (p. 464) while other discourses (e.g., feminism) are marginalized and unavailable to most people as viable subject positions. Thus, this thesis used the term interpretive repertoire - "a culturally familiar and habitual line of argument comprised of recognizable themes, common places and tropes (doxa)" (Wetherell, 1998, p. 400) - to indicate instances when the participants relied on familiar or shared discursive constructions during their respective interviews. This thesis examined the myriad discourses that framed the participants' "meaning-making," the interpretive repertoires they selected, and the subject positions they occupied as they spoke about their bodies, their sexual and gender identities, and the intersections between sexuality, gender, and the body.

Throughout the analysis, the transcripts were treated as texts of experience, as the "embodiment of various discourses available in the social, cultural, and historical context of the author" (Gavey, 1989, p. 465) and not as objective or stable "truths." This thesis's approach to Critical Discourse Analysis (e.g., Edwards \& Potter, 1992; Potter \& Wetherell, 1987) focused on social rather than linguistic organization and had "a triple concern with action, construction and 
variability" (Edwards \& Potter, 1992, p. 28). The transcripts were carefully read with the intention of "discerning discursive patterns of meaning, contradictions, and inconsistencies" (Gavey, 1989, p. 476) and the conditions of possibility with respect to subjectivity. Then, as per Potter and Wetherell's (1987) recommendations, all 19 transcripts were reread to identify consistencies and inconsistencies and to determine the functions of particular linguistic strategies by noting their effects in relation to larger discursive regimes of power and ideological practice. Because the researcher inevitably influences the materials used in both quantitative and qualitative research, the analysis was both inductive and deductive: many of the interview questions were theoretically-driven, but the coding scheme developed inductively and was iteratively informed by the participants' theories and conclusions and by the academic literature that was read concurrently. Thus, a coding scheme was not rigidly adhered to or viewed as a "validity check," because that implies a form of "naïve" realism (Yardley, 1997). Among the key questions guiding the analysis were: What dominant/subordinate discourses do the participants adopt/resist? What interpretive repertoires do the participants rely on when describing their lives? What subject positions do the participants take up? What conclusions can be drawn from what the participants say? 


\section{Results and Discussion}

\section{The Gay Male Body Dissatisfaction Imperative: From Abnormal Psychosexual Development to Internalization}

This first analytic section presents a queer, feminist reading of the state of the literature on body image among gay men. First, the existing explanatory models of gay male body dissatisfaction are summarized, deconstructed, and critiqued for essentializing homosexuality for presenting a gay identity as a fixed orientation and implicating some aspect of said orientation (e.g., gay men's abnormal psychosexual development, the gay community's bodyobsession) in their rationalization of gay male body dissatisfaction. This thesis' deconstruction destabilizes the epistemological foundations upon which certain stereotypic, normalizing claims are produced, reified, and disseminated by psychology. Such claims include the belief that there exists a monolithic gay identity, community, body ideal, and the notion that gay male bodies can be thought of only as sites of dissatisfaction. Second, the gay and queer participants" "voices" are integrated into this analysis in order to ascertain whether the explanatory models adequately reflect their experiences of gay/queer embodiment. In particular, the participants' interpretive repertoires suggested that they all view gay/queer identities, communities, and body ideals as diverse, which further problematizes psychology's naturalizing tendencies. However, their exaltations of diversity were deployed through two ideologically distinct strategies: the gay participants relied on neo-liberal individualism whereas the queer participants relied on queer epistemology.

Deconstructing psychology's explanatory models. Psychology has done more than simply "find" that gay men are more dissatisfied with their bodies than heterosexual men through a formulation of an essentialized sexuality that does not reflect the stated experiences of 
the participants; its minoritizing discourse dissembles a universalizing one wherein the distinctions between homosexuality and heterosexuality are an "issue of continuing, determinative importance in the lives of people across the spectrum of sexualities" (Sedgwick, 1990, p. 1). Many social postmodernist writers contend that the late $19^{\text {th }}$ century witnessed the emergence of an influential distinction between homosexuality and heterosexuality, one that is often referred to as the homo/hetero binarism (e.g., Halperin, 1990; Sedgwick, 1990), an idea that served as the foundation for queer theory. The term queer theory was originally introduced by Teresa de Lauretis at a 1990 University of California, Santa Cruz conference as a means of "propelling lesbian and gay sexualities to the forefront of rethinking sexualities" (Gurevich, Bailey, \& Bower, 2009, p. 238). This involved moving beyond the minoritizing tendencies of gay and lesbian studies, which often overlooked the regulatory function of all identity categories, or a focus on gaining acceptance or assimilation. Queer theory adopted a universalizing discourse that thinks about sexuality - particularly, homo/hetero binarism - as an epistemic foundation of virtually any aspect of Western metaphysics: secrecy/disclosure, private/public, masculine/feminine, natural/artificial, minority/majority, knowledge/ignorance. Queer theory reproaches the patriarchal and homophobic basis of heterosexuality by proposing that the homo/hetero binarism presents homosexual as the subordinated term and heterosexual as the ontologically valorized term (Sedgwick, 1990). Heterosexuality is never an object of study, but, rather, a condition for "objectively" scrutinizing other objects - namely, homosexuality. Thus, heterosexuality remains unmarked and unproblematized while homosexuality functions as a discursive construction that does not denominate a real or determinate class of persons but delimits and defines - through negation, or différance - the privileged term (Halley, 1993). In $O f$ Grammatology, Derrida (1974) is famous for producing critical readings of texts (and society, 
more broadly) intended to destabilize binarisms, called deconstructions. Often described as a method of semiotic analysis or a type of critique, they attempt to understand the double binds and tensions articulated in a text of culture, not just its presumed content, meaning, or referent. "Reading" (i.e., analyzing, critiquing) should highlight signifying structures, the relationships unperceived by the "author," and the interconnections between binarisms in order to work toward overcoming them. Given that psychologists are very much authors, just as their research outputs are very much texts, the following deconstruction emphasizes how the discursive construction of a particular gay identity occasions an essentialist commitment that, in turn, defines a class of "non-homosexuals."

The quantitative literature, and some of the qualitative literature, on body image among gay men reproduces a representationalist theory of language that naturalizes a gay orientation; that orientation is then purported to refer to a circumscribed characterization of a gay identity and a gay "community" - one that is pathologized and solely implicated in its own dissatisfaction. Filiault and Drummond (2009) conducted a systematic literature review of relevant peer-reviewed articles and found little consistency with regard to the definition of gay and homosexuality; 11 studies neglected to address the simple issue of how the participants were defined as being gay. Most studies relied on scales of erotic attraction, like the Kinsey Scale (Kinsey, Pomeroy, \& Martin, 1948), a seven-point Likert scale ranging from zero (entirely opposite sex attraction) to six (entirely same-sex attraction). Though this scale and others like it place sexuality on a continuum, many quantitative researchers have transformed them into dichotomous variables - gay or straight - in order to yield groups with sufficient sample sizes to conduct comparisons of means. This kind of methodological procedure (e.g., dichotomization, forced choice questions, or any other gesture that creates two monolithic sexual orientation 
categories) becomes especially problematic when researchers like Yelland and Tiggemann (2003) divide participants into homosexual and heterosexual groups (based on a five-point Kinsey-type scale), conduct statistical analyses, and find a difference (e.g., "homosexual men do experience more body concern and disordered eating than their heterosexual counterparts" $[\mathrm{p}$. 113]) and explain it by suggesting that homosexuality - the very category they constructed ineluctably refers to a monolithic "gay community" where "gay men experience [pressure] to be attractive and muscular from within their own community" (p. 114).

Kane (2009) divided the literature on body image among gay men into an old orthodoxy and a new orthodoxy. The old orthodoxy ${ }^{7}$ relied upon a stereotypic notion of the slender, epicene "homosexual," which, according to Weeks (1989), belongs to a long historical lineage that dates back to the Oscar Wilde indecency trials, to establish a theoretical doctrine that purposes that gay men, like, presumably, heterosexual women, are obsessed with a need to appear thin and attractive. In the late-1980s, early clinical studies, like Schneider and Agras' (1987), attributed body dissatisfaction to cultural pressures on gay men to be willowy and beautiful. These studies also suggested that boys and male adolescents who exhibited "atypical" - that is, stereotypically feminine - gender-role behaviours caused by "abnormal" psychosexual development were at greater risk for developing Anorexia Nervosa or Bulimia Nervosa (e.g., Fichter \& Daser, 1987). This mode of theorizing is muddied by the sediments of the effeminophobia that Sedgwick (1993) found typical of the revisionist psychoanalysis, and, especially, ego-psychology, of that era that posited, for instance, a boy's desire to participate in "girls" pastimes or games as a pathology involving his Core (Gender) Identity. Such an normalizing, minoritizing gesture is symptomatic of larger medical discourses that naturalize homosexual "behaviour" and position it as an inherent "condition" (Weeks, 1990). 
Also operating within the old orthodoxy were early non-clinical studies that reinforced the notion that heterosexual women are the most concerned with their physical appearance, then gay men, followed by lesbians, and, finally, heterosexual men, though a few studies (e.g., Herzog, Norman, Gordon, \& Pepose, 1984) actually demonstrated "a greater diversity of body preference than the authors acknowledged" (Kane, 2009, p. 23). Though questionable for a legion of reasons, these models all exhibited the epistemological confidence indicative of psychology's essentialist definition of homosexuality, where that very homosexuality is positioned as the cause of its own pathology, of gay men's body dissatisfaction. Furthermore, they perpetuated the heterosexist notion that heterosexual men and lesbians, as the agents - and not the objects - of attention or desire, are immune to pressures to appear in a particular manner, because, to quote Siever (1994), "physical attractiveness is less essential [emphasis added] in attracting a female partner" (p. 252). Such neglect is especially egregious given the manner in which consumer capitalism, as Bordo (1999) documented in The Male Body, has increasingly highlighted the - often, heterosexual - male body since, at least, the early 1990s. For instance, Soderbergh's (2012) recent film about male strippers, Magic Mike, earned a healthy $\$ 39.16$ million in its opening weekend on a production budget of only $\$ 7$ million. Indeed, Berger's (1972) well-known act/appear dichotomy has been thoroughly deconstructed - men now regularly appear, in mainstream advertising, as passive, erotic objects, subordinate to a genderless gaze. In the last three decades, for instance, the musculature of Playgirl centrefolds (Leit, Gray, \& Pope, 2001) and action figures (Pope, Olivardia, Gruber, \& Borowiecki, 1999) has steadily increased, as Western culture - and media images, in particular - has placed mounting emphasis on particular iterations of a heterosexual male body ideal in multiple ways (e.g., Barlett, Vowels, \& Saucier, 2008). 
Still part of the old orthodoxy, later non-clinical studies situated internalized homophobia, or internalized homonegativity, as an alternative explanatory model, a hypothesis that creeps toward surmounting the more unfortunate features of the aforementioned models. Williamson and Hartley (1998) compared 41 gay men to 47 heterosexual men on three measures of eating disturbance and body dissatisfaction; gay men scored significantly higher on several of the measures' subscales. Based on this result, the authors concluded that a young gay man's nascent (sexual) identity formation may be hindered or distorted by his disadvantaged positioning within a largely homophobic global culture; thus, he "may project feelings of the 'bad me' onto his body” (p. 166), spurring an intraphsychic drive to compensate for his perceived inferior sexual orientation by obsessively working on his body, endeavouring for perfection. Certainly, the noxious effects of heterosexism must be considered when contemplating the aetiology of supposedly higher levels of body dissatisfaction among gay men - indeed, as will be discussed shortly, a consideration of just such a system of attitudes, biases, and discriminations is undoubtedly crucial. Though Williamson (1999) was careful not to present gay men as "powerless, passive, consumers" (p. 3), he suggested that the "almost universal" (p. 2) experience of internalized homonegativity is only particularly troublesome because its effects are exacerbated by a "toxic" (p. 2) gay community, which perpetuates, partly through its internal media, a "culture of narcissism, objectification, and commodification" (Williamson \& Hartley, 1998, p. 166). Presenting internalized homonegativity, sexuality, and the notion of a ghettoized "gay community" - including its media - as fixed, easily quantifiable variables propagates the old orthodoxy's earlier insistence that, inherently, homosexuality is the site wherein gay male body dissatisfaction is conceived. Disorder is located within gay men as opposed to within psychology and culture, which is akin to impugning women, not patriarchal ideology, for 
restrictively demarcating what women eat, how women dress, and the daily rituals through which women attend to their bodies (Bayer \& Malone, 1998).

The new orthodoxy (e.g., Hospers \& Jansen, 2005; Kaminski, Chapman, Haynes, \& Own, 2005; Kassel \& Franko, 2000) developed from the old orthodoxy and maintained its central supposition that matters of appearance consume gay men, as a homogenous, immutable group, but amended its focus to the scrutiny of gay men's contradictory pursuit for thinness and muscularity. Kane (2009) listed three main explanatory theories that operate within this orthodoxy. First, Strong, Singh, and Randall (2000) stressed the role of childhood gender nonconformity. This theory is similar to the abnormal psychosexual development model promulgated by the old orthodoxy's early clinical studies and proposed that a subset of gender non-conforming boys typically mature into stereotypically feminine gay men who are more dissatisfied with their bodies than heterosexual men or masculine gay men. Second, Kimmel and Mahalik (2005) developed a minority stress model that similarly relies on a stereotypic depiction of femininity and masculinity: gay men internalize homophobia, but "seek ways to compensate for perceptions that they are less masculine" (p. 1185) by sculpting "a powerful physique" (p. 1185); the physical body is thus self-consciously disciplined into a paragon of masculine strength and virility. Though Connell's $(1987,2005)$ notion of hegemonic masculinity can greatly inform our understanding of queer embodiment, with the childhood gender non-conformity model, one, once again, encounters effeminophobia, this time, as the palimpsest of psychiatric and medical discourses that imagine that effeminate boys turn out gay because they were never validated as masculine (Sedgwick, 1993). Likewise, the epistemological determinism of the minority stress model forecloses, for instance, a queer interest in citationality or an awareness of the subtlety of signifying practices - it expunges the playfulness of a Tom of Finland cartoon, it situates gay 
machismo, as it was elaborated in New York and San Francisco in the late 1970s, as another just form of what Foucault called "phallocratic culture," a gesture that he believed sterilizes, for instance, the gym bunny's capacity to, whether intentionally or not, ironize or subvert hypermasculinity (Halperin, 1995). Third, the role of gay culture has been implicated by numerous researchers, such as Brown and Graham (2008) and Yelland and Tiggemann (2003). This theory reproduces the old orthodoxy's mistaken assertion that Western culture does not sanction heterosexual male objectification by suggesting that gay men, alone, are members of a narcissistic, self-harming subculture that places undue pressure on its members, through oppressive internal media images, to embody a lean, yet muscular, monolithic gay body ideal. Again, such an assertion duplicates an essentialist understanding of homosexuality; it contradicts research that has demonstrated that greater acceptance in gay communities is actually associated with less desire to ascribe to a muscular body ideal (Levesque \& Vichesky, 2006) and that, as mentioned previously, heterosexual men feel pressure to look a certain way, a burden that is, in fact, related to body dissatisfaction, low body esteem and self-esteem, increased psychological disorders - such as, Major Depressive Disorder - and negative behavioural consequences, including dangerously excessive exercising (Barlett et al., 2008).

This brand of theorizing is not limited to quantitative literature. Over a series of studies, Drummond (2005a, 2005b, 2010), for instance, conducted a slate of individual, in-depth interviews with gay men between the ages of 18 and 25 , who were recruited from a gay men's counselling service in Adelaide, South Australia and provided life historical accounts of their difficulties "with body identity and masculine identity growing up in masculinized domains" (Drummond, 2005a, p. 292). Operating within an empowerment paradigm, his work represents 
an earnest effort to broaden how psychologists contemplate body image (Drummond, 2005b); however, in the introduction to one of his studies, he wrote the following:

Gay men exist in a culture that is heavily aesthetically oriented ... A gay man's body and overall "looks" play a significant role in determining his cultural status and sex appeal to other men. The look of his body has the capacity either to attract or deter potential sexual partners; such is the image-driven gay culture. (Drummond, 2005a, pp. 292)

The implication is that gay culture is more imagine-driven than that other culture with which it is "engaged in a diacritical struggle" (Halley, 1993, p. 85), that unmarked, privileged class, habitually able to hide its existence as a class. The aforementioned quote may seem rather innocuous - or, may even read as a nod to a more Foucauldian understanding of the body - when taken in its own right, but, when examined alongside the more problematic literature Drummond generously references, this construction of gay culture and its media appears far more insidious. If you follow the breadcrumbs of his and the two orthodoxies' justificatory logic, you will be led to a host of articles purporting to "find" that gay men are more dissatisfied with their bodies than heterosexual men, a finding that is explained by an image-obsessed gay culture, which is presented as such because gay men are purportedly more dissatisfied with their bodies than heterosexual men; ultimately, will find yourself walking in a circle. Thus, one is left with an essentialist understanding of homosexuality through psychology's epistemological authority to know and to designate what, and who, a homosexual is, through a rigid, fixed deployment of a gay identity as constitutive of the definitional essence of a gay man. On one side of homo/hetero binarism there lays obsession, narcissism, pathology; on the other, there does not. What Seidman (1993) called the exclusion, repression, and repudiation of homosexuality - in this case, a 
thoroughly (dis)ordered, (dis)satisfied homosexuality - builds the coherence of the ontologically valorized term as ordered, as satisfied.

Psychology's homo/hetero binarism inculcates a gay male body dissatisfaction imperative: being gay automatically procures one's membership to one "gay community" and one's subsequent adherence to one restrictive dictum of gay male beauty. Tellingly, the only gay writers referenced by psychologists who research gay male body image are those who reproduce an ethnic/minority sociopolitical agenda (Seidman, 1993). The centerpiece of today's Gay Rights Movement's identity politics and its neo-liberal claim to rights (Duggan, 2003), this agenda developed in the late 1970s in response to Gay Liberation and skirted liberationism's kinship with postmodernism for an emphasis on a unitary gay identity and an institutionally complete subculture, a move that constructs a circumscribed characterization of homosexuality, much like the aforementioned explanatory models. In particular, books like Daniel Harris' (1999) The Rise and Fall of Gay Culture, Michelangelo Signorile's (1997) The Life Outside: The Signorile Report on Gay Men: Sex, Drugs, Muscles, and the Passages of Life, and Andrew Sullivan's (1996) Virtually Normal are routinely cited in the extant body image literature: these gay writers tarred gay culture with the same brush and castigated what they ironically view as its personalistic neo-liberalism, promotion of consumerism, expressive-hedonistic values, and alleged body fascism - that is, "a rigid set of standards of physical beauty that pressures everyone within a particular group to conform to them" (Signorile, 1997, p. 27-28). Much like the old and new orthodoxies, the gay male body - notably, a young, White, professional body - is presented as controlled, commodified, and commercialized by the "gay community" and gay media alone. Liberationist or queer writers - like Weeks (1985) and Halperin (1995) - who regard, for instance, 1970s and 1980s gay gym culture, gym bunnies, and gay machismo as ironizing 
hegemonic masculinity, as "modes of cultural critique and resistance to the prevailing hetero/sexist gender system" (Wood, 2004, p. 51), are virtually never cited. Neither are late1980s writers - mainly, queers of colour and sex rebels - whose radical gay politics sought to disassemble an ethnic/essentialist model that exhibited a White, middle-class bias and ignored marginalized social interests (e.g., race, bisexuality, non-conventional or queer sexualities). Indeed, a whole politics of difference developed in the 1990s, yet the authors of that decade chosen by the new orthodoxy to substantiate its belief in gay culture's culpability are the ones who hypocritically rebuked gay men for apparently instantiating an ethnic/minority sociopolitical agenda that bred their own dissatisfaction, while neglecting to problematize the material-discursive processes that actually produce such characterizations of gay men or to propose queer forms of resistance to allegations of body fascism (Eng, Halberstam, \& Muñoz, 2005).

Indeed, these gay writers possessed ideological commitments of their own: to promote the visibility of "the worthier pillars of the [gay] community" (Warner, 1999, p. 49) through a "hierarchy of respectability...built on embarrassment" (p. 49) and shame, shame of the "gay clones," ${ }^{\prime 8}$ of the gym bunnies self-flagellating with dumbbells, of the freaky leather Daddies and sadomasochistic sex fiends, of the limp-wristed fags, of the stigma associated with being "Other," being gay. As Halberstam (2005b) noted, it is White male shame that "proposed 'pride' as the appropriate remedy and that focuses its libidinal and other energies on simply rebuilding the self that shame dismantled rather than taking apart the social processes that project shame onto queer subjects in the first place" (p. 224). In other words, Sullivan's (1996) assimilationism, his call for gays and lesbians to pursue the "normal," epitomizes the temptation to believe that the way to overcome stigma is to win acceptance by the dominant culture rather than to change 
the self-understanding of that culture. Akin to the gay and lesbian studies to which queer theory is ideologically opposed, Sullivan's (1996) totalizing narrative - which is the position of current mainstream gay identity politics - is wedded to a neo-liberal, standard Enlightenment "scientistic" self-understanding and a narrow single-interest-group politic that promotes a consumerist focus on "gay pride" - and "the faux-radical chic of white gay shame" (Halberstam, 2005b, p. 223) - and marginalizes gays or queers who deviate from its conservative social norms. For instance, queer Torontonian filmmaker, photographer, and author Bruce LaBruce (2012) recently reconceptualized Signorile's (1997) characterization of the gay clone's conformist body fascism: yes, they projected a highly masculinized and sexualized posturing the Burt Reynolds moustache, sideburns, and chest hair; the body-conscious white tee-shirts tucked into snug hi-rise "501 Originals"; the dirty tube socks and rugged boots - that may be interpreted as signifying a 1970s/1980s ethnic/minority sociopolitical agenda, but La Bruce's (2012) point is that their look was actually an "extreme statement" (para. 2) of sexual variance, an example of subalterns "adamantly asserting their difference by all being the same" (para. 2), which is vastly different from the two orthodoxy's naturalization of homosexuality or today's "new 'born-this-way,' absolutist gay mentality" (para. 3) and its insistence on presenting the monolithic "good" kind of gay, the "flag-waving, military-supporting, monogamy-advocating, family values type of gay" (para. 1).

\section{Gay identities, communities, and body ideals: The participants problematize}

psychology's explanatory models. The explanatory models' reproduction of an ethnic/minority sociopolitical agenda, through their reliance on assimilationist gay writers, is opposed to the articulation of dissenting voices in a social postmodernist direction, or to an understanding of the immense sociohistorical diversity of meanings and social arrangements of homosexuality 
(Seidman, 1993). For all of the participants interviewed for this thesis, a one identity, one community, one body ideal formulation of gay male body image was decidedly problematic. They expressed ideas that were antithetical to the explanatory models' restrictive formulations of homosexuality, but through divergent discourses. Both those who identified as gay and those who identified as queer deployed a "more than clubs and bars" interpretive repertoire to assert that gay identities, communities, and body ideals are necessarily diverse. However, the gay participants relied on neo-liberal individualism and the queer participants relied on queer epistemology. For the gay participants, homosexuality is culturally diverse because each gay subject is inherently unique; this "I am what I am/I like what I like" interpretive repertoire instantiates a neo-liberal remaking of the self in accordance with one's "authentic" sexuality. In contrast, the queer participants adopted a "subjectless" critique that dismantles hegemonic social structures in order to open up spaces for queer forms of difference and resistance.

The gay participants made distinctions between an innate homosexuality, as a basic character trait defined by a mutually exclusive gender preference, and the cultural meanings attached to that homosexuality. But, for all of their references to biological essentialism, the gay participants spoke at length about homosexuality as a highly variable cultural practice and not as a fixed trait. Many delineated elaborate lists of what gay may mean:

I think "twink,"9 for example, someone who, um, is skinny, smaller, youngish looking (...) and then there's like, like the larger like a really large gay man, you know that's like um...I think it's called a bear (...) [others] who seemed to like be into leather or something like that (...) Um... what else do we have? There's like the extremely effeminate, I don't know a name for that but like an extremely effeminate guy like in their voice for example (...) Um, I think there's the straight-acting guy which is either 
like you know an everyday sort of like Bay Street sort of business guy or it could be like a sports kind of guy who doesn't manifest anything like in his voice, you don't hear a lisp of anything like that. (Jayden, 30, gay)

Gay has no referent; homosexuality does not refer to a "natural" social group or a universal and transhistorical "gay man's experience," but encompasses myriad subgroups, each of which may consider the body in different ways (Morrison \& McCutcheon, 2011). Furthermore, individuals are never simply gay; rather, they occupy multiple identities and subject positions simultaneously, each of which, depending on context, may be rendered more or less salient at any given point in time. In fact, Jayden does not even have the language to describe the many manifestations of gay.

Likewise, the queer participants defined their sexual identities in similarly complicated ways while not relying on an ontology of the sexual. In order words, they did not presuppose gendered object-choice as the "master category of sexual and self-identity" (Seidman, 1993, p. 121), where "you match everything else, but the only difference is you put the tab in the wrong slot." Bennett (30, gay/queer), for instance, described fitting into a "gay classical mould" and feeling a "brotherhood" with other gay men who "have an interest in theatre, interests in classical stuff, a love of the over-the-top aesthetic, Oscar Wilde-y" - a clear reference to camp subculture and its "attraction to hedonism, kitsch, mimicry, effeminization, and transgender carnival" (Padva, 2000, pg. 216). Bennett had "to elect to be gay (...) to make a conscious step to enter a culture" and "claim [a gay identity]" - but what that gay identity means has no naturally identifiable referent. Skylar (31, queer) explained his queer sexual identity as "sort of 'verb-ing' instead of "noun-ing," as an "amorphous set of continual negotiations where not much is off the table" - it is "what one does as opposed to what one is." For the queer participants, sexuality was 
not determined by an innate attraction to a gendered object but was constituted by the enactment of liminal identities, by heterogeneous desires and interests that are marginalized and excluded in the heterosexual and gay mainstreams. Indeed, Skylar's queer sexual identity developed through "sleeping with women for the first time and recognizing that [he] didn't have to say 'no." The queer participants viewed sexual identities as socially produced with manifold social significance, as sites of ongoing regulation and contestation rather than as quasi-natural substances or social facts that refer to a unitary community demarcated by a particular set of ideological commitments (Seidman, 1993). They spoke about wilfully eccentric subcultural practices, non-conventional sexualities, alternative methods of alliance, and non-normative logics and organizations of identity, community and embodiment; they emphasized social difference and the multiplication of identities because gay "means different things to different people" (Ashley, 24, gay/queer). For instance, Morgan (22, queer) spoke about his sexual identity as neither fixed nor stable:

Interviewer: How would you describe your sexual identity? Morgan: I would say queer.

I: OK. So, what does that mean to you?

M: Um, well, I think it's something that, you know, I came to throughout university and speaking with, you know, speaking with people involved in different sort of, uh, queer activism on campus and stuff and just coming to see, um, sexuality through a bit more of a fluid lens than the, uh, the past. I mean, if I'm speaking with, if I'm speaking with family or people I don't know I'll often - or people outside of the LGBT community, I'll often say like gay and that's how I'll identify. But I feel like the term queer it carries a, uh, what I think is a bit more of, a, uh, accurate representation of how many people's 
sexuality is. Like, I definitely lean towards preferring men, but it's not to say that I haven't found a woman or you know someone, a trans person very attractive or something like that. (...) And so, I just feel that queer is just much more of an inclusive term. It encapsulates, I think, a lot more of the experiences that people really have with their sexuality. And it's not to say that, you know, you're going to, you know, go off and have, you know, like all these sexual relations with, you know, people of the opposite sex or something like that, but just even a recognition of the attraction there and not feeling like somehow you're not really, you know, a real gay if you have any sense of attraction to a, you know, to the opposite sex or something like that. And I find that just a lot of people, you know, a lot of like, you know, like people my age and stuff like that seem to be identifying more with the term queer.

Morgan is sometimes gay, sometimes queer; his identifications shift as he moves through the world and enters disparate spaces: when he is with his family or others "outside of the LGBT community," he is gay because that is how he is "read"; when he was on campus or engaged in queer activism, he was queer. Morgan's sexual identity is made meaningful only through différance: gay or queer are not terms that he possesses, they pre-exist him and come from outside, they mean whatever the shared or public possibilities of certain signifiers permit, which is a process of constant negotiation and not a natural given. There is no final answer to the question of what any sexual identity means or ultimately refers to. Overall, the gay and queer participants embraced an anti-representationalist, universalizing discourse to rail against the "globalizing of gay identity" (Manalansan, 1997, p. 502) and other constructions of "sameness" at odds with their virtually unanimous exaltation of difference. 
This exaltation of difference was also evident in all of the participants' descriptions of the "gay community" and the "gay body ideal." In terms of gay/queer communities, the gay and queer participants adopted a "more than clubs and bars" interpretive repertoire:

Well, I always say the gay community is what you make of it. It's funny, people will go to like one gay bar or a few gay bars, a few gay clubs, and have a bad experience, or a good experience, and then decide that based on that experience, that's what the gay community is. And I think for a lot of people, the gay community is only bars and clubs and parties and the Village. Um, it certainly was for me until I got more involved in political activism, and the interest groups, book clubs, movie clubs, or things like that, or we were having political discussions - I think it's important to have the bars and clubs because it's a place where people were like, all you have in common at this moment is that you are both gay. Here is a way to meet. But I think that you start to get a stronger sense of the communities when you do things that are not alcoholically lubricated. (Bennett, 30, gay/queer)

The participants' awareness that, "whether it is the effeminate camp, the muscular macho, the hairy sadomasochistic 'bear,' or the boyish 'twink,' the [gay community] has been marginalized by the straight bourgeoisie" (Padva, 2002, p. 282), seemed to manifest as a deliberate presentation of gay/queer communities - global and local - as more than frivolity or narcissism; more than the source of inflexible body norms and other beliefs that "encourage [gay men] to value themselves...for how they look" (Beren, Hayden, Wilfrey, \& Grilo, 1996, p. 136); more than the new orthodoxy's pathologizing, stereotypic representation; and more than Signorile's (1997) ethnic/essentialist ghettoized urban conformity of gyms, bars, and sex clubs. Rather, gay and queer communities were positioned as "very accepting communities" (Brock, 24, gay) that 
defy a Signorilean one-size-fits-all classification. In particular, the queer participants' use of the "more than clubs and bars" interpretive repertoire centred on queer political activism. Ashley (24, gay/queer) spoke about "the main group of the gay community" and a legion of alternative "subgroups" with "different reasons for wanting to associate with [each] other" but all informed by a politically motivated desire to "further" their version of the "quote unquote 'gay cause' or whatever." Similarly, Ben (30, queer) criticized a myopic view of gay/queer culture as nothing but an "apolitical mainstream gay scene." He discussed his support of "a lot of rallies and protests and things surrounding that" and his recent attendance at a 2012 Quebec student strike "casserole march" where he found himself stomping along a pedestrianized Saint Catherine Street East ${ }^{10}$ with his "fat dyke lesbian of colour" friend "shouting at the top of [their] lungs (...) 'Remember Stonewall! Remember Stonewall!'” at a gaggle of disaffected young gay men "giving them nasty looks" from the sidelines. There is something beyond the mainstream, and that something is distinctly political.

Ben's earnest image of queer youth in revolt aptly characterized the queer participants' reliance on queer epistemology. In Bodies That Matter, Butler (1993) proposed that queer should never "fully describe" (p. 230) those is seeks to represent, but remain amenable to assuming "meanings that cannot now be anticipated by a younger generation whose political vocabulary may well carry a very different set of investments" (p. 230). Eng et al. (2005) labelled queer theory's openness as one of the field's key theoretical and political promises: "What might be called the 'subjectless' critique of queer studies disallows any positioning of a proper subject of or object for the field by insisting that queer has no fixed political [emphasis added] referent" ( $\mathrm{p}$. 3). Queer epistemology is tremendously democratizing, because it does not presuppose whom or what is queer; rather it is the "biggest box (...) outside of the mainstream" (Skylar, 30, queer), a 
“doing," a mode of critique wherein one "says 'yes' to communities of resistance." Making theory queer involves more than proposing a theory about queers; it is "a way of reading or way of looking at the world" (Gerhard, 24, gay/queer) that points "out a wide field of normalization, rather than simple intolerance, as the site of violence" (Warner, 1993, p. xxvi). Queer is "not just a placeholder for LGBTQ" (Luca, 28, queer), because it attends to the "hegemonic social structures by which certain subjects are rendered 'normal' and 'natural' through the production of 'perverse' and 'pathological' others" (Eng et al., 2005, p. 3). In particular, Warner (1993) rejected a "minoritizing logic of toleration or simple political interest-representation in favor of a more thorough resistance to regimes of the normal" (p. xxvi) that involves the continuous deconstruction of the tenets of positivism at the heart of identity politics. For instance, Phelan (32, gay/queer) rejected the classic humanist, neo-liberal coming out narrative - that is, gay men discover the "truth about themselves" (Connell, 2005, p. 151) as they pass through six linear stages: prehistory, preparation, contact, acknowledgement, immersion, and consolidation - by asserting that:

You come out all the time (...) um, because the assumption, I think, goes in this order for me when I bump into people I don't know: "this one is asexual," followed by "this one is heterosexual," followed by 'oh, this one is gay," OK?

The coming out narrative produces an inside/outside binarism: those in the dark, marginal, false closet are stigmatized for ostensibly living "inauthentic" lives; but this rhetoric disguises "the fact that most of us are both inside and outside at the same time (Fuss, 1991, p. 5). According to Phelan, whether one is in or out depends on "the assumptions (...) of heterosexuals"; especially because of his cerebral palsy (e.g., Shuttleworth, 2000), he "encounters [the assumptions] all the time, that truly healthy people are cisgendered, heterosexual men who are male and women who 
are female." The implications of Phelan's deconstruction of the inside/outside binarism nicely captured the principles of queer epistemology: it celebrates difference, non-conventional sexualities, liminal identities, all the "many diverse interests at play" (Luca, 28, queer) through a deliberate rejection of hegemonic social structures that dissemble the effects of sexual, gender, racial, and classist oppression (among others). This subjectless critique is subsumed under the undifferentiated sign queer, united not as a unitary identity but as an anti-identity with a shared epistemological framework - "a shared relationship to norms" (Gerhard, 24 gay/queer) - and a common opposition to normalizing narratives.

When I asked Gerhard, "How would you describe the gay community?" he responded: Gerhard: Oh, that's a hard one. Um, I feel like the - I go to a gay church here and I like try to do volunteer stuff here and I feel like part of the reason I do that is because it reminds me that the gay community isn't just about drinking and sex, as fun as those things can be. And I feel like, I'm actually quite impressed with a lot of aspects - with those aspects of the gay community, um in Toronto. Like I think it's Interviewer: The church or the drinking and the sex? (Laughter) G: Well, it's all had its moments. But, yeah, the church and the whole thing about Queers Against Israeli Apartheid was really interesting to me 'cause that couldn't even happen in New York, where people say "We want to be queer and we're not anti-Semitic, but we also want to be critical of some of the things that Israel's doing." Um, like, that, that couldn't even happen in New York, which is supposed to be so progressive and so enlightened. Uh, but it could happen here. I'm not saying it wasn't complicated, but that happened right as I was getting ready to move here and it was like, "Whoa, that's cool." But, it's funny, because I think we do, rhetorically at least talk about the gay community 
as this monolithic thing that is always shallow, is always about bars and hooking up. And that stuff is important for a whole lot of reasons but, um, there's so many, there's so much more to being gay and certainly in this city than, like, trying to go out and get laid. Um, and that's not to say that's petty, but, um, yeah. So, it's so complex.

I: Would you describe yourself as a member of a gay community?

P: Yeah. Or like a gay mafia? Um, I guess.

I: And if so, why or why not?

P: Sure, I mean, if that's helpful to people to understand, like, what, the relationship I'm in or what I'm trying to do. Certainly it's not the same thing as being in like an immigrant community or something like that. And there's also not just one gay community, I guess. So, yeah.

He deployed the "more than clubs and bars" interpretive repertoire: gay communities involve more than "getting laid" or consuming alcohol and drugs. It is not that Gerhard was interested in rendering a moral judgement; those libations are certainly "fun," but he situated as problematic a Signorilean positioning of one aspect of gay culture "central stage, as if it represented all gay men, rather than emphasizing the diversity of subcultures" (Wood, 2004, p. 56). According to Gerhard, there is more to gay culture than psychology's portrayal, than "bars and hooking up" or other stereotypic notions of shallowness or promiscuity. Not "this monolithic thing," it is also "progressive" and "enlightened," it harbours denizens whose anti-conservative political aspirations and subjectless critique may be broadly applied to multiple social antagonisms. For Phelan (32, gay/queer), "gay male communities are much more diverse and much less sort of politically aligned than a lot of people would like to think." When people talk about the gay community "in the singular," Phelan stated that he asks them, "'What do you mean?' Because 
we don't even know how to talk to each other." Specifically, he considered the current mainstream gay identity politics' transphobia, exemplified by privileged White cisgendered male gay activists, like Dan Savage, who are “sort of like, 'I don't want to talk to you, you're a freak! You're not in my community. Go away. Bisexual men: go away. You're not part of my community." Normalizing discourses are problematic - in any form, from essentializing scientific theory to Sullivan's (1996) assimilationism - because they standardize the gay subject as White, middle-class, and male while silencing other voices and stymieing necessary modes of queer critique, including, as Phelan noted, trans activism, but also feminism and racialized critique (e.g., Ferguson, 2003). Though the queer participants viewed gay communities as diverse, they acknowledged "some sort of unifying thread between all these different, different communities" (Morgan, 22, queer): many gay/queer men/genderqueers live their lives "differently than sort of what mainstream heteronormative society does" as the dissatisfied, disturbed, disordered term in the homo/hetero binarism. Understanding abjection as a shared condition (Warner, 1999), Gerhard (24, gay/queer) depicted queer subjects as possessors of a "responsibility to challenge homophobia," as agents of resistance destabilizing "notions of the normal" (Halberstam, 2005a, p. 4) and sowing the seeds of a queer way of life.

Generally, diversity for the gay participants was not diversity in politics or any other interest in dismantling hegemonic social structures; rather, their diversity was consumed by a neo-liberal remaking of the self and a concomitant espousal of individualism. For instance, Vito (23, gay) stated, "the gay community in Toronto is very like, very open and very, very trusting, and very like, accepting"; like the queer participants, he relied on the "more than clubs and bars" interpretive repertoire: "Because there's a lot of like outlets that you can go to, other than like the night scene (...) there's the 519, there's [community organizations for] like people with AIDS, 
and, there's a lot of resources and outlets." Before coming out, Bruce (28, gay) thought that "the gay community [was] the bars and the clubs and things like that on Church Street or kind of this idea of what a small town boy might have saw Toronto as the big city - as an escape from that situation." Now, having escaped, his "scope has opened and [he's] starting to see that there is diversity in that community" - there are "a lot of subcategories that exist like the trannies, the bears or - and people with different ethnicities." Bruce positioned himself, pre-coming out, pre"big city," as peripatetic, seeking the proper gay identity to call home much like an itinerant, impressionable freshmen whose first day at a high school is spent discovering its cliques and "fitting in" means the difference between a letterman bomber and a black leather jacket. Bennett (30, gay/queer) affectionately, shrewdly lampooned Bruce's narrative:

Interviewer: So, Bennett, what does exist?

Bennett: Oh my god. Skinny, sparkly, blonde twinks with bad eyebrows. (Laughter) Like even I was at 18, the jock muscle boys that wear like varsity shirts even though, you know, they don't play sports, but they go to the gym. The leather daddies, the bear daddies, the skinny club guys, the fat club guys, um the "wigger"" boy thugs, the White boys that try to look like they are ghetto gangsters, but they're from Brampton so why are you trying? (Laughter) The newbies that always have the bleach blonde die job and frosted tips because they've come to the big city from a small town, and "I need highlights!" And then there's the guys that you know the older daddy types that aren't trying to be daddies, but they're sort of like they dress like 20-something gay boys, but they're 45 ?

Throughout his interview, Bennett spoke affirmatively about the generation and celebration of camp subculture as a resistant political manifesto aimed against heteronormative structures of 
identity and identification (Padva, 2000), and he encouraged the proliferation of representations of cultural/alternative gayhood; his laughter was not directed to the frivolity of appearance norms among gay/queer subcultures. In fact, Bennett recognized that, as free subjects, gay men may plan their lives (of course, within certain constraints), affirm their values, choose their friends and "cliques" - give accounts of themselves - but they do so on the condition that they invoke that is, subject themselves to - the terms, meanings, and categories that they and others recognize, the signifiers we have learned in the process of acquiring our native languages (Belsey, 2002). Bennett found humorous, for instance, White gay men "from Brampton" who view their "wigger boy thug" presentation as the authentic expression of their "true" "ghetto gangster" selves. The gay participants situated gay communities as diverse out of necessity: one adopts, say, a bear or twink aesthetic not as a homecoming but as a coming into one's authentic self. The "gay community" was fashioned into identificatory diversity to reflect the innate "reality" of its unique constituents, allowing them to "not really care what other people think, and just be them. They're them, they are who they are" (Vito, 23, gay). Likewise, Jayden (30, gay) described gay communities as "so diverse, so diverse" yet similar because "[gay men] are all striving to...to enjoy who we are."

In Flexible Bodies, Martin (1995) warned about our new "age of flexibility" and its patina of postmodernism: over half a century, our understanding of the immune system has been gradually supplanted, from the Cold War metaphor of an army defending the body against foreign invaders to a "field" whose dysfunctions contribute to allergies, cancer, heart disease, and AIDS, among others. A corollary of this emergent view of the body as a complex, constantly changing system is the notion that some people are more flexible than less adaptable others. Flexibility has become a virtue for individuals and their bodies. Halberstam (2005a) noted that 
personal and bodily flexibility has become a commodity and a form of commodification:

"Promoting flexibility at the level of identity and personal choices may sound like a postmodern or even a queer program for social change and liberation" (p. 18), but it often has the opposite effect. Rosalind Gill's extensive research on post-feminism and neo-liberalism has highlighted flexibility's regressive, capitalist underpinnings. Post-feminism is a newer mode of feminism that emphasizes "autonomy" and "choice." For instance, a pre-teen girl's "choice" to wear a sexy Abercrombie \& Fitch thong is deemed an expression of her agency and not the net result of patriarchal media culture. Gill (2008a) wondered, "Why the emphasis on young women pleasing themselves when the look that they achieve - or seek to achieve - is so similar?” (p. 435). Why are free choice, flexibility, and diversity so fetishized? Because, according to Gill (2008a), "just being one's self" has become a neo-liberal marketing ploy: the advertising strategies of large corporations sell products by casting consumers as simultaneously all the same and all different. Popular makeover shows operate similarly: when a woman's "staid" style is replaced with something "trendier," she has not been radically altered, apparently; rather, the makeover simply "enhanced" the "real" "her." People buy to be more themselves. To quote a passage from The Invisible Committee's (2009) recent anarchist manifesto:

"I AM WHAT I AM." This is marketing's latest offering to the world, the final stage in the development of advertising, far beyond all the exhortations to be different, to be oneself and drink Pepsi. Decades of concepts in order to get to where we are, to arrive at pure tautology. I = I. He's running on a treadmill in front of the mirror in his gym. She's coming back from work behind the wheel of her smart car. Will they meet? (pp. 29) In the case of post-feminist discourses, women buy into the sale of "empowerment" while very circumscribed "socially constructed ideals of beauty or sexiness are internalized and made our 
own, that is, really, truly, deeply our own, felt not as external impositions but as authentically ours" (Gill, 2008a, p. 436). Such an emphasis on autonomous choice is problematic, because it "remains complicit with, rather than critical of, post-feminist and neo-liberal discourses that see individuals as entrepreneurial actors who are rational, calculating and self-regulating" (p. 436). Similarly, the recent proliferation of diverse, post-feminist representations of (speciously) emancipated women in advertising - the young, heterosexually desiring "midriff," the "vengeful women," and the "hot lesbian" - actually construct oppressive heteronormative gender relations (Gill, 2008b). Images of "empowering" "sexual agency" are forms of regulation that necessitate the remodelling of the self - and, in this case, feminine subjectivity - to fit the current postfeminist, neo-liberal adulation of flexibility and diversity. The emergence of what Probyn (1997) called the discourse of the choiceosie treats choice "as devoid of social and political ramifications" (Gill, 2009, p. 363); thus, a woman's freedom to "choose" to re-embrace traditional femininity is viewed positively, as authentically her own.

The gay participants' characterization of gay communities echoed a parallel post ethos: they spoke about living in a post-race, post-gender, post-gay milieu, an undifferentiated mass of difference reflecting the infinite assortment of flavours in the gay ice cream parlour. A gay man's freedom to choose to be his authentic (twink, bear, leatherman, gym bunny) self - and discover his rightful home within the gay kingdom - was similarly celebrated. Halberstam (2005a) noted that the rise "of this liberal, indeed neo-liberal, notion of 'uniqueness as radical style" (p. 19) is nothing more then "transgression [marketed] as individualism" (p. 19). It is not comparable to queer epistemology, which contests dominant heteronormative and masculinist assumptions and institutions, as Morgan (22, queer) previously noted, in order to make room for different ways "of organizing relationships, families, households, communities etcetera, etcetera, 
etcetera." Instead, the gay participants relied on a neo-liberal queer posturing that begins “'inside' of the subject” (Berlant, 2002, p. 74). In other words, their talk of diversity focused on interiority, on a remaking of the self without a concomitant attention to social, political, and economic relations (Halberstam, 2005b). The differences between the two strategies were particularly evident when the participants discussed whether they believe a gay body ideal exists. All participants - gay and queer - rejected the notion of a thin yet muscular (e.g., Martins et al., 2007) monolithic ideal, but - as with their perspectives on the "gay community" - their strategies differed. For the gay participants, "I AM WHAT I AM" (The Invisible Committee, 2009) morphed into an "I like what I like" interpretive repertoire:

Interviewer: OK. Um, do you think a gay body ideal exists?

Vito: Um, I guess like the one that's projected in the media, it's like someone, someone who's like very, muscular and who works out, and who's like... who is, that can be promiscuous but that's not the case. You know like for me and for a lot of other gay men, you, you, there's not a lot of - there's not a lot of gay men who do work out or like, or, or, or who love to workout but they just you know, are, they are who they are. (Vito, 23, gay)

The "shameful" stereotype of the gym bunny - one of mainstream media's tried and true representations of gay men - belies a community of authentically diverse men who all have different tastes in men. There is "not a single [ideal], because everyone has different preferences" (Jian, 25, bisexual/gay); if hierarchies exist, they only exist "inside" of the subject as "there's certainly hierarchies for each person [emphasis added]" (Jian). Within the "I like what I like" framework, all bodies are equal. When I asked Jian, "Where do you think these ideals come from in terms of body ideals and stuff like that?" he asserted that it depends on 
"personal definitions," knowing "what you like," and having "a gut reaction to what you see." And, ostensibly, the "gay community" is supplied with enough stock characters or "types" to fit every gay man's needs: the hirsute bear, the hairless twink, the brawny leatherman, etcetera. This strategy, wherein "the body ideal can be in the eyes of the beholder" (Vito), was also effected by Ahmet (27, gay):

Interviewer: Ok. Um, do you think a gay body ideal exists?
Ahmet: Gay?

I: Uh, body ideal...

A: No, no, everybody likes something different, definitely not.

I: Ok. Um, so you think that there are many different body ideals?

A: Yeah, even the color. For example, I'm into Black guys, but my friends hate, don't hate but don't like - I put them on the list first place, not on the bottom. Some people like Asian, some people like feminine, some people like masculine, some people like slim. It's very different.

For Ahmet, a gay body ideal is essentially an oxymoron, because each gay man possesses a unique understanding of what is and is not attractive. His talk harkened to the explosion of psychological research over the last 20 years (e.g., LeVay, 2012) clamouring to "prove," once and for all, that homosexuality is caused by some mysterious, peculiar admixture of genetic material, hormones, and foetal endocrine environment, invariably couched in terms of "excess," deficiency," or "imbalance." According to Sedgwick (1993), discourses that ground "identity in biology or "essential nature"' (p. 78) have been adopted by mainstream gay identity politics and positioned as " authentically gay-affirmative" (p. 79). Essentializing same-gender desire presents an avenue to prove "the new right" (Patton, 1993) wrong and exclaim, "See, it's not a choice!" But, apparently, neither are a gay man's racial "preferences," which Ahmet depicted as 
analogous to leasing a car and choosing its colour: What will it be, titanium white or charcoal black? What happens when not "liking" "Black guys" is cast as firmly entrenched in one's genetic make-up? Is such a stance not complicit with - as opposed to apprehensive of racialized discourses that subjugate gay/queer of colour bodies in numerous gay/queer and heteronormative environments (Drummond, 2005a; Kong, 2004)?

Queer epistemology is suspicious of such a manoeuvre, which is likely why the queer participants, many of whom viewed "queerness [as] refusal of that ruling [of] a neo-liberal agenda" (Skylar, 31, queer), spoke about multiple, diverse subcultural body ideals - expanding not only what gay means, but how it appears - while maintaining an awareness of, for instance, "how exclusionary uh a lot of the [gay] scene feels for fat femme queers of colour" (Ben, 30, queer). Their subjectless critique highlighted how certain hegemonic social structures position some bodies as beautiful and others as less desirable. For instance, Bennett (30, gay/queer) reminisced about his experiences moving through various "queer identifying and more alternative fringy gay communities" where "you are getting a combination of really skinny guys, slightly chubby guys, um, occasionally big fat guys with girl - crazy amazing girls' curves all over - also a lot have still very lean bodies kind of like the yoga-looking body." Likewise, Gerhard (24, gay/queer) identified Boylesque - Toronto's all-male queer burlesque revue - as a "world where [the notion of a gay body ideal] is interrupted," a "space where every body is OK, whatever shape it is." Unlike the gay participants, who categorized distinctive gay subcultures, like bears, with exacting, easily identifiable codes of adornment (Hennen, 2008), as examples of gay body ideal diversity, the queer participants were less inclined to specify exactly what diversity looks like. Rather, they concentrated on explicating their shared opposition to disciplining, normalizing social forces in order to open-up space for queer iterations of 
embodiment. Many queer anti-assimilationist social organizations and liberation movements, like Queer Nation, employ a similar strategy: under queer, they affirm an abstract unity of differences without wishing to name and fix these (Seidman, 1993).

Certainly, neo-liberal individualism problematizes psychology's bounded depiction of gay aesthetics through its promotion of boundless diversity, but, like Bordo's (1993) anorectics, it presents an ineffectual critique. The gay participants' "technocratic" (Morgan, 22, queer) approach to diversity was less inclined to consider, for instance, "bear culture" (Gerhard, 24, gay/queer) as an example of "fat positivity," as a queer subculture united by the embodiment of its outcry, “'Oh, we don't need to look like that ideal of man!' Of, you know, tall and fit and stuff like that." Instead, they presented the "gay community" as "accepting of everyone" (Vito, 23, gay) - including fleshy, burly bears - and their bodies, gender expressions, races, socioeconomic statuses, etcetera. This strategy instantiated multiple politically castrated ethnic/essentialist identities, multiple institutionally complete subcultures with concomitant body ideals - a jejune "multiculturalism" where "bears go with bears, twinks go with twinks" (Jayden, 30, gay). Instead of the resistant "bear who ironizes hegemonic images" (Phelan, 32, gay/queer), one is left with "the bear ideal" (Morgan) - the emblem or manifestation of an idiosyncratic, though "true" self or the object of a "natural" sexual "preference." Thus, Antonio (19, gay) lamented how "[the gay community] gets very high school, really quick, like there's a lot of like social like cliques." He and many other gay participants discussed cliques, not critiques: diversity without hierarchies. Alternatively, the queer participants' strategy generally acknowledged that a "person who is disabled through one set of oppressions may by the same positioning be enabled through others" (Sedgwick, 1990, p. 32). They situated issues of self, subject, and identity as marking social junctures in the institutional, administrative, juridical 
organization of society, as axes of social stratification (Seidman, 1993) and were more apt to explore how certain discourses align to imbue specified bodies - typically masculine, fit, youthful, wealthy, able bodies - and not others with embodied cultural capital.

Unlike the new orthodoxy, which posited one gay body ideal, Skylar (31, queer) stressed that queer communities flaunt "a set of minority tastes." Much like how Ashley (24, gay/queer) spoke about "the main group of the gay community" and a legion of alternative "subgroups," Skylar noted that “there's one mainstream gay body ideal I think, uh, and then anything that isn't [becomes] very explicit (...) so there are more than one, but there's definitely sort of a hierarchy of desire that exists." As an amorphous mass, queer bodies - inculcated in opposition to more mainstream gay "tastes" - reflect diverse ideals less inclined to jockey for positions along a shifting "hierarchy of desire" than to demolish it. As per mainstream gay identity politics, "there's sort of a global circulation of the White, well-oiled or twinky kind of body" (Gerhard, 24 gay/queer), but, within queer communities, where "people's interests are always overlapping," "that ideal's really displaced, you know." As one example, Gerhard mentioned his "queer Filipino artist" friend "who is really trying to displace the way, um queer Asian men are kind of exoticized in his art" and emphasized how such queer "displacements" or "interruptions" construct spaces "where Black and some Asian bodies [take] centre stage," where "not everyone cares what White, gay men think or even are misplaced by their racist desires or whatever, you know." But, these spaces are only realizable through a "queer coalition oriented politics" - a politics of resistance that is guided by a transformative and affirmative social vision - that, for instance, increases awareness of the subjugated position of Black and Asian bodies within gay communities - "something that haunts heterosexual people," too: 
I think, you know, I mean, Whites are usually on top, right, or, um, I mean on top of the hierarchy. And, uh, there is a sort of ranking of people of colour sometimes. I mean, you even hear that in the way that different races are talked about in the pejoratives. You know, if you like Whites, you're a "snow queen," if you like Asians, you're a "rice queen," if you like Latinos, you're "bean queen," if you like South Asians, you're a “curry queen". Then if you like Black guys, you're a "dinge queen" - that one's talked about not even as food that can be consumed, but dirt. You see that in porn descriptives, right? (...) Yeah, I think those hierarchies are very much - you see them on Grindr ${ }^{12}$ profiles, you see them in a lot of places. Um, but, I don't know if that's the whole story. (Gerhard)

Similarly, Phelan (32, gay/queer) noted that, on some "Platonic ontological level," an "actual ideal gay" does not really exist; rather, body ideals are "social perceptions" informed by "hegemonic masculine images," among other oppressive discourses where "class is involved and (...) you know, skin tone is involved and musculature and all this sort of thing." Furthermore: What about disabled bodies? Effeminate bodies? This thesis's deconstruction of psychology's dominant explanations of gay male body dissatisfaction was not intended to just problematize the two orthodoxies' representationalist, essentializing accounts of identity, community, and body ideal - the point is not that body fascism does not exist or that body norms do not exist, because clearly they do. More precisely, the intimation that body image researcher's may properly comprehend gay/queer male/genderqueer embodiment without casting their theoretical nets beyond the strict community boarders they discursively delineated seems particularly troublesome. From the gay and queer participants' interviews, it is apparent that there is something going on beyond the insular machinations of a normalized gay community; as Skylar 
noted, gay/queer communities are "not self-perpetuating closed-systems." Such an essentialist commitment forecloses the consideration of how gay/queer bodies are discursively produced and instantiated through technologies of power, through the panoptic mechanisms by which they self-regulate. Yes, there are men who engage in the kinds of behaviours Signorile (1997) labelled body fascistic, but how are they located within a paradoxical relationship to enduring hegemonic definitions of masculinity? If psychology seeks to "explain" gay male body dissatisfaction, should it not explore the hierarchical organization of masculinities and sexuality in modern social life (Duncan, 2010)? What about queer forms of resistance made possible because one is subject to knowledge/power? For these reasons, the old and the new orthodoxies' accounts are incomplete. The remainder of this thesis destabilizes the gay male body dissatisfaction imperative and explores the material manifestations of discourse through the Foucauldian notion of subjection. The following analytic section presents a theoretical account of gay/queer male/genderqueer embodiment by explicating how the participants developed their individual understandings of sexual identity and embodiment while navigating discourses about heterosexism, hegemonic masculinity, neo-liberalism, and queer epistemology.

\section{Heterosexism, Hegemonic Masculinity, Neo-liberalism, and Queer Epistemology: From Internalization to Subjection}

Messiness is absent from the old and new orthodoxy's construction of gay culture and how it may, or may not, influence gay men's body image. As Duncan (2010) noted, most research that compares gay and heterosexual men draws "on a psychological model of the subject familiar to body image research more broadly, in which individuals are understood to be vulnerable to 'social forces,' unless they demonstrate rational self-control and exercise autonomous resistance to them" (p. 437). Apparently, gay media produces negative gay images, 
in a cultural vacuum, which are internalized by gay men, thus resulting in dissatisfaction, disturbance, and disorder. However, "body image research more broadly," if Levine's work is any demonstration, is beginning to ponder messiness. For instance, Smolak, Murnen, and Thompson's (2005) tripartite influence model or Cafri et al.'s (2005) - both developed to theorize the origins of disordered eating and the pursuit of muscularity among heterosexual men - move beyond an understanding of internalization as a facile, top-down process. Indeed, Frederickson and Roberts' (1997) Objectification Theory and, in particular, its recognition that feminine body standards are regulated by patriarchal ideology, has done so for at least 15 years. The role of gay culture, as it is rendered in the old and new orthodoxies, must be similarly problematized. If a gay man walks through one of Toronto's gay villages and encounter a camp image of a topless, muscular man, contrapposto, speckled with digitally-rendered glitter, in a club event advertisement hastily taped to a utility pole, is that necessarily an oppressive aspirational image? And, if aspirational, why is it presented as such? What about larger discursive regimes of power or ideological practice? What about the sort of resistance that is made intelligible because he is a subject of power?

Subjection is predicated on a Foucauldian conceptualization of power. In "The Subject and Power," Foucault (1982) suggested that, since the $16^{\text {th }}$ century, a new political form of power has been in a state of perpetual development. Unless they broke the law, most premodern persons lived in deep obscurity, unnoticed by various authorities; modern societies, however, intervene from birth to shape, train, and normalize. This new political structure, the modern Western state, is able to wield an individualizing and totalizing power, because it has integrated an older power technique that originated in Christian institutions, called the "pastoral power." To quote Foucault (1982): 
[Pastoral power] is salvation oriented (as opposed to political power). It is oblative (as opposed to the principle of sovereignty); it is individualizing (as opposed to legal power); it is coextensive and continuous with life; it is linked with a production of truth - the truth of the individual himself. (pp. 783)

Pastoral power has multiplied and spread beyond ecclesiastical institutions. Now, the modern Western state is a very sophisticated structure: the officials of its new pastoral power have increased, as have their aims. Knowledge/power is exercised, rather than possessed, and productive, rather than suppressive: it does not emanate from one specific location, but is diffused throughout social institutions where it is implemented by innumerable, replaceable functionaries (Foucault, 1977, 1978, 1982). Foucault (1977) opens Discipline and Punish by detailing the violent, chaotic public torture of Robert-François Damiens, who was convicted of attempted regicide in the mid- $18^{\text {th }}$ century, his limbs dismembered by harnessed horses as was typical for absolutist France. He juxtaposed this gruesome scene with a list of regulations for institutionalized young offenders, whose daily lives were highly regimented, in early-1 $9^{\text {th }}$ century France, less than fifty years later. The rules prescribed the exact distribution of their time: up at six; five minutes to dress in silence, another five to make their beds; work until ten and then a meal, after washing their hands; school at twenty to eleven for two hours; and so on, until bed-time at half-past eight. Why the radical change? If the public execution was a spectacle in which the state demonstrated its cruel power to punish those who challenged the sovereign, the institution seems almost too human, lenient, constructive. Of course, it is, but that is not the point. The institution's agenda is a discipline that subjects the inmates to a regime designed precisely to construct them as conforming citizens - which is to say subjects, in both senses of 
that term - who learn to work by themselves in submission to the values of society, under its panoptic surveillance.

In “The Carceral," Foucault (1977) regarded modern society since the 1740 s as a series of increasingly prisonlike institutions that work toward "the accumulation and useful administration of men” (p. 303), conceived as docile subjects. Indeed, Foucault's writings from 1969 to 1980 centred on the processes through which subjects are produced: for instance, he developed the phrase technologies of the self to connote individualized practices, enacted by subjects and encouraged by discourse (Foucault, 1988). For instance, discourses about the healthy or beautiful body are accompanied by exercise, diet, adornment, embellishment/ornamentation, beautification, surgery, etcetera. We are subject to said technologies - established through knowledge/power, through discourses of "expertise," like medicine, law, and science - as we are inculcated as subjects under the condition that our individuality "be shaped in a new form and submitted to a set of very specific patterns" (Foucault, 1982, p. 783). We are not regulated by an exterior relation to power; rather, our bodies are the sites at which technologies of power normalize and are deployed as panoptic mechanisms of self-regulation as we approximate an ideal, a norm of behaviour that we experience as a kind of psychic identity. According to Butler (1997), subjection is "the process of becoming subordinated by power as well as the process of becoming a subject" (p. 2); through discursive productivity, the subject is initiated by a primary submission to power. The claim that discourse "forms" our identities does not mean that it “causes" or "determines" them - disciplinary regimes, which "systematically form the objects of which they speak" (Foucault, 1972), are far messier. Thus, the notion that gay culture, irrespective of other technologies of power, produces media/cultural messages/images that are 
imposed upon gay men, who, weakened by their force, come to internalize or accept their terms, is problematized.

And, what about a gay identity? Writing about the history of sexuality as a history of discourses and bodies (as opposed to a history of science), Foucault (1978) proposed that modern power produces the very categories, desires, and actions it strives to regulate; it names certain sexual acts criminal or perverse while increasing its opportunities for intervention and structuring the world in certain ways. For Foucault (1978), the medical categorization of homosexuality in 1870 is an example of a disciplinary power that discursively produced homosexuality by labelling certain actions as homosexual, behaviours that had previously been called "sodomy" - a catchall term that included bestiality and some non-reproductive heterosexual acts. The desire for a precise, "scientific" categorization, by the medical profession - and by psychologists - of human sexual behaviour constituted and constitutes specific incarnations of subjecthood. Thus, sexuality serves as a "dispositive" - or, device - connecting power/knowledge with new objects, domains, and bodies (Foucault, 1978). Modern science and expert techniques do not uncover, say, the "truth" of the gay male "experience" so much as they exercise power through the production of knowledge: "In this formulation, [Foucault] suggests that power acts not only on the body but also in the body, that power not only produces the boundaries of a subject but pervades the interiority of that subject” (Butler, 1997, p. 89). The label sodomite says nothing beyond pointing to the commission of particular acts; but the homosexual carries his homosexuality within himself at every moment: through the connection of actions to "being," of what I do to what I am, he is subjectivated, an object of analysis and a target of intervention, whose gay identity must be figured out through an interpretation of his actions. Is psychology, and, in particular, its quantitative comparative research, not thoroughly 
implicated in the construction of a particular gay identity? Furthermore, to what extent do these studies fail to integrate elements of a Foucauldian account of discursive productivity into their explanatory models of gay male body dissatisfaction because their position as a disciplinary power delimits such a self-reflective distancing?

Heterosexism, hegemonic masculinity, and neo-liberalism. Given that one's identities, behaviours, and expressed beliefs are largely engendered by one's cultural history and social positionings (Shotter \& Gergen, 1989), it was not surprising that many participants described, at length, how their sexual identities - gay and queer - and accompanying embodiments were negotiated against heterosexist discourses. Heterosexism may be defined as:

A diverse set of social practices - from the linguistic to the physical, in the public sphere and the private sphere, covert and overt - in an array of social arenas (e.g., work, home, school, media, church, streets, etc.), in which the homo/hetero binary distinction is at work whereby heterosexuality is privileged. (Plummer, 1992, pp. 19)

Throughout this thesis, heterosexism is used interchangeably with heteronormativity, which may similarly be defined as a broad set of "lifestyle norms" that propose that individuals neatly fall into two distinct and complementary genders with "natural" accompanying life roles. Heteronormativity refers to the contention that heterosexuality is the "normal" sexual orientation and that sexual (and marital) relations are more (or only) fitting between a man and a woman. Accordingly, a heteronormative worldview involves the alignment of "biological" sex, sexuality, gender identity, and gender roles (Lovaas \& Jenkins, 2007). In psychology, the closest analogue is Meyer's (1995) oft-cited minority stress, a concept based on the premise that gays, like members of other "minority groups," are subjected to chronic stress related to their stigmatization. As argued in this thesis, the minority stress models developed to theorize gay 
male body dissatisfaction exhibit a kind of epistemological determinism - negative regard from others ineluctably leads to negative self-regard (Rosenberg, 1979) and adverse mental health outcomes (Crocker \& Major, 1989) and other "traits due to victimization" (Allport, 1954), "including shyness [and] obsessive concern with [one's] stigmatizing characteristic" (Meyer, 1995, pg. 39) and "masculine body ideal distress" (Kimmel \& Mahalik, 2005). Likewise, any model that is developed through testing "a sample of [741] socioeconomically advantaged men" (Meyer, 1995, pg. 39) - 89\% of whom were White - and claims to account for the experiences of all other "minority groups" should be subject to scrutiny. Nevertheless, Meyer's (1995) conceptualization of the three processes of minority stress - internalized homophobia, expectations of rejection and discrimination (or, perceived stigma), and actual prejudice events as a "matrix" is pertinent. Heterosexism is not just about abuse and negative family experiences, though there is a relatively high prevalence of childhood sexual, physical, and verbal abuse among LBGT youth (Corliss, Cochran, \& Mays, 2002; Grossman \& D’Augelli, 2007); or overtly stigmatizing attitudes, though they are widespread among youth and adults (Sharpe, 2002); or "sexual orientation victimization," though over a third of undergraduates in one sample reported experiencing derogatory remarks, verbal harassment, threats of physical violence, and physical assaults (D'Augelli, Pilkington, \& Hershberger, 2002); it is also about an all-encompassing sense of oneself as lack, as finding oneself on the oppressed end of the homo/hetero binarism in ways that are overt, but also ineffable and insidious, and that function through macro-level social policies and micro-level patterns of social interaction (Yardley, 1997). Heterosexism is an intangible subjectivating force, well encapsulated by Jian's (25, gay/bisexual) admission that, before 12 years of age, "[he] was sort of like straight by default" or straight until proven 
otherwise. This points to his implicit acknowledgement that an expansive swath of the world's including, Toronto's - sexual default setting is heterosexual.

Consequently, several participants discussed feeling continually "othered" throughout their lives. Vito (23, gay) reminisced about his childhood, noting that he "was always used to like, seeing heterosexual (...) examples on screen or like on TV. And I'm the type of person who's like really into pop culture, so like that's where I get all like, that's where I learn all my lessons." And those lessons imparted a strict, "traumatizing" (Vito) heteronormative worldview: "when I would see a straight couples on screen, or straight activity on screen (...) I would feel like 'Oh, this is what I, I should be doing. This is what I, like should strive for."” But, that "was not always the case." Vito did not have "gay examples, or homosexual examples of people and characters on screen" - television or movie screens were not sites of identification, but projections of a way of life from which Vito felt estranged, the inscription of a longstanding feeling of difference experienced by many gay/queer youth (D'Augelli, 2002). Similarly, Skylar (31, queer) plainly noted that, "Yeah, obviously we live in a culture that's heteronormative": he felt it when he met friends at a "hipster bar" only to discover that he had been invited to a “"boy/girl' dance night"; when he "went to the symphony with friends of [his] - two straight couples $-(\ldots)$ and felt lonely in ways that [he] didn't think they did," something that "was beyond a fifth wheel loneliness"; "growing up in the LDS culture," where he experienced a definite "gender segregation," yet "felt more comfortable" in the company of women though "it was made very, made very clear," implicitly, that he "wasn't allowed in the kitchen doing women's work." For Skylar, heterosexism is “there and it's present and it's active but I think that, um, it's also clear and explicit enough that anything else that's on the table gets rooted through this very explicit sort of sluice channel." 
What gets through, and sanctified as acceptable, was positioned as restrictive and disciplining. For instance, as an actor, Ben (30, queer) has discovered just how "very, very conservative the film and television industry is," which he views as reflective of his family environment and society, more generally:

If you're going out for an audition and, and the part is not specifically a gay role, you should not present anything queer about yourself generally, um and so yeah I've been you know been taught to uh repress that a little bit um and I mean my family, well my dad specifically is happier not seeing aspects of my queerness, and yeah society in general, even you know in spaces that, where I have not experienced any specific homophobia or anything, just to feel comfortable and more at ease, it's just a lot easier to move through those spaces with less queer expression. Um, which is frustrating, and sometimes will force me to do the opposite and think, "Well, fuck you. I'm going to be as queer as I want."

This erasure of signifiers of gayhood will be discussed shortly as it is typically manifested as the concealment of effeminacy. Here, emphasis is on how heterosexism inculcates vigilance reminiscent of the anxiety with which Goffman (1963) suggested some stigmatized individuals approach social interactions. Ben knows that there are consequences (perceived disapproval, rejection, discrimination, violence) for being as queer as he wants, which is why he "sways back and forth" between "rejecting [and not rejecting] the norm (...) the assimilation of heteronormativity." Similarly, Gerhard (24, gay/queer) "had a very Pleasantville childhood": he was raised in a "not super conservative, but traditional" household with parents who harboured "a very specific idea of what it means to be gay" and were "very critical of how femme [he] was for a while." As a result, he felt "accountable to (...) mostly middle-class, White" 
heteronormative individuals, even in the assimilationist gay politics he flirted with in high school. His "politics were really put into crisis" only when he moved away for university and developed friendships with people "who were, like, from working-class backgrounds or were trans or of colour." This constant self-regulation necessitates the development of an ability to keenly assesses social interactions, to "suss out" situations "where [one] feels there may be strong views around homosexuality" (Bruce, 28, gay):

If I'm with more a female group, or if I'm with my gay friends, I feel more comfortable with it and I feel that I may act in a way that's more quote unquote "gay," than I might if I' $m$ in a more professional setting or if I' $m$ in a situation where there, especially if there are a lot of heterosexual men, I may um kind of butch it up a bit.

Some places are safe, sometimes, when populated by some people - it is up to Bruce to figure out where, when, and by whom. But he does not have a guide or a rulebook. When Ashley (24, gay/queer) was asked how his sexual identity has been shaped by heterosexist discourses, he answered:

All the information that I'm getting about how to um sort of live my life in a way that is not heteronormative is all being exposed to me now, and I don't have all these years of upbringing to have prior exposure to that, and because of that I'm taking in ridiculous amounts of information in my mind now, like right away and not having proper time to reflect on it or, and not having the childhood exposure to it, and so it's very difficult for me to understand how to interact or how I would like to interact because it's, I'm like getting all the information as I'm doing it, right, and I think that's like the major way in which it affects my sexual identity, is that I don't know how to um like I feel like I'm just 
sort of going with things, and I don't even have a lot of information to, to go on and that I'm just sort of winging it.

According to Ashley, someone who "tells you that they know everything about how things are [in gay culture] is ridiculously lying," because no one has "been consistently exposed to [it] their whole life or like, unless it's under really specific circumstances, that would be almost nobody right." How one negotiates one's gayhood - what it means, how it looks, behaves, etcetera - that assimilation of "ridiculous amounts of information" does not occur against a backdrop of unmitigated play or experimentation; it is a process tightly controlled by heterosexist discourses. But, clearly, the process through which one comes into social being (as gay or queer) does not exist in a vacuum; it involves ideological interests and power relations with material consequences for how one's gayhood is manifested or embodied. To quote Foucault (1980), "nothing is more material, physical, corporeal than the exercise of power." The material dimension of human lives is always socialized - mediated by language and modified by social activity - while the discursive dimension is inevitably physically manifested, for instance, in our speech, behaviour, and institutions (Yardley, 1997).

Indeed, as Denis Altman (1971) noted in the early 1970s, queer ways of being, queer communities, and queer bodies are all fashioned in relation to heterosexuality and its accompanying ideas of what it means to be a man. Camp first appeared when the bourgeoisie equated an affected body style, holding one's arm akimbo with one's hand turned back, with the effeminate sodomite; molly identification took place upon entry into certain subjugated spaces molly houses, cruising grounds, and the like - where the desire to have sex with other men became simultaneously perceptible as taking on and embodying a marginalized identity (King, 1994). Similarly, the homophile movement of the 1940s and 1950s materialized because, at the 
end of the $19^{\text {th }}$ century, as more men began to make their living through wage labour instead of as a part of an interdependent family unit, they became able to construct a personal life based on attraction to other men, which proliferated inventive ways of meeting one another, of sustaining an urban subculture, of embodying what they viewed as a trait that set them apart from the majority (D'Emilio, 1993). Gay Liberation was a struggle against the homo/hetero binarism, against the pressure to embody a sex-role system that views masculinity and femininity as mutually exclusive categories of gender identity (Seidman, 1993). The assimilationist tendencies of the ethnic/minority sociopolitical agenda and its penchant for eradicating or denigrating the markers of homosexuality may be viewed, as Warner (1999) proposed, as the embodiment of an identity ambivalence Goffman (1963) found characteristic of some stigmatized individuals. Other gay/queer subcultures - bears, leathermen, radical faeries ${ }^{13}$ - were born out of resistance to, in part, heterosexism (Hennen, 2008): in the early 1980s, men who frequented leather bars in San Francisco and other large cities wore coloured hankies in their back pockets as a safe, covert way of signalling their interest in a variety of sexual practices "to those 'in the know"' (Clarke \& Turner, 2007); in turn, some men began to place a small teddy bear in their shirt or hip pocket as a way of "refuting the clone coloured-hanky code" (Hennen, 2005, pg. 26) in order to declare, "I'm a human being. I give and receive affection" (Wright, 1990, pg. 54). Subsequently, bear culture was established, including its "all-natural," rural, everyman look: jeans, baseball caps, tee-shirts, flannel shirts, and beards (Hennen, 2005). As Ben (30, queer) asserted, queer forms of visibility - as multifarious as they may be - are organized around a common thread: "rejecting the assimilation of heteronormativity." He spoke about queers as "living in their bodies":

Like I don't have any tattoos, that's something that a lot of people use with regards to their bodies to express themselves, um and I have a friend that has a tattoo on his leg that 
just says "fag," and it shows when he's wearing shorts, and I think that's amazing, and I uh I mean there's a lot of reasons why I don't have tattoos, but I, like I would have trouble walking around in a shirt that says fag on it, for instance, um yeah, it's interesting.

Through his queer activism, Bennett (30, gay/queer) came to realize that "it is important to have [his] signifiers": his tattoo ("It's a tribute to the Civil Rights Movement and to Harvey Milk that says, 'You got to give em hope,' that was his slogan and 'never blend in' and it has the anniversary of the Stonewall riots at the bottom"), his "rainbow equality bracelet," his combat boots, his shaved head.

The participants spoke about heterosexism as a subjectivating force, as instantiating complex communities or other ways of being that foster or dictate particular embodiments. Though a gay or queer rulebook does not exist, one eventually comes to recognize, even learn or master, the "cultural stuff" (Skylar, 31, queer) - not just the codes of adornment or rules of recognition between gays/queers or within gay/queer subcultures (so that "the sort of underground languages become less and less underground"), but how to negotiate one's sexual identity, corporeally, while embedded within a heterosexist society (in other words, "knowing where the circles are.”) Gerhard (24, gay/queer) described this as a lifelong process:

Like, figuring out context and audience and how different they can be, like, that's the negotiation I'm always making, you know. Like, whether it's dating or job interviewing or whatever. So, um, and I never know how formal or informal to be or gay or not [emphasis added] 'cause I think I'm always out or like it's more like an open secret, I guess. Um, and I feel very grateful that I live in a time when I, I probably - there's still a lot of institutionalized homophobia, but I don't feel that I have to conceal it in order to 
get a job, right? So, yeah, it's about sexual identity (...) there's still really homophobic codes that we live, but, yeah.

Interviewer: You were also talking about, um, like "how gay I could be"? So, like, what would it mean for you to be very gay?

G: That's a great question. Um, 'cause even that's catering to people's expectations, right? Like, I have straight female friends from high school who watch Absolutely Fabulous and, like, that's there idea of - or, like, Will and Grace. And I think I sort of ham it up and perform that for them. Like, I see them twice a year and we have drinks. But I don't know if that's what I am all the time or what anybody's who gay is all the time. Um, but I, I, yeah, um, it's funny, like, I do think, without even thinking about it, probably assume it a little bit more. Like, I talk, like I'm obviously gay when I'm teaching, but I also talk a little more straight Marxist. But, I think that's also because the kids I'm working with - the judgement of what, what conversation would be most helpful for all of us in that space. And I might be wrong, you know. It's a calculation. Like, I'm still obviously gay, probably, I assume. But, um, that conversation, like, about class issues, because I teach urban geography, that feels like the most urgent conversation to have.

I: It sounds - right, contextually.

G: Yeah, yeah. And the funny thing is that as contextual as we all are, I'm still struggling to figure out certain contexts.

Just as Bordo (1993) theorized, Gerhard's talk harkens to the reciprocal tension between cultural images - his high school girlfriends' ideas about gayhood, his students' expectations of proper (heterosexual) pedagogical comportment - and the practical life of his body. Here, he, like many 
other participants, alluded to a turning on/off gay interpretive repertoire: one's gayhood was represented as a peripatetic phantasm, floating in to reanimate one's body, but dematerializing when necessary. Given the situation at hand, one can be more or less gay - the hammy queen or the "straight" Marxist. How one dresses, walks, talks, etcetera are perpetual sources of signification, but what gay "really" means or "actually" looks like is completely incidental. Jian (25, bisexual/gay), for instance, works in a small town that is "not as open or, um, forwardthinking as Toronto." He finds it difficult to meet other bisexual or gay men, because he is "slightly limited by, um what other people just walking around would think or (...) negative vibes from someone who doesn't agree with what you're doing." As a result, he is restricted to clandestine encounters in parks:

Jian: Yeah, for sure. If I'm walking in the park and I want to sort of send signals, like, I don't know, you sort of lighten your step. It's hard to exactly describe, but...sort of less heavy.

Interviewer: Uh, uh-huh. Is it easier or harder in [redacted]?

J: It's about the same, because the people who have an issue with this don't really notice these things, so I don't really feel inhibited by that.

I: Gotcha.

$\mathrm{J}$ : It's the more overt things that people notice, like holding hands or whatever.

I: Right. And you wouldn't feel you could do that?

$\mathrm{J}$ : Well, it depends on the, like, if there's a lot of people around or depending on what area of the city you're walking in. But you would feel like there's sort of limitations. For Jian, turning on gay entails an adjustment of gait so subtle it is indescribable, almost imperceptible. Similarly, when Morgan (22, queer) is "walking by [himself] at night and, just, 
you know, a group of guys approaches [him] then that's a moment where [he's] like, 'I shouldn't even seem, you know, even remotely gay." Thus, he feels compelled to "stand up a bit straighter (...) throw back [his] shoulders a bit (...) walk, like, a bit stiffer kind of thing" - he does not want his "arms to flail, flail all around kind of thing." In "the Village or even just, you know, walking down the street in Toronto pretty much anywhere during the day or something like that," he is "most comfortable," he can "just sort of let [his body] go and do it's thing" - in these spaces, under these circumstances, his body - not just its appearance, size or shape, but its physical movements - is uncontained and his gayhood may be amplified. Morgan's gay walk may not appear the same as Jian's or Gerhard's, but they are all defined through a differential opposition to heterosexuality: Morgan's walk is not gay when it is straight, and vice versa. When he thinks, “'Ok, I'm in a situation where I should probably seem straight,"” he quite literally straightens out, enacting "how [he believes], you know, how a straight man would carry himself, you know, a lot like stiffer kind of thing." Because homosexuality often functions as a discursive dumping ground for inversion, flamboyance, campiness, or weakness (e.g., Foucault, 1978; Miller, 1995) - in addition to dissatisfaction, disturbance, and disorder - most participants tended to rhetorically link male heterosexuality with masculinity: Morgan's stiffened walk approximates "how 'real men' are when they're walking down the street," Jian's straight "step" is firmer, heavier. Overwhelmingly, turning off gay meant camouflaging effeminacy and its opposite, amplification.

Wood (2004) noted that, to date, gay and lesbian studies research on body image disturbance among gay men has "primarily relied on heterosexism and homophobia to conceptualize the psychosocial and political context of gay men" (p. 57). He suggested that a focus on heterosexism, alone, insufficiently theorizes gay lives because it makes "sexual 
orientation instead of gender the central category of analysis" (p. 57). Yes, the study of sexuality is not coextensive with the study of gender (Sedgwick, 1990), but, definitionally, heterosexism or what Butler (1990) calls the "heterosexual matrix" - "is culturally instituted at the price of stable gender identities" (p. 70), which helps stabilize heterosexuality and define its other in prescriptive, often pathologizing ways, like the marriage of effeminacy and homosexuality (Hennen, 2008). Consequently, Connell's $(1987,2005)$ notion of hegemonic masculinity drawn from feminist post-structuralism and Gramsci's (1971) cultural hegemony - provides an avenue to more fully theorize gay/queer male/genderqueer embodiment. She defined hegemonic masculinity as a dynamic configuration of gender practices that secure the dominant position of certain men and ensure the subordination of women and other lesser-status men. Masculinity is not a monolithic entity; there are vast differences in the degree to which men may either benefit or suffer from the prevailing gender order, because competing masculinities - hegemonic, marginalized, stigmatized - are hierarchically organized. Typically, the most visible possessors of hegemonic masculinity are individual bearers of institutional power and wealth. However, culturally normative ideals of masculinity are historically specific, heterogeneous and encompass a range of roles, perspectives, behaviours, and personal characteristics (Ricciardelli, Clow, \& White, 2010). In particular, this thesis is interested in how this mobile framework of dominance and subordination may be extended to relations between groups of men. Indeed, Connell (2005) suggested that the marginalization of a "homosexual or gay identity" (p. 78) positions gay men lower on a gendered hierarchy of masculinities, because, in patriarchal ideology, gay men purportedly lack masculinity.

Branding gay men as insufficiently masculine, through a deontic coupling with effeminacy, is a widespread heterosexist, misogynistic strategy, deployed to subordinate 
homosexuality. Effeminacy stabilizes Western culture's masculinity, controlling the conduct of its men "based upon a repudiation of the feminine that recognizes it as a "present absence" (Hennen, 2008, p. 48) - ineffable, yet engulfing, it polices the boundaries of acceptably masculine behaviour, delimiting the symbolic differences between effeminate men and "real" men, despite its widely varying historical and cultural variations. Effeminacy has not always been associated with homosexuality: for instance, in ancient Greece, moderation was considered an inherently masculine trait and immoderation was associated with feminine passivity, a "position of weakness and submission" (p. 84). Immoderate sexuality of any kind was viewed as a distraction from a man's participation in the public life of the polis; thus, "the dividing line between a virile man and an effeminate man did not coincide with our opposition between hetero- and homosexuality; nor was it confined to the opposition between active and passive homosexuality" (p. 84). Effeminacy was not wedded to homosexuality until the $18^{\text {th }}$ century, when London authorities raided molly houses scattered north of the Thames, first in 1699, then in 1707 and 1726 (Trumbach, 1977). Official documentation, like police reports and court transcripts, revelled in recounting the "perverse" minutia of this burgeoning, distinctly homosexual subculture, especially its cosmetic effeminacy:

The men calling one another "my dear" and hugging, kissing, and tickling each other as if they were a mixture of wonton males and females, and assuming effeminate voices and airs (...) Some were completely rigged in gowns, petticoats, headcloths, fine laced shoes, furbelowed scarves, and masks; some had riding boots; some were dressed like milkmaids, others like shepherdesses with green hats, waistcoats, and petticoats; and others had their faces patched and painted and wore very extensive hoop petticoats. (Bray, 1982, pp. 87) 
Effeminacies currently circulating in the industrialized West reflect a high degree of gender polarity - mutual exclusivity between effeminacy and masculinity - as well as a minoritizing discourse - only a relatively small number of men are invested with the qualities of effeminacy and the concept of the effeminate figures prominently. Thus, the logic of hegemonic masculinity functions as a disciplining, normalizing force, bolstering the "natural," necessary legibility between effeminacy and homosexuality while enacting an impressive level of gender conformity among most men. It is no wonder that Skylar (30, queer) situated "this sort of unassailable pattern of masculinity" as beyond his grasp, like "the monolith of 2001." His simile is apropos: Skylar grew up with a single mother and attended missions until 19 years of age where he was taught that "boys do this and boys do this and boys do that," but he "never knew how to do any of those things, [he] was never a boy." Luca (28, queer) also considered himself "not male in the strict sense," he does not "identify with this male thing"; in fact, he spoke about his queer sexuality as a refusal of "the manly man meat-eating ideal." Likewise, Antonio (19, gay) deemed "the gay identity as a bit of a breach of [hegemonic masculinity] because people see like this idea of (...) gay men, and it's not, it's not um noble enough as a man." When he thinks about masculinity, he "automatically [thinks] of the stereotypical man," which "makes [him] feel um anxious, or nervous, because [he] always felt like that was something [he] was always lacking." Citing différance, Antonio maintained: "It's either you're it or not it, and if you're anything not it, then you're not it. Then you're not masculine."

How does this subordination manifest, corporeally? In psychology, aside from Kimmell and Mahalik's (2005) minority stress model, even the most comprehensive accounts of gay male oppression do not discuss gender oppression. As part of the new orthodoxy, Martins et al. (2007) tested the applicability of Objectification Theory to gay men, because "gay men, similar to 
heterosexual women, also may internalize the view that they should be concerned with their appearance and attractiveness" (p. 636), but, ironically, their use of this feminist model overlooked the regulatory function of hegemonic masculinity: apparently "the view" that they should be thin and muscular originates solely from "the increased importance of physical attractiveness in same-sex male relationships" (p. 636). Likewise, Williamson (1999), as part of the old orthodoxy, suggested that "the central tenets of societal homophobia regarding the inferiority or pathological nature of a gay orientation" (p. 1) causes eating disturbance among gay men through the internalization of homonegativity (which he viewed as effected by an insular gay community). Gender is, again, not mentioned; as such, one is left with the espousal of a facile, top-down internalization without any delineation of its social or psychic mechanisms. Connell (2005), however, theorized body-reflexive practices as one way to resist the determinist impulses of social constructionist theory of the body:

With bodies both objects and agents of practice, and the practice itself forming the structures within which bodies are appropriated and defined, we face a pattern beyond the formulae of current social theory. This pattern may be termed body-reflexive practices. (pp. 61)

Just like Foucault's technologies of the self or Bordo's (1993) useful/practical bodies, they are "onto-formative," in that they facilitate the (re)constitution of a discursively produced world that has a bodily dimension but is not biologically determined: "[material practice] always responds to a situation, and situations are structured in ways that admit certain possibilities and not others" (p. 65). Body-reflexive practices are not simply about culture imposing social meaning upon the surface of bodies, rather "they involve how a body, and the practices involved in managing, stylizing, and living as an embodied individual call social meaning into play" (Duncan, 2010a, p. 
440). In particular, Connell (2005) advocated the exploration of how the social organization of masculinity is multiply embodied. Her theories have proven useful for discursive psychologists interested in explicating the identificatory and corporeal boundaries of masculinity among heterosexual men (e.g., Edley \& Wetherell, 1997; Wetherell \& Edley, 1999).

For instance, in an account of the formation of male sexuality among 15 New Zealander men, Terry and Braun (2009) noted a sense of "slippage" in their participants" "identity work" manifested as an "almost reflexive awareness of the socially constructed nature of masculinity" (p. 176). Though focused on a reconstruction of masculinity within the context of heterosexual relationships, the researchers demonstrated that the convergence of these two axes (i.e., gender and sexuality) provided fertile soil for the participants' nascent projects of "constructing their notions of sexuality, sexual practices and what it is 'to be a man"” (p. 167). What Wetherell and Edley (1999) referred to as "bodily sense-making" allows men to navigate many afforded subject positions, which "are differently structured and so must intersect in complex embodiments [emphasis added]" (Sedgwick, 1990, p. 33); they are utilized by men in the formation and (re)articulation of their respective understandings of the world, subjectivities, and embodied identities (Gavey, 1989). Indeed, the body - as a bearer of symbolic value (Shilling, 1993) - may act as a defining source of masculinity (Glassner, 1989). But, it is specious to suggest that hegemonic masculinity is automatically or only associated with one look: just as gay has no visual referent neither does masculinity. For most participants, masculinity alternately meant "the breadwinner" (Luca, 28, queer), who supports and defends his family; "the working man" (Antonio, 19, gay), who is professional, clean-shaven, concerned with working out and looking his best; or "this sexist jerk" (Maks, 22, gay), who epitomizes misogyny. Skylar (31, queer) noted that "the ideal of a real man is very much changing," so "it becomes even trickier in terms 
of figuring out what that literally looks like in terms of how that's embodied." Certainly, muscles may signify power and dominance (Drummond, 2005b), as they did for some participates, but for several others they symbolized vanity or insecurity. Furthermore, as Bennett (30, gay/queer) noted, muscles do not always cite hegemonic masculinity:

Like, my friend (...) he looks like a fit guy with a [muscular] body (...) um, I used to go out with him totally dressing in like the genderfuck ${ }^{14}$ style like the guy had a dominatrix outfit, in fishnets with a full beard and shit like that just fucking with convention, and I think that's fun, I think it's frisky (...) We went to Folsom once you know the Folsom Fair? Well it angered a lot of the leather daddy muscle men there because they are sort of wallowing in a machismo and a macho aesthetic...but without a sense of awareness or irony $(. .$.$) they perceive it almost as a threat to them. I think a lot of male ideal is less$ about worshipping the man and more about almost being misogynistic in hating... and I think fear or being perceived as female.

Specifically, Bennett recounted a mode of embodied queer resistance that involves the subversion of hegemonic masculinity. His body reflexive practices are "less about muscle and flesh and skin than about [men's] own selves located within particular social, cultural and moral universes" (Gill, Henwood, \& McLean, 2005). According to the participants' accounts, bodily sense-making is messy, confusing process: it is not as simple as suggesting that, say, a gym membership and a really good personal trainer proffers admission to hegemonically masculine subject positions. Indeed, just as Drummond (2010) found with the sample of 14 young gay men he interviewed, the participants "struggled with trying to explain the term 'masculinity" (p. 34) - the stern patriarch, the well-tailored businessman, the muscular jock, among many others. But, 
given the West's gender polarity, the majority of the participants were well able to identify what masculinity is not: feminine or effeminate:

Interviewer: Um, do you think it's possible to have more than one type of masculinity? Morgan (22, queer): Um, yeah I think so. But I think it plays into the idea of also, um Oh, how do you say it? Um, I think it also plays into a lot about, you know, how we think about femininity and stuff like that and where we sort of draw the boundaries in there. Because, if we're going to define them as very strict, uh, very strict sort of category. I mean, maybe, there can only be one masculinity and one femininity, because they're so oppositional, you know. Masculinity is assertive, femininity is emotional, etcetera, etcetera, etcetera. Um, and so I think that, I mean, you can certainly have, I think, a masculinity that is, um, you know, like a lot more compassionate kind of thing and you can also have a femininity that maybe's a bit more assertive, but at the end of the day, it's really just a blending of the two kind of thing, maybe?

According to Morgan, there are many kinds of masculinities - some more "assertive," some more "compassionate" - all unified by their opposition to femininity. As such, how did the participants talk about negotiating this differential opposition, within a discursive environment that, in their estimation, deems them deficient as men, especially when they have no fixed referent of hegemonic masculinity for guidance?

It is important to recognize that hegemonic masculinity and non-hegemonic masculinity is not a dualism. Gramsci's (1971) original theory distinguished external and forms of hegemonic struggle. The reciprocal, appropriative process of "dialectical pragmatism" (Demetriou, p. 345) between what is considered hegemonic and non-hegemonic sustains hegemony. Accordingly, the regular usurpation of unique elements of diverse masculinities 
actually permits hegemony (and, thus, the reproduction of patriarchy and heterosexism). In fact, this process of "negotiation [emphasis added] rather than negation" (Bhabha, 1988, p. 11) requires the coexistence of, for instance, "hard" and "soft" expressions of masculinity (Allen, 2007). Consequently, in men's lifestyle magazines, for instance, one encounters several masculinities - not just traditionalism and muscularity. "Metrosexuality," for instance, places less focus on previously dominant manifestations of masculinity than on self-presentation, appearance, and grooming (Segal, 1993). "Laddism" emphasizes youthfulness, hedonistic consumption, bachelorhood, the objectification of women, and sexual conquest (Attwood 2005). All of these versions of masculinity have permeable boundaries, yet all are deployed to sustain hegemonic masculinity in its sundry manifestations (Ricciardelli et al., 2010). Gill et al. (2005) interviewed 140 young British men and explored how they talked about their own bodies and bodily practices, and those of other men, with specific focus on a variety of body modification practices, including working out, tattooing, piercing and cosmetic surgery. The researchers found that, in discussing their bodies, the men repeatedly drew upon a limited range of interpretive repertoires that extended "beyond the topic body modification to a broader set of issues concerned with the nature of men's embodied identities" (p. 37). The surfaces of their bodies, and particularly what they did with them, were charged primarily with identity functions (Featherstone, 1991), that, while multiple, without any referent, and purportedly individual, were all bonded by an overarching policing of masculine behaviours and identities:

It is interesting that despite the repeated emphasis on independence and autonomy there were clear, normative limits to individualism and libertarianism - although they were not understood reflexively as such by the men themselves, and instead operated as "obvious," 
taken-for-granted norms. We considered three in this paper - the injunctions not to be vain, not to become obsessional and not to "let yourself go." (Gill et al., 2005, pp. 58) The "normative limits" were experienced as an intimate regulation, articulated more readily as what they did not want to become (e.g., boring, conformist, fat, vain, feminine, effeminate, gay) through heterosexist exchanges "designed to disavow any homoerotic desire in the speaker and to cast aspersions on the others' (heterosexual) manhood" (p. 59). In Gill et al.'s (2005) sample, the participants' various body-reflexive practices sought to maintain hegemonic masculinity in subtle ways, all of which patrolled signs of homosexuality/effeminacy. As Drummond (2010) noted, the association between masculinity and the body is "made on the basis of not only what the body '[looks] like' but what the body [can] 'do'” (p. 35).

This self-surveillance in relation to hegemonic masculinity has been evident among queer communities, as has been resistance to it, from the cosmetically effete molly who cultivated the "pansy craze" in 1920s New York City (Chauncey, 1994) and the subsequent "butched up" (Levine, 1998, p. 56) aesthetic and "reformist image of the post-closet homosexual" (p. 28) in the 1970s to more recent gay/queer identities: "Bears are interested in repudiating effeminacy and capturing "authentic" masculinity, leathermen respond to the stigma of effeminacy with an exaggerated masculinity, and Faeries celebrate and embrace the feminine (Hennen, 2008, p. 23). All participants in the present study spoke about the negotiation of one's embodied identity as boarder control: one diligently monitors the distinct yet permeable membrane that separates masculinity and homosexuality/effeminacy in a fashion similar to the strategic or reflexive (re)calibration of gayhood instantiated by heterosexism. As Skylar (31, queer) explained, "it becomes this really profoundly ironic tension between um not knowing what a real man is and knowing that one seeks towards that completion of an ideal that is never going to allow you 
access." Morgan (22, queer) affirmed that Gerhard's notion of an "ideal" is on display on Manhunt and other hook-up websites where gay men "talk about [desiring to meet] 'No femmes' and 'Straight-acting' [men]' in their online profiles; he concluded:

And so I think it's, yeah, and I think it plays into that further ideal of what it is to be sort of a gay man. So we see the ideal of the body of, you know, strong, you know, maybe, or tall all the stuff like that. But I think the attitude [emphasis added] that comes with the ideal body is one that is sort of masculine, that will be associated with a straight man and the ideal straight man.

Essentially, the turning on/off gay interpretive repertoire, in many ways, was equivalent to turning on/off effeminacy. Gerhard (24, gay/queer) stated that heterosexism has most shaped his “gender identity because it's so related to sexuality and, like, feeling the need to act less effeminate, 'cause it's something that's being coded as being gay"; he spoke about "feeling that pressure to act masculine which is collapsed into straight, which is weird." Turning on/off gay/effeminacy, for some, was limited to façade, like cosmetic effeminacy, which emphasizes outward appearance (e.g., women's clothing, jewellery, make-up, transvestism, transgenderism) in addition to variants of somatic effeminacy, like kinaesthetic (i.e., whether a man speaks or moves "like a woman") and anatomical effeminacy (i.e., whether a man's genitals, build, or facial features are interpreted as feminine; Hennen, 2008). For instance, when Ahmet (27, gay) proclaimed that there are many "different types [of] gay guys," he was asked, "So, all these different identities that are out there, um how, like how can you tell, like how are their identities expressed?“"He answered as follows:

“Uh, trannies you know, they just look like women. I have a tranny friend, she's so nice. Um masculine guys, they look all like straight guys, the only thing you can know that if 
they, if you see them having sex with guys. The feminine guys, you can tell very easily from their clothes, from the way they talk. Um in between guys, like masculine, those are guys um, I don't know, you can see it, it's very easy. I don't know, for me, I can understand if someone is gay, straight so easily. So, it's not a big problem.

Ahmet can tell who is effeminate and who is masculine based on cosmetic and kinaesthetic features, but his talk makes room for something else, something that is "not a big problem" for him to identify, yet intangible and indescribable. Indeed, for others, boarder control was particularly insidious: Phelan (32, gay/queer) described it as "that sort of sense of people know in their bones without being able to articulate it intellectually, which doesn't make it less powerful, but that as a world we understand it." His talk was reminiscent of the process of subjection and implicated less cosmetic or somatic forms of effeminacy, opting for what Hennen (2008) called moral effeminacy, which "registers as a form of moral or ethical weakness" (p. 50). Much like Gill et al.'s (2005) sample of British men, the participants engaged in various subtle technologies of the self or body-reflexive practices all originating from some acknowledgement of oneself as positioned within the devalued end of at least one binarism. Turning on/off gay/effeminacy symbolically manifested alternately through the deployment of the shame/masculine compensation interpretive repertoire, neo-liberal discourse, and queer epistemology.

Shame/masculine compensation. According to this interpretive repertoire, recognition of the stigma of moral effeminacy incites a symbolic and material quest to purge oneself of the markers of effeminacy, while aligning homosexuality with hegemonic masculinity. In many respects, the mechanisms are similar to Frederickson and Roberts' (1997) Objectification Theory, which suggested that American culture socializes women to adopt observers' (sexually 
objectified) perspectives of their physical selves that spurs heightened self-objectification - or, habitual body monitoring or self/body surveillance - experienced as a body-based shame that, in turn, results in maladaptive behaviours, such as restrained eating (Frederickson et al., 1998). Ostensibly, one's adherence to patriarchal sexual and beauty ideals alleviates one's shame. Frederickson and Roberts' (1997) model is based on Du Bois' (1903/2008) doubleconsciousness: his treatise proposed that living as an African-American in the United Sates postEmancipation Proclamation involved viewing oneself through the eyes of others (i.e., racist White persons) and "measuring one's soul by the tape of a world that looks on in amused contempt and pity" (p. 2). Thus, one's behaviour may be influenced and distorted by others' negative images of one's race. Likewise, the way the participants spoke about boarder control and their subjection to ubiquitous discourses about heterosexism and hegemonic masculinity was reminiscent of double-consciousness. This is where the similarities ended: unlike embodied queer resistances, which were characteristic of the queer participants, several, through definitely not all, gay participants responded to double-consciousness with shame and their bodies became the primary sites through which they compensated for their homosexuality.

When Bruce (28, gay) was asked to describe what his gay identity means to him, he responded as follows:

Bruce: Yeah that is a big question, too. Um, for me, gay - I feel that I'm more sexually attracted to men. In terms of emotional connections with men, I feel that that's something I struggle with a bit. So, it's - the sexual attraction is a big thing, or just attraction in general. Um. 
Interviewer: That was an "emotional connection" you were saying that was? Ok. In terms of not necessarily having things in common? Or just... I guess I'm wondering what you mean by emotional connection.

B: Emotional connection. Um, I think that - that because there is a lot of kind of shame that's inherent in the gay community or the LGBT community that it's often difficult to be kind of like a marginalized person and to say that I feel comfortable being a gay man and being in a gay relationship uh when so often you know as a gay community we are told that this is kind of wrong or not the right way that things should be.

I: Right. So, um, how do you think that sense of shame can manifest for other men?

B: For other men?

I: Yeah.

B: Uh. Perhaps addictions, depression, body image issues, uh, things like that.

His account is Objectification Theory recapitulated: because "the gay community or the LGBT community" is branded, discursively, as "kind of wrong or not the right way," gay men experience shame, which leads to maladaptive behaviours (e.g., substance use) and compensatory behaviours, like developing muscles to communicate one variant of hegemonic masculinity (i.e., "body image issues"). According to Bruce and most other gay participants, once a (gay) man is subjectivated as homosexual, there is "comfort of having a label or a group to fit into, but also kind of reacting against the label that is currently there" - the "shameful" label that "society kind of accepts as what a gay man should be like." Gay shame becomes a "deep emotional reservoir on which an adult [gay man] draws, for better or for worse" (Halberstam, 2005b, p. 221) to transform past experiences with abjection, isolation, and rejection into privilege, pride. But, as in the earlier discussion of psychology's propagation of an 
assimilationist ethnic/minority sociopolitical agenda, the romanticization of gay shame - and a gay past, or "tradition" (Williams, 1977) - is deeply invested in the identity politics of White gay men who have obscured more radical agendas (e.g., feminism and racialized critique) in favour of "the normativity of a 'gay pride' agenda" (Halberstam, 2005b, p. 221) that emphasizes compensation. For instance, "queer of colour critique" is suspicious of the mythologizing of the gay male past that occurs in privileged, White urban gay communities: "Who bestows legitimacy on the narration of Stonewall as the origin of gay and lesbian development? What does this narrative of origins engender? What practices and locations are subordinated by privileging Stonewall as origin?" (Manalansan, 1997, p. 486). Manalansan's (1997) point is not to downplay the importance of the 1969 Stonewall riots, but to emphasize how shame/masculine compensation "has a tendency to universalize the self who emerges out of a 'shame formulation"' (Halberstam, 2005b, p. 223): a White gay male whose shame arises from the experience of being denied access to privilege and whose pride develops inside of the subject (Berlant, 2002). Take Bruce's answer to the question, "Do you think that you live in a culture that is heterosexist or heteronormative?":

Bruce: Um. I guess that's really situation-dependent as well. I live fairly close to the Village, just kind on the outskirts. So, in that situation, I feel like it's less heterosexist obviously, again, even on a broader scale Toronto is fairly accepting. Um. Society in general I think that there is more of a hetero-normal assumption that exists. Interviewer: Are there any ways in which that has affected or shaped your sexual identity? 
B: I think so, yeah. That oftentimes I may want to kind of tone down my sexual identity to not make people feel uncomfortable - or heterosexual community feel uncomfortable by my sexuality, which is kind of affected by self shaming and things like that.

This interpretive repertoire suggests that, in order to compensate for shame, the homosexual subject must turn inward to remodel his own gayhood in what ultimately amounts to a struggle to make privilege (e.g., masculinity, wealth, Whiteness) visible. Indeed, the centrepiece of today's gay pride movements is the reclamation of gay masculinity: "Shame is (...) a gendered form of sexual abjection: it belongs to the feminine, and when men find themselves 'flooded' with shame, chances are they are being feminized in some way and against their will" (Halberstam, 2005b, p. 226). In other words, gay men must work through shame by producing normative masculinity and by "presenting themselves as uncastrated, muscular, whole" (p. 228). Hence, body-reflexive practices (e.g., "toning down" one's sexuality to appease the heteronormative majority) function, in this case, as a distancing manoeuvre, displacing one's homosexuality from moral effeminacy.

Accordingly, the participants spoke about or occupied three associated subject positions: the hypertrophic hostage, the straight-actor, and the paragon of pride. The hypertrophic hostage is well summarized by Bennett's (30, gay/queer) claim that "a lot of gay guys get the really good body because it's a way of triumphing or compensating over insecurity of their youth or their pre-out lives"; they build muscles as a way of "making good" on their gayhood, symbolically shouting, "You see, we can be just as manly as straight men!" Hypertrophic hostages' "motivations for getting muscle is because they want to appear dominant, maybe because they're primarily, or are specifically a top. They want to have that dominant appearance, so that they attract those who want to be dominated" (Antonio, 19, gay). Antonio highlighted that particular 
embodiments of homosexuality are better able to convey masculinity, especially anatomically: gay men who are attractive and muscular, and therefore not effeminate, gender non-conforming, weak, overweight, unattractive, etcetera (Duncan, 2007). (Again, this was not the only interpretation of muscles.) Bruce (26, gay) concurred: “A muscular gay man. Um. I think that it would portray someone who has really bought into one of those male ideals of like muscles that we talked about"; someone who, "in [Bruce's] own experience (...) tend to have a lot more consciousness around their body" - like body monitoring - because of "broader society that wants to put down, put down the gay men and say that they are the sissies of society or things like that." Consequently, they find "a way of kind of like sublimating that into a good outlet, like they're not really shaming themselves, but they're saying, 'You know I'm going to go in and my focus will be more on working out or fitness and things like that.'” Likewise, Luca (28, queer) observed that some gay men build muscles as a means of "building [their] masculinity" and inoculating themselves against charges of effeminacy while building the coherence of their more masculine embodied identities:

I think that um muscles seem to be um seem to be a very important part of masculinity, um and I do think it has to do with the [male] ideal right, that picture that I would draw would involve a lot of lumpy muscles, and I guess you can see the same thing in like a woman body builder seems to have lost her effeminate nature, or whatever. Um muscles are reserved for men, and um, and so I can only imagine that a gay men would also fit into such desires.

Conscious of the political status attending his visibility in heteronormative social life, the hypertrophic hostage's gym-built body gestures toward ownership of that which he was discursively denied, perhaps a simulacrum of hegemonic masculinity, "driven by a (...) psychic 
sense of imperfection or lack" (Duncan, 2007, p. 339). Indeed, two gay participants who occupied this subject position considered themselves un-castrated, muscular, whole. Because Vito (23, gay) "lost the weight," he views his "body as something that's like, also - there's something to be proud of I guess" and possessed a "newfound confidence"; Antonio "built [his] muscular arms," and now he is "like successful."

The straight-actor serves a similar function to the hypertrophic hostage: he tries to appear straight to compensate for his homosexuality. For Bruce, straight-acting "is a shaming term," a practice inculcated by shame - "it's trying to kind of pass within the heterosexual community." This subject position came up routinely, once in virtually every interview. It is a term that Ben (30, queer) is "not fond of," but one "that you see on hook-up sites very often, or on Craigslist because it's usually a very desired thing by some compartment of the gay community at least." For instance, Bennett (30, gay/queer) directed me to me to a Reddit subgroup called "gaybros," which, on their homepage, is described as "A place for gay guys and men to get together and talk about, well, guy stuff. Sports, video games, military issues, grilling, knives, gear, working out, gadgets, tech, tv, movies and more. Plus gay stuff." I was also directed to an online community called G0ys - "spelled w. a zero" - for men who possess "same-gender affections" but do not identify as gay. The following appears on their homepage:

Don't identify with "GAY"? No! Men like us actually find the imagery \& stereotypes that are promoted from WITHIN the so-called "gay-male community" to be repugnant to our sensibilities of masculinity \& respect. We know instinctively that loving other men has nothing whatsoever to do with gender-bending, $\mathrm{x}$-dressing or playing the female role! G0YS, -by our very nature reject anything to do with playing inside another person's 
anus; -hence we find the entire notion of "anal-sex" to be dirty, degrading \& damn-unmasculine. Feel familiar? Know what? G0YS are right!

"Gay stuff" - not only "gender-bending, x-dressing or playing with the female role," but, more viscerally, (receptive) anal intercourse and sexual degradation as well as other practices deemed immoral (for men) and "damn-un-masculine - is situated as effeminate affectation, that which should be swiftly expunged, and "guy stuff" as a natural part of being a man. The term straightacting is actually a misnomer: paradoxically, if a gay man occupies the straight-actor subject position, he does not recognize himself as acting, because he is simply being a guy "who 'happens' to like guys" - therefore, there should be no acting involved. Ahmet (27, gay), who expressed affinity for straight-actors, stated, "they are just like a straight guy, but the only difference is that they don't have sex with girls, but other guys." If the straight-actor performs heterosexuality well, you “can't point [him] out right away, that [he's] gay” (Vito, 23, gay), because he "acts like, a masculine like man who, uh and a strong man like physically on the outside" - he "doesn't encompass like the flamboyancy or the effeminate, or the effeminate attitudes of a gay man." Appearing straight may mean adopting anatomical markers of masculinity, like a "strong," muscular physique, though, for the participants, it typically meant turning off gay/effeminacy:

Interviewer: OK, what does that entail? Straight-acting? Jayden (30, gay): So, I'm going to go with what it lacks, I'm sorry but I: Oh yeah, for sure...

$\mathrm{J}$ : So it lacks like a lisp or any of those effeminate like hand gestures or, or a swagger [mincing gait] while walking. Um... and I think...hmm, OK, so I think there's sort of like an acceptance, I'm trying to say a real man like probably wouldn't worry about like 
plucking his eyebrows or tweezing things or, or the details of whatever it may be, or like manicures and pedicures. So there's a certain realness like that, but again, like the long hair doesn't work for me.

Straight-actors turn off cosmetic and somatic effeminacy in addition to moral effeminacy: no self-respecting straight man is frivolous enough to worry about, for instance, scheduling his next mani/pedi. Given that previous qualitative research has demonstrated that some gay men identify "effeminacy and flamboyance as abnormal traits that [mark] one as visibly occupying a different, devalued cultural identity, at odds with the privilege associated with a conventional masculinity" (Duncan, 2010a), the straight actor attempts to "assimilate within the dominant culture I guess “ (Ben, 30, queer) in order to "prove that being gay does not equal being feminine, does not equal - you know, it says 'I can kick your ass, straight brother. Don't think I'm a limp-wristed faggot'” (Phelan, 32, gay/queer). Instead of resisting through or “"owning' that outsider status by not trying to remain assimilated within the dominant culture" (Ben), the straight-actor attempts to "live out a gay life and have [sex with men] without having to give up anything about the straight world, or straight life I guess."

A brief note on terminology: hypertrophic hostage was chosen for two reasons. First, the queer participants viewed masculine compensation vis-à-vis muscle-building, especially its myopic focus on "rebuilding the self that shame dismantled" (Halberstam, 2005b, p. 224), as a sort of self-flagellation. They positioned the hypertrophic hostage and the straight-actor as slaves to Western dictums of proper male embodiment. For the queer participants, feeling ashamed of one's homosexuality and adjusting oneself through a focus on interiority is a disastrous tactic for queer activism, because, worse than Bordo's (1993) anorectics, it fails voice critique and is unable to effect change, because these two forms of compensation project "shame, castration, 
and vulnerability onto the feminized and racialized body" (Halberstam, 2005b, p. 229). The hypertrophic hostage's muscles are not the subversive muscles of Bennett's (30, gay/queer) genderfucking Folsom friend. In fact, Bennett's queer activism was provoked by a rejection of straight-acting:

I remember once I met a friend of my sister's at her university and he was cool with me being gay because I wasn't a faggot like “I don't mind gay people I can't stand those you know stereotypical faggots," and at the time I was like "oh yeah, cool me too...oh my God, gulp." And I was thinking like "fuck you like who the fuck are you to say that you get to just hate people because you think they are stereotypical quote unquote 'faggots,"' and it was even hearing things like that that spurred me to have more of a queer identity because it's like I can be as gay or queer as I want to be, and that doesn't mean I should be discriminated against for it, and there was a time in my life - and I still see people now that they gauge their tolerance at their gay identity by how much it doesn't offend straight bigots. That ain't for me.

Second, though two gay participants claimed to be straight-actors, most viewed this subject position and the hypertrophic hostage negatively, but for different reasons than those provided by the queer participants: they distanced themselves from the hypertrophic hostage, because gay men who build compensatory muscles "are not doing it for themselves" (Jayden, 30, gay). Antonio (19, gay) relied on an obfuscating "I am what I am" neo-liberal discourse to claim that it is possible for gay men to build muscles "not because they are influenced by the dominant ideals of male beauty," but "because they are looking after themselves, umm because they're looking after their good health.” Likewise, the gay participants described straight-acting as dangerous affectation; it was denigrated because, as its label indicates, it involves acting and is, therefore, 
an unnatural expression of gay masculinity: "If [masculine gay men] are not authentic then that's a sign of weakness, that's a sign of um not coming into one's own complete self' (Russell, 32, bisexual). A naturally masculine gay man does not act: "Like he is, he is who he is, he's a man (...) for me it's just, they're just men, you know" (Vito, 23, gay). The gay participants' acceptance of straight-acting if it is natural may be a defensive gesture: given the gay male body dissatisfaction imperative, are working out (frequently enough to maintain a certain standard of musculature) and self-consciously calibrating one's heterosexual performance the best ways to enact the privileges associated with hegemonic masculinity? As Gill et al. (2005) found among their sample of heterosexual men, self-consciousness, vanity and body-obsession were "condemned and guarded against at all costs" (p. 50), lest one's "vain" body-reflexive practices implicate one as homosexual/effeminate. Similarly, Duncan (2010a) identified a similar strategy for negotiating the relationship between gay identity and embodiment. He interviewed 16 gay Australian men and found that some "actively worked to deploy an idea of themselves as incontrol, individual, and masculine as a way of resisting the notion that they may be overly concerned with appearance" (p. 447). In support of this suggestion, several gay participants readily admitted to engaging in another form of compensation not regarded as recognizably vain or body-obsessed: the paragon of pride subject position.

Interestingly, some queer participants also viewed this subject position more approvingly (though they did not endorse any form of compensation, per se):

Gerhard (24, gay/queer): There's something specific about being gay. Like, it's harder and there is a lot of insecurity and it brings out a lot of drama that we don't always have time or space to work through. (...) I feel like there is something very specific about the way gay people sometimes become conservative that it, it's closely related to their 
gayness and they feel like they're on the outside and then once they get in, they really have to hold on to that. But, um, yeah, I don't know.

Interviewer: Conservative in what manner?

G: Um, I think that there - having worked in a couple of different spaces, including in a specific gay fellowship in the US, where there were a lot of power gays, it felt like there was a lot of experience of pain and persecution for being gay - that was something that they channelled into, um, being really professional and sort of making peace with the system, whether through getting the right kind of degrees or working for the right kinds of corporations or, uh, um, having a kind of politics that was OK with being gay, but also reinforced a lot of dominant power structures. But then I wondered if it was sort of naïve for me to assume that being gay necessarily meant that you would be radical to begin with, you know?

According to Gerhard, becoming conservative, for gay men, means making homosexuality appear prideful. For the paragon of pride, appearing attractive certainly helps, but the spectrum of his compensation is wider: wearing the right clothes, receiving the right degrees, having the right job, earning the right salary, possessing the right politics, and other markers of a "successful claim to authority" (Connell, 2005, p. 77) are also key to a "positive" image of homosexuality. The paragon of pride considers his body as intrinsic to the reflexive project of self-presentation and identity (Giddens, 1991); what one does or earns with one's body, wears on one's body, etcetera are all involved in an ongoing process of signification, and by moving beyond muscles, he circumvents allegations of body dissatisfaction or body fascism while working to realign homosexuality with hegemonic masculinity. Every morning, before leaving the house, "even if it's just going to the dog park behind [his] building," Reid (26, gay) makes 
"sure [he's] wearing something that's presentable and well put together" in order to project power:

Interviewer: What are you seeking to present in the way you dress?

Reid: I guess the look that I'm - you know a look of more um I don't want to say like well-to-do, but you know a look of something that's like I don't worry about money, that I'm comfortable, that I've got money that I you know live a lifestyle that I'm not working very hard um that you know that I've got money to spend on clothing um and that you know, that I do care I guess about what I look like to a certain extent, yea. Umm, I just like to look good umm I don't know if it releases endorphins or what but that's what (chuckle) yeah it's just something that I've always been anal about, but I haven't given a whole lot of thought to why.

His self-presentation is not limited to adornment: Reid and his friends are "not the type who go out and do a bunch of drugs, [they] don't go out a whole lot you know (...) maybe once a month, once every six weeks (...) [They're] more like the preppier' ones, [they've] all been through university, [they're] all you know working on getting careers and building [themselves] and stuff." He spoke about looking "at gay culture in two ways":

I look at gay culture today and I look at gay culture of what it was because I really don't find that I fit in very well with gay culture today. (...) I find that you know if you look at in the past I feel like gay men felt more of a need to um prove themselves through being like really successful, and do all these like great things, be really smart, be really hard working. Whereas I find like now we've kind of shifted and I find that gay culture now is a bit more nonchalant um about stuff like that. I find that they sort of just embrace um I guess hedonism, like they're more concerned about fun and not necessarily concerned 
about working hard, being smart, being successful or anything like that. They just want to party and have a good time. Um, I mean not, clearly I'm - it sounds like I'm pigeonholing, like I mean I'm not saying that about everyone, I'm just saying that's sort of the general way it's been shifting and I sort of identify I guess with this, at least perception that I have of the former gay community. By "working hard" and "being smart," Reid places himself within a "more respectable" "gay community," solidifying his pride, his " $100 \%$ comfort in being gay." But, in his narrative, there are "heroes and villains" (Gerhard, 24, gay/queer). He does not "want to be seen as like the wrong kind of gay person" (Bennett, 30, gay/queer) - morally effeminate, concerned with frivolous matters, tempted by immoderation (Hennen, 2008). Much like the gay writers referenced by psychologists who research gay male body image, the paragon of pride strives to promote the visibility of worthier (i.e., more respectable, masculine) iterations of homosexuality (Warner, 1999). As Antonio (19, gay) noted, "how you present yourself links with your sexuality and how you identify. So, I feel like there's still like a stigma that you need to look a certain way to be like the best kind of gay person." Indeed, the paragon of pride, like the hypertrophic hostage and the straight-actor, rests "on the exclusion of sexual subjects and practices that transgress hegemonic gender and sexual norms producing a binary between 'good' and 'bad gay citizens" (Duncan, 2010b, p. 21). Though certainly instantiated by heterosexism and hegemonic masculinity, the shame/masculine compensation interpretive repertoire also intersected with neoliberal discourse to produce the new normal interpretive repertoire and an additional subject position, the pomo.

Neo-liberalism and gay equality. Technically, neo-liberalism is an economic policy, ${ }^{15}$ though "there is nothing purely 'economic' about it" (Griffin, 2007, p. 221). It constructs "a kind 
of nonpolitics" (Duggan, 2003, p. 10), a way of life, a way of being a "responsible" citizen who promotes the inevitable, universally desirable forms of economic expansion and democratic government around the world - like, individual rationality, freedom, and self-interest (e.g., Smith, 1776/2003). As a discourse, neo-liberalism dominates contemporary social relations by propagating "heterosexualized discursive binaries, 'natural facts' and gender/sex categories that sediments certain gendered subject positions while proscribing others" (Griffin, 2007, p. 223). According to the World Bank's policy interventions, for instance, women may be included in the definition of the modern "individual" (e.g., Ohmae, 1995, 2002) only if they demonstrate hegemonically masculine characteristics like competitiveness, rationality, and efficacy. Otherwise, unintelligible genders - non-men and non-masculine persons - are relegated to the spheres of non-productive or reproductive labour, where they are situated outside the "proper" society of male producers (Griffin, 2007). This regulatory notion of the "good" modern individual/citizen also manifests in conservative, assimilationist identity politics. ${ }^{16}$ Currently, gay civil rights lobbies have adopted neo-liberal rhetoric and corporate decision-making models: no longer a broad-based progressive-left movement, most lobbies have become public relations firms for an increasingly limited gay, moneyed elite wherein gay moralism is nurtured, and attacks on "promiscuity" and the "gay lifestyle" flourish as does advocacy of conservatizing institutions, like respectable, monogamous marriage (Warner, 1999; Baird, 2007). Gay marriage, in particular, is considered the best strategy for privatizing gay politics and culture for the new neo-liberal world order, a strategy "dressed up as a new maturity, the coming of age of the gay movement after AIDS, after AIDS activism, and after sex" (Warner, 1999, p. 51). ${ }^{17}$ Within mainstream gay sociopolitical life, gay rights, "gay equality," and gay marriage are virtually synonymous. ${ }^{18}$ Accordingly, living in Toronto, Jayden (30, gay) believes that his sexual identity 
has in no way been "directly" shaped by heterosexual culture, because he feels "like every opportunity is available to [him] to do um what would be available for any heterosexual person or couple" - like marriage and other legal same-sex partner benefits. Vito (23, gay) feels "very privileged to be living in Canada and having equal rights"; in order to underscore his point, he compared Canada with the United States, "where it's like still, still not legal to get married." Consequently, he viewed Canada as "not really a heterosexist [country]." In Turkey, when Ahmet (27, gay) spent time with his "family or anywhere [else]," he felt like he was "just in a play having to play almost twenty-four hours," even when he slept; "but here [he's] free (...) one hundred percent free, like in a movie, thanks Canada." Here, in Canada, he feels "normal," though his simile, "like in a movie," positions his normalcy as tenuous, even fictive. In contrast, Ben (30, queer) spoke about queer activism - not lobbying, litigation, electoral politics, diplomacy, negotiation, etcetera - and expressed concern about it falling to the wayside: "I think people talk about it in terms of it being history, and it being, 'well we're done now, we got what we wanted [gay marriage] so we're good.' Um, so yeah I guess what I - yeah I see, sort of complacency."

Indeed, the all-encompassing push for gay marriage is slowly replacing an array of political, cultural, and economic issues that once galvanized gay social movements: "The democratic diversity of proliferating forms of sexual dissidence is rejected in favor of the naturalized variation of a fixed minority arrayed around a state-endorsed heterosexual primacy and prestige" (Duggan, 2003, p. 65). Foucault (1982) suggested that identities are formed within the political arrangements and requirements of Liberalism that administer "rights" and claims to entitlement "on the basis of a singular and injured identity" (Butler, 1997, p. 100). Thus, neoliberal discourse, as a disciplinary apparatus, produces a field of possible homosexual subjects 
that is particularly constrained (i.e., mainstream gay identity politics). Duggan (2003) coined the term the new homonormativity to denote neo-liberal policies and practices that inculcate gay moralism: "it is a politics that does not contest dominant heteronormative assumptions and institutions, but upholds and sustains them, while promising the possibility of a demobilized gay constituency and a privatized, depoliticized gay culture anchored in domesticity and consumption" (p. 50). When the maintenance of one's equality - indeed, subjectivity - however narrowly defined, hangs in the balance, one discovers that particular embodiments are preferable to others. Duncan (2007) interviewed gay men who indicated that "society can more tolerate gay men provided they do not challenge the binary gendered order of masculinity and femininity" ( $p$. 340-341). These are the kinds of "conventional" gays who represent the "responsible" centre and embody the "socially desirable image of gay identity" (Duncan, 2010a), not the anachronistic, irresponsible "activists." Antonio's (19, gay) talk reflected this self-surveillance:

I think when you are out to people and they know that you are like gay, that you need, that you're kind of like, especially if you're meeting someone who may be a little closedminded, you're the representative of gay people everywhere for that person. All it takes is one (...) bad interaction with someone who's gay to change their perceptions negatively for the rest of their life. So, to me being a good gay essentially means like that you're aware that you're kind of a representative of the entire community.

Within the framework of neo-liberalism, "being a good gay" means publically clamouring for heteronormative private life, for what Duggan (2003) called heterosexual primacy and prestige. While discussing "gay rights," Maks (22, gay) acknowledged that he and "other individuals (...) use the body to portray their sexual identity," which is why he does "not want to be that overly skinny guy who other people may perceive as effeminate, and automatically make that 
distinction as gay." As a proper alternative, he wants "to look like somebody who is physically fit, and has a certain muscle mass that sort of makes [him] indistinguishable [emphasis added]." According to Reid (26, gay), "post-Mathew Shepard, post-George [Walker] Bush, postBrokeback Mountain," the "gay community" is "sort of hitting a - well it's like almost a miniature revolution almost": because gay equality has been achieved in Canada, Toronto's gay Generation Y is no longer "campy," "snobby," "glamorous," consumed with "the night club scene," no longer necessarily attached to a multiply dangerous, morally effeminate way of life. Instead, "[they're] all becoming a bit more, like a bit more down to earth" as a result of having been granted access to conservatizing institutions:

Reid: All my friends my own age are striving to just fit right in, blend right in and not do anything very exceptional.

Interviewer: Like, fit in with whom?

R: Like fit in with just um like the regular culture. They just want to be normal. They just want to be like everyone else. They don't really want to stand out, whereas I find, like my older friends they you know, I don't know if it's that they felt so much neglect or that you know, it was difficult for them coming out or whatever, but they need the [Gay] Village. (...) Now people are coming out in high school, first couple years of university (...) so they're becoming a bit more comfortable with it, which is great um and then because society's becoming a bit more accepting, I think that now they just want to, they just want to fit in and just be normal.

Several gay participants deployed the new normal interpretive repertoire to situate shame/masculine compensation as a quest for normalcy, linked to the security of legal recognition - namely, gay marriage, gay military service, and gay adoption. ${ }^{19}$ Like the 
hypertrophic hostage, the straight-actor, and the paragon of pride, the exaltation of normalcy and homonormativity (re)produces a narrative with legitimized heroes and those gay/queer men/genderqueers whose embodied identities - irresponsibly neglecting to turn off gay, to deflect shame projected by heterosexist and masculinist discourses - shriek moral effeminacy. Providing a queer perspective, Skylar (30, queer) was particularly critical of gay equality: Interviewer: What does - when people sort of deploy the term gay identity, what does that - what are your thoughts - for what does that mean for you?

Skylar: Mm, um. (Laugher) How bitchy can I be?

I: (Laugher) You can be as bitchy as you'd like.

S: I'm not gay. Because I think that gay is, is out of complacency. I think that gay becomes an act of sort of refusing politics. I think that being gay is being nice, and we don't get to spend a lot of - let me try that again: being gay is being nice, and we don't spend a lot - we don't - it's an interesting Freudian slip because I keep saying spend. Uh, we don't get anything by being nice. We don't get anything by agreeing to being, as I said earlier, contained. (...) We don't like to think of [gay/queer] bodies that are not mainstream as worth spending any time on. And bodies that can't work, or bodies who don't do the usual amount of work, and work in both senses of the word: work as in function and work as in engage in capitalism. They fail in ways that make people feel profoundly uncomfortable.

Skylar believes that any gay identity is a form of gay moralism, which is why he identifies as queer: he does not want to be "infantilized in a sense, you know, if you're a good boy or girl, and just a good boy or girl, and you behave yourself you get a cookie." He refuses the containment imparted not only heterosexism and hegemonic masculinity, but - as his Freudian slip revealed - 
neo-liberal discourse that situates an oppressively delimited gay equality as the proverbial cookie. He deemed Reid's assertion - that circumstances have "gotten better" for young gay men - as dubious: what about "uncontained sexual bodies," "class-related bodies," "disabled bodies," and other bodies that cannot or wilfully do not fit homonormative pronouncements of proper ideological practice? ${ }^{20}$

Gay/queer bodies are regarded as failing bodies, "unless they do the usual amount of work" (Skylar), unless they "function" appropriately by "engaging in capitalism," reproducing, at the material level, neo-liberal discourse. But, if one eats the cookie, what happens post-gay equality? Most gay participants who deployed the new normal interpretive repertoire adopted the pomo subject position as if to say, "If I have the same legal rights as a heterosexual man, why do I need to be gay, why do I need to wallow in subjugation?" Through the interview process, many participants made reference to an article - now infamous among Toronto's queers - that was published one year ago in The Grid, a weekly city magazine. The article is titled, "Dawn of the new gay: Why you won't find the younger generation partying in the Village or plastering rainbows on their bumpers" (Aguirre-Livingston, 2011). It jubilantly heralded the genesis of a new way of being gay that is "not about being gay at all" (para. 3). The writer and his interviewees argued that, because of gay equality, "a new generation of twentysomething urban gays" (para. 2) possesses the "freedom to live exactly the way [they] want" (para. 2). AguirreLivingston (2011) wondered, "Is there even a gay struggle to be had anymore?" (para. 4) but concluded that there is not, as "the process of assimilation has accelerated faster than anyone probably believed it could" (para. 4). "To be a twentysomething gay man in Toronto in 2011 is to be free from persecution and social pressures to conform [to] the stereotypes and the ideals associated with preceding gay generations" (para. 3); now, no longer "plagued with the pressures 
to be here and be queer" (para. 6), young (urban, White, middle-class, cisgendered) gay men are "emancipated" from their homosexuality, free to be post-gay and authentically themselves. The “post-modern homo" (para. 2) is positively bourgeois: he has abandoned Toronto's Gay Village, he is "tattooed and pierced and at the helm of billion-dollar industries like fashion and television" (para. 2), he vacations with his boyfriend "in fabulously rustic country homes that belong to [his] parents" (para. 2), and his "sexual orientation is merely secondary to [his] place in society" (para. 2).

As was demonstrated earlier, the gay participants viewed gay identities, communities, and body ideals as diverse, because how one presents oneself, where one socializes with likeminded gay men, and what one finds attractive are determined by innate, unique individual desires. This thesis suggested that the freedom to choose to act upon an essentialized desire simply reflects a neo-liberal remaking of the self that is neither empowering nor emancipatory. The pomo is similarly concerned with embodying authenticity; he ostensibly possesses the freedom to "choose" his own version of gay, but gay equality provides him with the necessary tools to pursue individuality, unconstrained by his homosexuality. For instance, Maks (22, gay) lives "a really great young, equal rights lifestyle" in Toronto, so he "[doesn't] see being gay as the pinnacle of [his] existence; he would "rather not pride [himself] in what's related to [his] sexual identity, [he'd] rather pride [himself] in something else." While describing his gay identity, he stated:

I guess I'm gay, I'm attracted to men and have sex with men. Uh, to further that though, I guess I have sort of distinguished myself from what people might consider the stereotypical gay community, especially in areas like Toronto, like in the Village or Queen West. It's just not really my scene, I don't really see myself there. I see myself 
associating almost more so with heterosexuals, uh heterosexual women and men and I guess it's - which is weird because I'm in the fashion industry, and I'm constantly exposed to homosexual themes, but I just don't know, I guess I just see myself (...) socializing with heterosexuals.

Like most gay participants, Maks relied on biological essentialism to present his same-gender attractions, or "sexual nature," as innate, bereft of any "homosexual themes." He was quick to clarify that he is not "closeted," he "just [doesn't] feel like [he has] to wear [his] sexual orientation on [his] sleeve." Though Maks acknowledged the diverse cultural aspects of sexual identity, he expressed his gayhood as the absence of gayhood; his "gay identity comes to the forefront" only when he has sex, "otherwise it sort of retracts":

Interviewer: So you were describing yourself as not fitting into either of those groups [the Gay Village versus Queer West]. Why is that?

Maks: I just, I guess just a difference of character almost, and what I do and do not like to engage in in terms of like social activities and what not, in terms of style and dress (...) it's just - in terms of how I associate with those people, and I don't know why, but it's just not what I prefer to do, and not how I tend to approach the situations that belong to a gay group I guess, and I think that it might be the distinction that I never found it important to define people based on their sexual orientation.

It is more important to be "an active member of society without being a gay active member of society." Throughout the interviews, there was an overwhelming concern among many gay participants about being "defined" by their sexuality or identified as gay because of "things like vocal intonation or just personality traits that are not typically heterosexual” (Maks). Jayden (30, gay) has "an aversion to [being] archetyped as gay": "So, I mean I've gone to Pride once, but 
like it's not something I'm dying to go to, because while I am proud, I'm just proud to be me." Brock (24, gay) “[doesn't] want to be defined by [his] sexuality": "it's just not something I'm constantly thinking 'I'm gay, I'm gay' or anything life that.” In fact, Brock “[doesn't] put out any indicators and most people don't know [he's] gay until about a month into knowing [him]." Though Ahmet (27, gay) is gay, above all else he is "an individual in this world and [doesn't] feel any different from anybody else because [he's] gay." When Vito (23, gay) goes out to a gay club, he is weary of the pressure to "dress a certain way (...) to follow, a certain, you now, guideline (...) that everybody [gay men] follows, which is, which is weird"; instead, he tries "not to follow it”:

Vito: Like I go to my, I go to the club like as myself. I usually don't get picked up at clubs or anything. I just go purely to dance and that's fine, it's like I - it's weird, like I don't really want to stay in the game, it's just, I'm just you know... Interviewer: So what's the game? $\mathrm{V}$ : I guess the game is like, you know, always having to pick up at bars, or having to be promiscuous I guess, but, I don't know, it's like, I don't care, like I just go to have a good time. But there's that shady, almost like (...) kind of negative I guess.

Vito positioned himself as naturally individual, unshackled by negative gay stereotypes promiscuity, superficiality, cattiness. Likewise, Antonio (19, gay) stated that his "body must be expressing [his] sexuality in some way" through "a lot of those signifiers (...) like body language, or attitude," so he makes sure to rein in "the stereotypes": "I do sometimes hate all those connotations (...) like how you walk, how you run, how you talk (...) I hate like the stereotypes." Antonio is gay, but he is "not one of those gays like that makes it obnoxious," which "annoys" him. He does not "feel the need to like push [his] sexuality on people," because 
he is "secure with [himself]" and refuses to "change who [he] really [is]." Authenticity was a central concern for these participants, and many situated themselves as normal (i.e., homonormative) everyday men for whom sexual identity is a small part of their daily lives. They worked to diminish the extent of any social difference on the basis of sexuality, a strategy that paradoxically required an ongoing self-consciousness about being marked as sexual subjects. Endorsing or occupying the pomo subject position means "liberating" oneself from a prior false identity in order to realize an authentic expression of selfhood intimately connected to "capitalism and a late modern emphasis on personal identity and appearance" (Duncan, 2010a, p. 446).

Indeed, in mainstream gay identity politics, ironically, "I AM WHAT I AM" (The Invisible Committee, 2009) has become a totalizing anthem; however, the pomo does not merely reflect some humanist quest for self-actualization:

Many young gays and lesbians think of themselves as part of a "post-gender" world and for them the idea of "labelling" becomes a sign of an oppression they have happily cast off in order to move into a pluralistic world of infinite diversity. In order words, it has become commonplace and even clichéd for young urban (white) gays and lesbians to claim that they do not like "labels" and do not want to be "pigeon holed" by identity categories, even as those same identity categories represent the activist labors of previous generations that brought us to the brink of "liberation" in the first place. Many urban gays and lesbians of different age groups also express a humanistic sense that their uniqueness cannot be captured by the application of a blanket term (Halberstam, 2005a, pp. 19)

Like Rosalind Gill's post-feminist participants, who were "empowered" by their ability to "choose" to re-embrace misogynistic traditional femininity, the pomo, who is beyond 
homosexuality, "chooses" to turn off not just gay/effeminacy, but any marker of homosexual culture (Halperin, 2012), in order to embody the new homonormativity that is attached to legal rights administered by neo-liberal discourse and material resources and made available only to good, normal (post)gay citizens. In other words, heterosexist, masculinist visibility procured through homosexual invisibility. When David, aged 24, who was interviewed for The Grid article (Aguirre-Livingston, 2011), states, "My buddies and I joke that we're not gay, we just fuck dudes. I always enjoy people's accusation that 'You can't be gay' because of my appearance, my tastes (in music, wardrobe, etc.) and my personality," is he not engaged in a body-reflexive practice as a (post)gay man conscious of the political status attending his visibility in heteronormative social life? Is he not self-consciously downplaying the significance of his sexuality and positioning himself as in-control, individual, masculine, because of the hierarchical organization of masculinities (Connell, 2005) or other gendered and sexed institutions - like psychology's gay male body dissatisfaction imperative - that pathologize gay bodies (Duncan, 2010)?

Embodied queer resistances. The closest analogue to the theory of gay/queer embodiment presented in this thesis is Kimmell and Mahalik's (2005) minority stress model. Their suggestion that "gay men compensate for perceptions that they are less masculine" (p. 1185 ) and build muscles to ward off "antigay attacks and discrimination" (p. 1185) is a similar, though more literal, account of the body-reflexive practices associated with the hypertrophic hostage, straight actor, paragon of pride, and pomo subject positions. What their model fails to consider is that not all gay men "develop a negative body image issue as a result of their own internalized shame" (p. 1185). If, as Foucault (1982) suggested, power is "always a way of acting upon an acting subject" (p. 789), then the subjectivated subject is capable of resistance - a 
sort of autonomy through heteronomy. Knowledge/power governs by structuring the possible field of action of others; therefore, "individual or collective subjects who are faced with a field of possibilities in which several ways of behaving, several reactions and diverse comportments, may be realized" (p. 790). In other words, discourse subjectivates, but the subject, through technologies of the self and other body-reflexive practices, has some say in its own subjection. Though discourse does not operate through "voluntary servitude" (p. 790), this does not mean that the subject's material practices are examples "of an essential freedom" (p. 790). Rather, Foucault (1982) proposed that said material practices may manifest resistance, or a "recalcitrance of the will [of the subject]“ (p. 790) - what he termed agonism - that is incited by the exercise of knowledge/power: "Every power relationship implies, at least in potentia, a strategy of struggle" (Foucault, 1982, p. 794). Elsewhere, Foucault (1978) called resistant agonism reverse-discourses (i.e., a course of subjection that struggles against or resists the normalizing aims by which it is mobilized). To quote Butler (1997): "the same 'homosexuality' [is] deployed first in the service of normalizing heterosexuality and second in the service of its own depathologization" (p. 93). Indeed, the queer participants spoke about rejecting the drive to compensate for their homosexuality. Where the gay participants experienced double-consciousness as a result of discourses about heterosexism and hegemonic masculinity, responded with shame, and engaged in a habitual body monitoring, the queer participants felt no shame. Certainly, many queer participants, like Gerhard (24, gay/queer), expressed "feeling that pressure to act masculine which is collapsed into straight" and discussed boarder control as "the risk of renormalization is persistently there" (Butler, 1997, p. 93), but as a whole, they were less inclined to turn off gay/effeminacy. Instead, they engaged in queer embodied resistances by increasing the visibility of homosexuality and non-hegemonic masculinities, especially in heteronormative social life. 
For the hypertrophic hostage, straight actor, and paragon of pride subject positions, selfpresentation is closely monitored. Even the pomo, who professes to not care about stereotypes or affectations, works very hard to present himself as a non-stereotypically (post)gay "individual." The queer participants, like the gay participants, were cognizant of the body's communicative and symbolic propensities, functions, and implications, but they did not stifle their bodies' capacities to communicate a devalued identity. They never embodied the shame/masculine compensation interpretive repertoire and considered their bodies as sites at which queer epistemology may be established and made perceptible. Skylar (31, queer) stated that "doing queer" means not engaging in body monitoring or boarder control:

I think the unruly body makes people feel uncomfortable. And the body that cannot be contained. And I think that queer sexuality with its culture of refusal - refuses the containment of the body. And so I think that, um, I think if we (...) treat [sexual identity] as a biological function or biological accident, like race, then it becomes an act of - it becomes an agreement to sort of um be ruled, and it's going with a neo-liberal agenda. And I think that queerness is refusal of that ruling uh it means that we're talking more about the body that cannot be controlled.

Queer bodies are bodies that do not take well to subjection - they resist heterosexism and hegemonic masculinity by troubling, violating, crossing, mixing, or otherwise confounding established boundaries between male and female, masculine and effeminate, normal and abnormal:

If you're looking at conservative responses to the Folsom Street Fair and things like that in San Francisco um and then the discourse around that becomes sort of people who don't control their bodies. And if you look at sort of conservative - really conservative 
discourses around Pride, it becomes people who refuse to control their bodies (...) Um, I think we talked about earlier about violently policing masculinity and how people who are most violently policed are those who aren't obeying. (Skylar)

Queer self-identification, for Skylar, "has always been about that sort of oblique angle, about sort of refusal of the obligatory - the politicization of sexuality." Embodied queer resistances "politicize sexuality" by not "obeying"; rather, they make evident homosexuality's construction, specifically, and destabilize the regulatory function of identity categories, generally. Because sexual identity is not something planted in us to be discovered, but something that is performatively produced by acts that "effectively constitute the identity they are said to express or reveal" (Butler, 1990, p. 279), embodied queer resistances work to problematize the naturalization of identity categories. A queer's material practices, for instance, may question why gay men must engage in a performance of hegemonic masculinity in order to be considered sufficient as men. Consequently, a queer may take pride in the shame associated with embodying moral effeminacy (Halberstam, 2005b). In doing so, embodied queer resistances "set up sort of settlements on spaces between identities" (Skylar), "liminal spaces" - they reject "that sort of gender baggage" (Morgan, 22, queer), the "construction of an absolute gender binary and of sexual orientation as being a binary" (Phelan, 32, gay/queer), "the identity checklist" (Gerhard, 24 , queer), and "fuck with sexuality in a way that makes people feel really uncomfortable" (Skylar). The queer participants advocated for material practices that discard constrictive notions of normalcy and acceptable homosexuality or masculinity; they sought to create more space for and recognition of the various actions performed daily in a social landscape blinded and hostile to difference. 
As a case study, take Bennett's (30, gay/queer) response to the question, "In what ways is your sexual identity shaped by gay and or queer culture?”

Well, it's shaped and created by queer culture because it's shown me to be unapologetic for one, to be embracing of whatever quote unquote "freak" is in you. It's - the queer community is shaping me more than the gay community because the queer community I find is much more open to anything that's outside the norm or different...or there is even a gay norm [the new homonormativity], and the gay norm is to be actually as straight as you can be which is so stupid. It's not liberating at all.

Bennett positioned his relatively newfound queerhood a source of security, a way to "feel good about [himself]" and his gay/queer sexuality. Throughout his adolescence, he lifted weights "like crazy, but [he] was working out like crazy for the wrong reasons" - because of shame, in order to compensate. At 25 years of age, his "priorities then changed (...) and then, like [he] said, "fuck this shit"”:

Incidentally, I was more insecure when I had the 'rocking' muscular body, and I was so focused on it, and when I stopped caring, I stopped getting attention from certain people, but my life got better because I was hanging out with queers that I had things in common with."

The queers he met "were lesbian, trans," they relished "not fitting into any perceived cultural norm as opposed to trying to attempt normalcy," they were "empowered" by not giving "a fuck quite frankly," and they "moved [him] to find the same thing in [himself]." Now, Bennett embraces "existing outside of the norm and seeing it as a good thing." No longer making up for "quote unquote 'gay mannerisms or affectations,"” he is more interested in using his body to 
express the queer aspects of his sexual identity through "aesthetic choices": his Harvey Milk tattoo, his rainbow bracelet, his combat boots, his shaved head and facial hair:

Like I mean I wear my rainbow bracelet everyday on my arm, not to say I'm gay or queer specifically, because my parents wear them as well. It's just to show any stranger on the street (...) a symbol - I identify at least with support you know being gay and queer and supporting visibly LGBT and queer communities. I think that iconography is powerful. I don't want people to not be able to tell when they meet me. I want them to know that I am gay because I think I'm a good person, and I can be a good...I have been a lot of people's first gay person they have ever met and I think that uh, it's important to never pass an opportunity up when you can open someone's eyes.

Bennett does not shy away from gay stereotypes, "mannerisms or caricatures" - he has "an interest in classical music and opera, and affinity for 1940s films, Bette Davis, Jane Austin, um camp horror movies, queer literature." In fact, he viewed gay stereotypes as indicative of a gay sensibility, a way of being that should be celebrated and made visible, not disavowed: "I think it's you know the stereotypical campy queens, but there's more to these quote unquote 'stereotypes.' They are actually rooted more in um expression and...trying to communicate something, like a way of seeing the world that is resistant." Recently, prominent queer theorist David Halperin (2012) suggested that, because homosexuality is a social rather than an individual condition, one is never inherently gay, and one learns how to be gay through an initiatory process that is internal to gay male communities. Halperin (2012) proposed that this process of counter-acculturation involves being taught "how to transform a number of heterosexual cultural objects and discourses into vehicles of gay meaning" (p. 7) in addition to adopting a gay sensibility and a specific, non-standard attachment to certain cultural objects and 
forms (e.g., art and architecture, opera and musical theatre, pop and disco, style and fashion, emotion and language). This distinctively gay way of being is often denigrated as stereotypic, usually by post-gay and straight-acting gay men, but Halperin (2012) maintained that “"gay’ refers not just to something you are, but also to something you $d o "$ (p. 13) and is rooted in a particular "queer way of feeling" (p. 12) and a "queer subjectivity [that] expresses itself through a peculiar, dissident way of relating to cultural objects (...) and cultural forms in general." Queer subjectivity, according to Halperin (2012), resists the norm, it involves "receiving, reinterpreting, and reusing mainstream culture (...) decoding and recoding the heterosexual or heteronormative (...) so that they come to function as vehicles of gay or queer meaning" (p. 12). In this vein, Bennett's adoption of gay stereotypes - in addition to other queer signifiers of non-normality symbolizes the embodiment of queer epistemology and an attendant dismantling of hegemonic social structures that once dictated how Bennett should appear as gay. As Morgan (22, queer) noted:

Among queer these days there seems to be this sort of attempt to reinvigorate "faggy" culture you know where the idea of being faggy wasn't like an insult and didn't carry the kind of baggage that it does. And I think that that sort of thing is something that we're seeing more and more of when we move so close to this idea of, like you know, 'oh, gay men should fit into straight society, straight-acting to fit into this heteronormative ideal of, you know, what a male should look like' (...) Being flamboyant and being, sort of, you know out there with, you know, like boas and sequins and stuff like that, there's nothing inherently wrong with that.

Not fitting into "straight society" or the "heteronormative ideal" of hegemonic masculinity may be multiple embodied: 
Yeah, I think it's just, like, walk, the way that people walk, the way that they carry themselves. I think even to a much lesser extent, even myself, often in the street someone will yell something really offensive or what have you, um, and at first, sometimes, there's definitely like I feel a little bit nervous and scared. But other times, it's just like, you know what, "fuck them" I'm going to be queer in a particularly flamboyant sort of sense. (...) Um, and, and I think also just even, just sort of the amount in which [queers] try to put themselves out into the public [emphasis added], you know what I mean, and find public places where they can express their sexuality. (Morgan) Bennett's body-reflexive practices - his walk, his dress, his "fuck you" sensibility - work to increase the visibility of markers of homosexuality - and not just assimilationist gayhood, but "alarming," militant queerhood - and refuse Western dictums of proper male embodiment. $\mathrm{He}$ wants to be the "deviation from the norm...unusual, unexpected, um...different, I think that can be a good thing, I like that."

Overall, the queer participants shared stories similar to Bennett's, stories about moving from dissatisfaction with an apolitical gay mainstream to "doing" queer, from feeling, in many ways, trapped by a gay identity to rejecting a hardening of fluid and heterogeneous possibilities into rigid, binarized categories. When asked how queers can display resistance, most inadvertently or directly cited Butler's (1990) Gender Trouble and other comparable ideas foundational to queer theory by naming gender and sexuality parody, like genderfuck and drag performance - "Dzi Croquettes" (Alvarez \& Issa, 2009; Skylar, 31, queer), "The Sisters of Perpetual Indulgence" - but also "gay men who are disabled" (Phelan, 32, gay/queer), "gay trans men," "transgendered folks who refuse surgery" (Skylar), "kitschy gay masculinity from the 1960s and 1970s, like Tom of Finland," "bear culture" (Ben, 30, queer), "queer punk people 
[who] reject a lot of uh male and gay body ideals," and other subversive "performances" that reveal that the seemingly "natural" is actually socially constructed and, thus, contingent. For instance, Bennett's genderfucking Folsom friend is subversive and the hypertrophic hostage is not because the former, through a ridiculous pastiche of masculinity and femininity, deconstructs said binary, and the latter does not. Likewise, Tom of Finland's hypertrophic leathermen shrewdly perform a wildly exaggerated masculinity that highlights gender performativity. They "flaunt the unpredictability of social gendering" (Halberstam, 2005a, p. 51) by manifesting a "realness" (p. 51) that imitates and appropriates "the real and its effects" (p. 51) - that is, hegemonic masculinity - whereas the hypertrophic hostage embodies the quest for "the real [for] that which always exists elsewhere" (p. 52), a fantasy of belonging and being. Indeed, for these participants, queer self-identification meant engaging in a "coalition oriented politics" (Gerhard, 24 gay/queer) that avoids disputes over purity (of identity, of doctrine, of commitment) that often tear apart movements, like mainstream gay identity politics, dependent on complete agreement among members over long periods of time. They situated queer identity as an anti-identity, as political agency, social collectives, moral bonds not grounded in a shared identity, but subsumed under an undifferentiated sign and unified by a desire to embody practices that "resignify" received meanings - actions that lead to a proliferation of the constitutive categories into which all subjects are constrained to fit. Resistance, for the queer participants, went beyond the taking of a name ("I am queer) to mobilizing agonistic reverse-discourses in order to assume and empower a marginalized positionality and produce creative new ways of being. 


\section{Conclusions and Future Directions}

Psychological research about body image among gay man should not be treated as indicative of evidence that body dissatisfaction is an essential part of a supposed "gay male experience." Though not the focus of this thesis, it should be noted that, when asked outright, none of the participants claimed to feel dissatisfied with their bodies. Satisfaction/dissatisfaction was not positioned as a binarism: often, the participants described feeling satisfied and dissatisfied, concurrently - their feelings were situated as contextual, not global, and dependent upon the body "part" in question (e.g., hairline, facial features, height, weight, chest, buttocks, legs, arms, etcetera) in addition to what they can do with their bodies. Satisfaction/dissatisfaction was communicated in embodied terms: the participants portrayed themselves as subjects in dynamic states of continuous, purposeful engagement with multiple environments. Often, the boundary between discourse and corporeality was blurred, the mind/body binarism deconstructed. ${ }^{21}$ As demonstrated in this thesis, the explanatory models developed primarily by quantitative comparative researchers pathologize gay men by suggesting that homosexuality inherently causes body dissatisfaction. Furthermore, they propagate the notion of an essentialized, monolithic gay identity, community, and body ideal in the service of stabilizing a satisfied, ordered heterosexuality. This thesis relied on the voices of 19 gay/queer men/genderqueers to explore the boundaries of psychology's epistemological determinism; they expressed ideas that were antithetical to the explanatory models' restrictive formulations of homosexuality, but through divergent discourses. Both those who identified as gay and those who identified as queer deployed the "more than clubs and bars" interpretive repertoire to assert that gay identities, communities, and body ideals are necessarily diverse. However, the gay participants relied on neo-liberal individualism and the queer participants relied on queer 
epistemology. For the gay participants, homosexuality is culturally diverse because each gay subject is inherently unique; this view instantiates a neo-liberal remaking of the self in accordance with one's "authentic" sexuality. In contrast, the queer participants adopted a subjectless critique that dismantles hegemonic social structures in order to open up spaces for queer forms of difference.

This thesis not only deconstructed the existing models of gay male body dissatisfaction, but also, in its place, constructed a theory of gay/queer male/genderqueer embodiment based on the Foucauldian concept of subjection wherein the participants' body-reflexive practices were explored in relation to overarching discourses about heterosexism and hegemonic masculinity. The materiality of the participants' bodies mattered not as templates for homosexuality, but as citations of a fluid, historically contingent configuration of material practices deemed gay or queer. Overall, the gay participants deployed the shame/masculine compensation interpretive repertoire to describe "turning off gay/effeminacy" in order to overcome the shame associated with homosexuality. This interpretive repertoire was embodied through three main subject positions - the hypertrophic hostage, the straight-actor, and the paragon of pride - and intersected with neo-liberal discourse to produce the new normal interpretive repertoire and the pomo subject position. With the aim of detaching homosexuality from its association with moral (and other forms of) effeminacy, the hypertrophic hostage builds muscles, the straight-actor presents as heterosexual, and the paragon of pride works toward achieving hegemonically masculine indicators of success. In contrast, the queer participants rejected compensation. They engaged in embodied queer resistances that increase the visibility of homosexuality and nonhegemonic masculinities in heteronormative social life and that problematize the naturalization of identity categories. Like the gay participants, the queer participants were attuned to the body's 
communicative and symbolic propensities, but they viewed the body as a playful site in which multiple identities or ways of life may be manifested and expressed.

This thesis filled three identified gaps in psychological literature on gay male body image. In a recent review, Morrison and McCutcheon (2011) noted that most research focuses on muscularity, weight, and overall body dissatisfaction. Though these components "are certainly important, they do not capture the full scope of body image (...) there is more to the male body than musculature and fat" (p. 218). Given this thesis' focus on what the gay male body can mean, say, or do, aside from its current positioning as a site of dissatisfaction, it addressed the aforementioned limitation by considering the meaning of body image among gay men in a broader, more encompassing manner. Instead of a narrow focus on body shape or size, this thesis addressed how the body plays a role in producing sexual and gender identities. Second, Morrison and McCutcheon (2011) suggested that simply documenting "that cultural artefacts such as media depict a given body type as 'ideal' does not explain why specific groups evidence poorer body image than other groups" (p. 219). This thesis provided fertile ground for moving beyond a simplistic understanding of body image as the net result of the internalization of harmful gay media/cultural messages/images. Instead, it sought to explore and understand how certain discourses disseminate ideas about particular bodies and how those ideas are then embodied through material practice. Third, Morrison and McCutcheon (2011) recommend that researchers "examine the 'strategies of resistance' that gay, lesbian, and bisexual individuals may employ to counter hegemonic messages about the body" (p. 219), which is what this study accomplished. Interviewing queer-identified participants proved to be invaluable for a number of reasons: not only did their views destabilize psychology's explanatory models, they helped establish a grounded account of queer epistemology, of how one can actually go about living a queer way of 
life and what that entails at the level of material practice and not just discourse, and of how that is different from queer posturing or transgression marketed as neo-liberal individualism. In general, the queer participants were particularly self-reflexive when discussing their sexual identities and the ways in which their material practices are subjectivated by larger regimes of discursive power.

Though men of diverse self-identified backgrounds and countries of origin were interviewed for this thesis, only $14.7 \%$ of participants were men of colour. Issues pertaining to race and ethnicity were not the focus of this thesis; nevertheless, the inclusion of more men/genderqueers of colour would have increased the diversity of the participants and may have provided further specific insights into the complex process of subjection. Throughout the interviews with the three men of colour recruited for this thesis, race and ethnicity rarely came up. If they did, the participants' endorsed a post-race ethos in which they distanced themselves from the label "queer of colour," much like how the pomo distances himself from the label gay. To be sure, the interview did not ask about racialized discourses; however, several of the queer participants discussed how race/ethnicity intersects with heterosexism and hegemonic masculinity to produce a hierarchy of gay masculinities wherein White bodies are situated on top. For instance, the feminization of certain races suggests that one way hegemonic masculinity subordinates different groups of men is by race (Connell, 2005). This Western racialized hierarchy posits a dangerous and hypersexual Black masculinity at one extreme and a passive, asexual Asian masculinity at the other (Hennen, 2008). How differently would the shame/masculine compensation interpretive repertoire or embodied queer resistances manifest among a diverse group of Black or Asian men/genderqueers (among other races/ethnicities)? Given that the "the subject who emerges as the subject of gay shame is often white," 
(Halberstam, 2005b, p. 223), future research should focus its efforts on intersectionality to explore how race/ethnicity figures into the theory of gay/queer embodiment presented in this thesis. In particular, Halberstam (2005b) proposed that queer of colour critique (e.g., Ferguson, 2003) counters the "shame formulation" (p. 223), which may prove to be a viable epistemological framework for future qualitative research in the field. Similarly, many participants were well educated and several queer participants were able to articulate their ideas about queerhood in a particularly erudite manner. Future research should explore body-reflexive practices among gays/queers who have received less education or who live in less urban areas. Embodied queer resistances may be expressed idiosyncratically among different classes. Furthermore, they may also contend with discourses about neo-liberal individualism dissimilarly, because, as many queer participants indicated, the neo-liberal remaking of the self is often quite expensive (e.g., clothes, grooming products, gym membership). One problem with queer theory is that it occasionally produces a divide between middle-class urban queers and working class rural gays: urban environments are positioned as the queer's "natural" environment and rural towns as hostile to gays/queers. However, queer subcultures do not only thrive in well-educated urban areas (Halberstam, 2005a) and future research should not situate queer life as essentially urban.

Finally, one key difference between the gay and queer participants is that the former responded to double-consciousness with shame and the latter did not. Both considered their bodies as texts of culture. However, the gay participants positioned their minds as active in the process of self-presentation and their bodies as passively awaiting inscription. They deployed a Cartesian framework wherein the mind (self) is freed from bodily (other) determination and free to govern how the body looks, speaks, walks, gestures, etcetera. In doing so, the gay participants 
situated the mind as separate from the body, as the site at which one works to purge one's body of moral effeminacy. Conversely, the queer participants did not privilege mind over body; rather, they circumvented notions of mind/body dualism to express connections with their bodies in particularly embodied ways. Typically, they spoke about how the mind and body are connected and function as a productive force capable of instantiating multiple queer identities. Instead of fighting with the body to turn off gay/effeminacy in order to make privilege (e.g., masculinity, wealth, Whiteness) visible, the queer participants described their embodied identities as playful, democratizing "doings" that subvert discourses that narrowly ascribe privilege to few bodies. If both gays and queers are similarly subjectivated by heterosexism and hegemonic masculinity, why do some persons submit to body monitoring and compensation whereas others adopt reverse-discourses? Future research should explore the discursive and psychic mechanisms that push some persons toward, for instance, remaking themselves in the image of hegemonic masculinity and others toward dismantling that very masculinity through body-reflexive practices. Indeed, embodied queer resistances may be central to theorizing positive body image among gay men. According to Menzel and Levine (2011), positive body image is multidimensional and involves "embodying experiences," like "valuing one's body in terms of competence (as opposed to engaging in self-surveillance)" (p. 167) and viewing one's "body as a key aspect of (...) competence, interpersonal relatedness, power, self-expression, and wellbeing” (p. 170). They proposed that embodying experiences lead to fewer and less intense negative self-evaluations (e.g., body shame) as a result of failing to meet culturally accepted ideals of beauty. Consequently, embodied queer resistances present an avenue for psychologists to consider body image among gay men detached from discourses about body dissatisfaction wherein gay/queer bodies are refigured as "events" (Budgeon, 2003) and not as objects. This 
entails reconceiving bodies not in terms of "who" they are, with reference to an essential underlying "self," or as sites of (dis)satisfaction or distress, but according to what they can do, what they can produce, and how they can resist. 


\section{References}

Altman, D. (1971). Homosexual: Oppression and liberation. New York, NY: Avon.

Aguirre-Livingston, P. (2011, June 9). Dawn of a new gay. The Grid. Retrieved from http://www.thegridto.com

Allen, L. (2007). "Sensitive and real macho all at the same time": Young heterosexual men and romance. Men and Masculinities, 10, 137-152.

Allport, G. W. (1954). The nature of prejudice. Reading, MA: Addison-Wesley.

Andersen, A. E. (1999). Eating disorders in gay males. Psychiatric Annals, 29, 206-212.

Attwood, F. (2005). "Tits and ass and porn and fighting": Male heterosexuality in magazines for men. International Journal of Cultural Studies, 8, 83-100.

Baerveldt, C., \& Voestermans, P. (1998). The body as a selfing device: The case of anorexia nervosa. In H. J. Stam (Ed.), The body and psychology (pp. 161-181). London, UK: Sage.

Baird, B. (2007). "Gay marriage," lesbian wedding. Gay and Lesbian Issues and Psychology Review, 3, 161-170.

Barlett, C. P., Vowels, C. L., \& Saucier, D. A. (2008). Meta-analysis of the effects of media images on men's body-image concerns. Journal of Social and Clinical Psychology, 27, 279-310.

Barry, D. (2012, July 29). More cheery millennial news: 18-29-year-olds aren’t even close to fledging. Jezebel. Retrieved from http://jezebel.com

Bayer, B. M., \& Malone, K. R. (1998). Feminism, psychology and matters of the body. In H. J. Stam (Ed.), The body and psychology. London: Sage.

Belsey, C. (2002). Poststructuralism: A very short introduction. Oxford, UK: Oxford University 
Press.

Beren, S. E., Hayden, H. A., Wilfley, D. E., \& Grilo, C. M. (1996). The influence of sexual orientation on body dissatisfaction in adult men and women. International Journal of Eating Disorders, 20, 135-141.

Berger, J. (1972). Ways of Seeing. Great Britain: Penguin Books.

Berlant, L. (2002). Two girls, fat and thin. In S. M. Barber \& D. L. Clark (Eds.), Regarding Sedgwick: Essays on queer culture and critical theory (pp. 71-108). New York, NY: Routledge.

Berry, K. (2007). Embracing the catastrophe: Gay body seeks acceptance. Qualitative Inquiry, $13,259-281$.

Bersani, L. (1988). Is the rectum a grave? In D. Crimp (Ed.), AIDS: Cultural analysis, cultural activism. Cambridge, MA: MIT Press.

Bhabha, H. K. (1988). The commitment to theory. New Formations, 5, 5-23.

Bordo, S. (1993). Unbearable weight: Feminism, Western culture, and the body. Berkeley, CA: University of California Press.

Bordo, S. (1999). The male body: A new look at men in public and in private. New York: Farrar, Straus, and Giroux.

Borough, M., \& Thompson, J. K. (2002). Exercise and sexual orientation as moderators of body image disturbance and eating disorders in males. International Journal of Eating Disorders, 31, 302-311.

Bourdieu, P. (1986). Distinction: A social critique of the judgement of taste. London, UK: Routledge.

Brand, P. A., Rothblum, E. D., \& Solomon, J. L. (1992). A comparison of lesbians, gay men, 
and heterosexuals on weight and restrained eating. International Journal of Eating Disorders, 11, 253-259.

Bray, A. (1982). Homosexuality and Renaissance England. Boston, MA: Gay Men's Press.

Buchholz, T. G., \& Buchholz, V. (2012, March 10). The go-nowhere generation. The New York Times. Retrieved from http://www.nytimes.com

Butler, J. (1990). Gender trouble. New York, NY: Routledge.

Butler, J. (1993). Bodies that matter: On the discursive limits of "sex." New York, NY: Routledge.

Butler, J. (1997). The psychic life of power: Theories in subjection. Stanford, CA: Stanford University Press.

Cafri, G., Thompson, L., Ricciardelli, L., McCabe, M., Smolak, L., \& Yesalis, C. (2005). Pursuit of the muscular ideal: Physical and psychological consequences and putative risk factors. Clinical Psychology Review, 25, 215-239.

Cash, T. F., \& Smolak, L. (2011). Understanding body images: Historical and contemporary perspectives. In T. F. Cash \& L. Smolak (Eds.), Body image: A handbook of science, practice, and prevention ( $2^{\text {nd }}$ ed., pp. 3-11). New York, NY: Guilford.

Cassidy, J. (2012, May 14). A politician shows real courage on gay marriage. The New Yorker. Retrieved from http://www.newyorker.com

Chaney, M. P. (2008). Muscle dysmorphia, self-esteem, and loneliness among gay and bisexual men. International Journal of Men's Health, 7 (2), 157-170.

Chauncey, G. (1994). Gay New York: Gender, urban culture, and the making of the gay male world, 1890-1940. New York, NY: Basic Books.

Clarke, V., \& Turner, K. (2007). Clothes maketh the queer? Dress, appearance and the 
construction of lesbian, gay and bisexual identities. Feminism and Psychology, 17, 267-276.

Cohen, J. (1992). A power primer. Psychological Bulletin, 112, 155-159.

Connell, R. W. (1987). Gender and power. Cambridge, UK: Polity.

Connell, R. W. (2005). Masculinities ( $2^{\text {nd }}$ ed.). Berkeley, CA: University of California Press.

Corliss, H. L., Cochran, S. D., \& Mays, V. M. (2002). Reports of parental maltreatment during childhood in a United States population-based survey of homosexual, bisexual, and heterosexual adults. Child Abuse and Neglect, 26, 1165-1178.

Crocker, J., \& Major, B. (1989). Social stigma and self-esteem: The self-protective properties of stigma. Psychological Bulletin, 96, 608-630.

D'Augelli, A. R. (2002). Mental health problems among lesbian, gay, and bisexual youths ages 14-21. Clinical Child Psychology and Psychiatry, 7, 433-456.

D’Augelli, A. R., Pilkington, N. W., \& Hershberger, S. L. (2002). Incidence and mental health impact of sexual orientation victimization of lesbian, gay, and bisexual youth in high school. School Psychology Quarterly, 17, 148-167.

D’Emilio, J. (1983). Sexual politics, sexual communities: The making of a homosexual minority in the United States, 1940-1970. Chicago, IL: University of Chicago Press.

D’Emilio, J. (1993). Capitalism and gay identity. In H. Abelove, M. A. Barale, \& D. M. Halperin (Eds.), The lesbian and gay studies reader (pp. 467-478). New York, NY: Routledge.

Demetriou, D. Z. (2001). Connell's concept of hegemonic masculinity: A critique. Theory and Society, 30, 337-361.

Derrida, J. (1974). Of grammatology. Baltimore, MD: John Hopkins University Press.

Drummond, M. J. N. (2005a). Asian gay men's bodies. Journal of Men's Studies, 13, 291-300.

Drummond, M. J. N. (2005b). Men's bodies: Listening to the voices of young gay men. Men 
and Masculinities, 7, 270-290.

Drummond, M. J. N. (2010). Younger and older gay men's bodies. Gay and Lesbian Issues and Psychology Review, 6, 31-41.

Du Bois, W. E. B. (1903/2008). The souls of black folk. Oxford, UK: Oxford University Press.

Duggan, S., \& McCreary, D. (2004). Body image, eating disorders, and the drive for muscularity in gay and heterosexual men: The influence of media images. Journal of Homosexuality, 47, 45-48.

Duggan, L. (2003). The twilight of equality?: Neoliberalism, cultural politics, and the attack on democracy. Boston, MA: Beacon Press.

Duggan, L., \& Hunter, N. (1995). Sex wars: Sexual dissent and political culture. New York, NY: Routledge.

Duncan, D. (2007). Out of the closet and into the gym: Gay men and body image in Melbourne, Australia. The Journal of Men's Studies, 15, 331-346.

Duncan, D. (2010a). Embodying the gay self: Body image, reflexivity and embodied identity. Health Sociology Review, 19, 437-450.

Duncan, D. (2010b). Gay men, body identity and the politics of visibility. Gay and Lesbian Issues and Psychology Review, 6, 20-30.

Edley, N., \& Wetherell, M. (1997). Jockeying for position: The construction of masculine identities. Discourse Society, 8, 203-217.

Edwards, D., \& Potter, J. (1992). Discursive psychology. London, UK: Sage.

Eng, D. L., Halberstam, J., \& Muñoz, E. (2005). What's queer about queer studies now? Social Text, 84-85, p. 1-17.

Featherstone, M. (1991) Consumer culture and postmodernism. London, UK: Sage. 
Ferguson, R. A. (2003). Aberrations in black: Toward a queer of color critique. Minneapolis, MN: University of Minnesota Press.

Fichter, M. M., \& Daser, C. (1987). Symptomatology, psychosexual development and gender identity in 42 anorexic males. Psychological Medicine, 17, 409-418.

Filiault, S. M. (2010). Editorial. Gay and Lesbian Issues and Psychology Review, 6, 1-3.

Filiault, S. M., \& Drummond, M. J. N. (2009). Methods and methodologies: Investigating gay men's body image in Westernized cultures. Critical Public Health, 19, 307-323.

Flax, J. (1990). Thinking fragments. Berkeley, CA: University of California Press.

Foucault, M. (1972). The archaeology of knowledge. New York, NY: Pantheon.

Foucault, M. (1977). Discipline and punish: The birth of the prison. New York, NY: Vintage.

Foucault, M. (1978). The history of sexuality: An introduction (Vol. 1). New York, NY: Vintage.

Foucault, M. (1980). Power/knowledge: Selected interviews and other writings 1972-7. London, UK: Harvester Wheatsheaf.

Foucault, M. (1982). The subject and power. Critical Inquiry, 8, 777-795.

Foucault, M. (1988). Technologies of the self. In L. H. Martin, H. Gutman, \& P. H. Hutton (Eds.), Technologies of the self: A seminar with Michel Foucault (pp. 16-49). Amherst, MA: University of Massachusetts Press.

Fox, D., Prilleltensky, I., \& Austin, S. (Eds.). (2009). Critical psychology: An introduction (2 ${ }^{\text {nd }}$ ed.). London, UK: Sage.

Frederickson, B. L., \& Roberts, T. (1997). Objectification theory: Toward understanding women's lived experiences and mental health risks. Psychology of Women Quarterly, 21, 173-206.

Freidman, M. (1962). Capitalism and freedom. Chicago, IL: University of Chicago Press.

French, S. A., Story, M., Remafedi, G., Resnick, M. D., \& Blum, R. W. (1996). Sexual 
orientation and prevalence of body dissatisfaction and eating disordered behaviours. International Journal of Eating Disorders, 19, 119-126.

Fuss, D. (1989). Essentially speaking: Feminism, Nature, and Difference. New York: Routledge.

Fuss, D. (Ed.). (1991). Inside/out: Lesbian theories, gay theories. New York, NY: Routledge. Gavey, N. (1989). Feminist poststructuralism and discourse analysis: Contributions to feminist psychology. Psychology of Women Quarterly, 13, 459-475.

Gettelman, T. E., \& Thompson, J. K. (1993). Actual differences and stereotypical perceptions in body image and eating disturbance: A comparison of male and female heterosexual and homosexual samples. Sex Roles, 29, 545-563.

Giddens, A. (1991). Modernity and self-identity: Self and society in the late modern age. Stanford, CA: Stanford University Press.

Gil, S. (2007). Body image, well-being and sexual satisfaction: A comparison between heterosexual and gay men. Sexual Relationship Therapy, 22, 237-244.

Gill, R. (2008a). Culture and subjectivity in neoliberal and postfeminist times. Subjectivity, 25, $432-445$.

Gill, R. (2008b). Empowerment/sexism: Figuring female sexual agency in contemporary advertising. Feminism and Psychology, 18, 35-60.

Gill. R. (2009). Mediated intimacy and postfeminism: A discourse analytic examination of sex and relationships advice in a women's magazine. Discourse and Communication, 3, 345369.

Gill, R., Henwood, K., \& McLean, C. (2005). Body projects and the regulation of normative masculinity. Body and Society, 11, 37-62. 
Glaser, B. G., \& Strauss, A. L. (1967). The discovery of grounded theory: Strategies for qualitative research. New York, NY: Aldine.

Glassner, B. (1989). Men and Muscles. In M. S. Kimmel \& M. A. Messner (Eds.), Men's lives (pp. 310-320). New York, NY: MacMillan.

Goffman, I. (1963). Stigma: Notes on the management of spoiled identity, Englewood Cliffs, NJ: Prentice-Hall.

Gough, B., \& Flanders, G. (2009). Celebrating "obese" bodies: Gay "bears" talk about weight, body image and health. International Journal of Men's Health, 8, 235-253.

Gramsci, A. (1971). Selections from Prison Notebooks. London, UK: Lawrence and Wishart.

Griffin, P. (2007). Sexing the economy in a neo-liberal world order: Neo-liberal discourse and the (re)production of heteronormative heterosexuality. British Journal of Politics and International Relations, 9, 220-238.

Grossman, A. H., \& D’Augelli, A. R. (2007). Transgender youth and life-threatening behaviors. Suicide and Life Threatening Behavior, 37, 527-537.

Guest, G., Bunce, A., \& Johnson, L. (2006). How many interviews are enough? An experiment with data saturation and variability. Field Methods, 18, 59-82.

Gurevich, M., Bailey, H., \& Bower, J. (2009). Querying theory and politics: The epistemic (dis)location of bisexuality within queer theory. Journal of Bisexuality, 9, 235-257.

Halberstam, J. (2005a). In a queer time and place: Transgender bodies, subcultural lives. New York, NY: New York University Press.

Halberstam, J. (2005b). Shame and white gay masculinity. Social Text, 84-85, 219-233.

Halley, J. E. (1993). The construction of heterosexuality. In M. Warner (Ed.), Fear of a queer planet: Queer politics and social theory (pp. 82-104). Minneapolis, MN: University of 
Minnesota Press.

Halperin, D. M. (1990). One hundred years of homosexuality. Chicago, IL: University of Chicago Press.

Halperin, D. M. (1995). Saint Foucault: Towards a gay hagiography. Oxford, UK: Oxford University Press.

Halperin, D. M. (2012). How to be gay. Cambridge, MA: The Belknap Press of Harvard University Press.

Harré, R., \& Gillett, G. (1994). The discursive mind. London, UK: Sage.

Harris, D. (1999). The rise and fall of gay culture. New York, NY: Ballantine.

Hennen, P. (2005). Bear bodies, bear masculinity: Recuperation, resistance, or retreat? Gender and Society, 19, 25-43.

Hausmann, A., Mangweth, B., Walch, T., Rupp, C. I., \& Pope, H. G. Jr. (2004). Body-image dissatisfaction in gay men versus heterosexual men: Is there really a difference? Journal of Clinical Psychiatry, 65, 1555-1558.

Hennen, P. (2005). Bear bodies, bear masculinity: Recuperation, resistance, or retreat? Gender and Society, 19, 25-43.

Hennen, P. (2008). Faeries, bears, and leathermen: Men in community queering the masculine. Chicago, IL: University of Chicago Press.

Henriques, J., Hollway, W., Urwin, C., Venn, C., \& Walkerdine, V. (1984). Changing the subject: Psychology, social regulation and subjectivity. London, UK: Methuen.

Herzog, D. N., Newman, K. L., \& Warsaw, M. (1991). Body image dissatisfaction in homosexual and heterosexual males. The Journal of Nervous and Mental Diseases, 179, 356-359. 
Herzog, D. B., Norman, D. K., Gordon, C., \& Pepose, M. (1984). Sexual conflict and eating disorders in 27 males. American Journal of Psychiatry, 141, 989-990.

hooks, b. (1990). Yearning. Boston, MA: South End Press.

Hospers, H. J., \& Jansen, A. (2005). Why homosexuality is a risk factor for eating disorders in males. Journal of Social and Clinical Psychology, 24, 1188-1201.

The Invisible Committee. (2009). The coming insurrection. New York, NY: Semiotexte.

Johnson, J. (2002). In-depth interviewing. In J. Gubrium \& J. Holstein (Eds.), Handbook of qualitative research (pp. 103-119). Thousand Oaks, CA: Sage.

Jowett, M., \& O’Toole, G. (2006). Focusing researchers' minds: Contrasting experiences of using focus groups in feminist qualitative research. Qualitative Research, 6, 453-472.

Kaminski, P. L., Chapman, B. P., Haynes, S. D., \& Own, L. (2005). Body image, eating behaviors, and attitudes toward exercise among gay and straight men. Eating Behaviors, $6,179-187$.

Kane, G. (2009). Unmasking the gay body ideal: A critical analysis of the dominant research on gay men's body image issues. Gay \& Lesbian Issues and Psychology Review, 5, 20-33.

Kane, G. (2010). Revisiting gay men's body image issues: Exposing the fault lines. Review of General Psychology, 5, 311-317.

Kassel, P. E., \& Franko, D. L. (2000). Body image disturbance and psychodynamic psychotherapy with gay men. Harvard Review of Psychiatry, 8, 307-317.

Kimmel, S. B., \& Mahalik, J. R. (2005). Body image concerns of gay men: The roles of minority stress and conformity to masculine norms. Journal of Consulting and Clinical Psychology, 73, 1185-1190.

King, T. A. (1994). "Performing akimbo": Queer pride and the epistemological prejudice. In M. 
Meyer (Ed.), The politics and poetics of camp (pp. 182-201). London, UK: Routledge.

Kinsey, A. C., Pomeroy, W. B., \& Martin, C. E. (1948). Sexual behavior in the human male. Philadelphia, PA: W. B. Saunders.

Kong, T. S-K. (2004). Queer at your own risk: Marginality, community, and Hong Kong gay male bodies. Sexualities, 7, 5-30.

LaBruce, B. (2012, June). Gays are like snowflakes. Vice. Retrieved from http://www.vice.com

Lakkis, J., Ricciardelli, L. A., \& Williams, R. J. (1999). Role of sexual orientation and genderrelated traits in disordered eating. Sex Roles, 41, 1-16.

Ledger, B. (2010, August 6). A little friendliness does not a gay neighbourhood make. The Toronto Star. Retrieved from http://www.thestar.com

Leit, R. A., Gray, J. J., \& Pope, H. G. (2001). Cultural expectations of muscularity in men: The evolution of Playgirl centerfolds. International Journal of Eating disorders, 29, 90-93.

LeVay, S. (2012). Gay, straight, and the reason why: The science of sexual orientation. Oxford, UK: Oxford University Press.

Levesque, M., \& Vichesky, D. (2005). Raising the bar on the body beautiful: An analysis of the body image concerns of homosexual men. Body Image, 3 (1), 45-55.

Levine, M. (1998). Gay macho: The life and death of the homosexual clone. New York, NY: New York University Press.

Lofstrom, J. (1997). The birth of the queer/the modern homosexual: Historical explanations revisited. Sociological Review, 45, 24-41.

Lovaas, K. E., \& Jenkins, M. M. (Eds.). (2007). Sexualities and communication in everyday life: A reader. Thousand Oaks, CA: Sage.

Malson, H. (1998). The thin woman: Feminism, post-structuralism and the social psychology of 
Anorexia Nervosa. London, UK: Routledge.

Manalansan, M. (1997). In the shadows of Stonewall: Examining gay transnational politics and the diasporic dilemma. In L. Lowe, \& D. Lloyd (Eds.), The politics of culture in the shadows of capital (pp. 485-504). New York, NY: New York University Press.

Manley, E., Levitt, H., \& Mosher, C. (2007). Understanding the bear movement in gay male culture: Redefining masculinity. Journal of Homosexuality, 53, 89-112.

Martin, E. (1995). Flexible bodies. Boston, MA: Beacon Press.

Martins , Y., Tiggemann, M., \& Krikbride, A. (2007). Those Speedos become them: The role of self-objectification in gay and heterosexual men's body image. Personality and Social Psychology Bulletin, 33, 634-647.

Menzel, J. E., \& Levine, M. P. (2011). Embodying experiences and the promotion of positive body image: The example of competitive athletics. In R. M. Calogero, S. Tantleff-Dunn, \& K. J. Thompson (Eds.), Self-objectification in women: Causes, consequences, and counteractions (pp. 163-186). Washington, DC: American Psychological Association.

Meyer, I. H. (1995). Minority stress and mental health in gay men. Journal of Health and social Behavior, 36, 38-56.

Miller, N. (1995). Out of the past: Gay and lesbian history from 1869 to the present. New York, NY: Vintage.

Morrison, T. G., \& McCutcheon, J. M. (2011). Gay and lesbian body images. In T. F. Cash \& L. Smolak (Eds.), Body image: A handbook of science, practice, and prevention ( $2^{\text {nd }}$ ed., pp. 214-220). New York, NY: Guilford.

Morrison, M., Morrison, T., \& Sager, C. (2004). Does body dissatisfaction differ between gay men and lesbian women and heterosexual men and women? A meta-analytic review. 
Body Image, 7, 127-138.

Nelson, J. A. (1993). The study of choice or the study of provisioning? Gender and the definition of economics. In M. A. Ferber \& J. A. Nelson (Eds.), Beyond economic man: Feminist theory and economics (pp. 23-36). Chicago, IL: University of Chicago Press.

Ohmae, K. (1995). The end of the nation state, the rise of regional economies: How new engines of prosperity are reshaping global markets. New York, NY: The Free Press.

Ohmae, K. (2002). The borderless world: Power and strategy in the global marketplace. London, UK: Profile Books.

Olivardia, R., Pope, H. G., \& Hudson, J. I. (2000). Muscle dysmorphia in male weight-lifters: A case-control study. American Journal of Psychiatry, 157, 1291-1296.

Olivardia, R., Pope, H. G., Mangweth, B., \& Hudson, J. I. (1995). Eating disorders in college men. American Journal of Psychiatry, 152, 1279-1285.

Padva, G. (2000). Priscilla flights back: The politicization of camp subculture. Journal of Communication Inquiry, 24, 216-243.

Padva, G. (2002). Heavenly monsters: The politics of the male body in the naked issue of Attitude magazine. International Journal of Sexuality and Gender studies, 7, 281-292.

Parker, I. (1999). Critical psychology: Critical links. Annual Review of Critical Psychology, 1, 118.

Patton, C. (1993). Tremble, hetero swine! In M. Warner (Ed.), Fear of a queer planet: Queer politics and social theory (pp. 143-177). Minneapolis, MN: University of Minnesota Press.

Plummer, K. (Ed.). (1992). Modern homosexualities: Fragments of lesbian and gay experience. London, UK: Routledge. 
Pope, H. G., Hudson, J. I., \& Jonas, J. M. (1986). Bulimia in men: A series of fifteen cases. The Journal of Nervous and Mental Disease, 174, 117-119.

Pope, H. G., Olivardia, R., Gruber, A., \& Borowiecki, J. (1999). Evolving ideals of male body image as seen through action toys. International Journal of Eating Disorders, 26, 65-72.

Pope, H. G., Phillips, K. A., \& Olivardia, R. (2000). The Adonis Complex: The secret crisis of male body obsession. New York: Free Press.

Potter, J., \& Wetherell, M. (1987).Discourse and social psychology. London, UK: Sage.

Potts, a. (2002). The science/fiction of sex: Feminist deconstruction and the vocabularies of the heterosex. New York, NY: Routledge.

Probyn, E. (1997). New traditionalism and post-feminism: TV does the home. In C. Brunsdon, J. D’Acci, \& L. Spigel (Eds.), Feminist television criticism: a reader (pp. 126-137). Oxford, UK: Blackwell.

Radley, A. (1998). Displays and fragments: Embodiment and the configuration of social worlds. In H. J. Stam (Ed.), The body and psychology (pp. 13-29). New York, NY: Sage.

Ricciardelli, R., Clow, K. A., \& White, P. (2010). Investigating hegemonic masculinity: Portrayals of masculinity in men's lifestyle magazines. Sex Roles, 63, 64-78.

Ridgeway, R. T., \& Tylka, T. L. (2005). College men's perceptions of ideal body composition and shape. Psychology of Men and Masculinity, 6, 209-220.

Rosenberg, M. (1979). Conceiving the self. New York, NY: Basic Books.

Russell, C. \& Keel, P. (2002). Homosexuality as a specific risk factor for eating disorders in men. International Journal of Eating Disorders, 31, 125-132.

Sampson, E. E. (1998). Establishing embodiment in psychology. In H. J. Stam (Ed.), The body and psychology (pp. 30-53). London, UK: Sage. 
Saussure, F. (1986). Course in general linguistics. Peru, IL: Open Court.

Schneider, J. A., \& Agras, W. S. (1987). Bulimia in males: A matched comparison with females. International Journal of Eating Disorders, 6, 253-242.

Schneider, J. A., O’Leary, A., \& Jenkins, S. R. (1995). Gender, sexual orientation, and disordered eating. Psychology and Health, 10, 113-128.

Sedgwick, E., K. (1990). Epistemology of the closet. Berkeley and Los Angeles: University of California Press.

Sedgwick, E. K. (1993). How to bring your kids up gay. In M. Warner (Ed.), Fear of a queer planet: Queer politics and social theory (pp. 69-81). Minneapolis, MN: University of Minnesota Press.

Segal, L. (1993). Changing men: Masculinities in context. Theory and society, 22, 625-641.

Seidman, S. (1993). Identity and politics in a "postmodern" gay culture: Some historical and conceptual notes. In M. Warner (Ed.), Fear of a queer planet: Queer politics and social theory (pp. 105-142). Minneapolis: University of Minnesota Press.

Sharpe, S. (2002). It's just really hard to come to terms with: Young people's views on homosexuality. Sex Education, 2, 263-277.

Shilling, C. (1993). The body and social theory. London, UK: Sage.

Shotter, J., \& Gergen, K. J. (Eds.). (1989). Texts of identity. London, UK: Sage.

Shuttleworth, R. P. (2000). The search for sexual intimacy for men with cerebral palsy. Sexuality and Disability, 18, 263-282.

Siever, M. D. (1994). Sexual orientation and gender as factors in socioculturally acquired vulnerability to body dissatisfaction and eating disorders. Journal of Consulting and Clinical Psychology, 62, 252-260. 
Signorile, M. (1997). Life outside: The Signorile report on gay Men: Sex, drugs, muscles, and the passages of life. New York, NY: Harper Collins.

Silberstein, L. R., Mishkind, M. E., Striegel-Moore, R. H., Timko, C., \& Rodin, J. (1989). Men and their bodies: A comparison of homosexual and heterosexual men. Psychosomatic Medicine, 51, 337-346.

Slife, B. D., Yanchar, S. C., \& Reber, J. S. (2005). Introduction: Thinking critically about critical thinking. In B. D. Slife, J. S. Reber, \& F. C. Richardson (Eds.), Critical thinking about psychology (pp. 3-14). Washington, DC: American Psychological Association.

Smith, A. (1776/2003). The wealth of nations. New York, NY: Bantam.

Smolak, L., Murnen, S. K., \& Thompson, J. K. (2005). Sociocultural influences and muscle building in adolescent boys. Psychology of Men and Masculinity, 6, 227-239.

Strauss, W., \& Matson, R. J. (2000). Millennials rising: The next great generation. New York, NY: Vintage.

Strong, S. M., Singh, D., \& Randall, P. K. (2000). Childhood gender nonconformity and body dissatisfaction in gay and heterosexual men. Sex Roles, 43, 427-439.

Strong, S. M., Williamson, D. A., Netemeyer, R. G., \& Geer, J. H. (2000). Eating disorder symptoms and concerns about body differ as a function of gender and sexual orientation. Journal of Social and Clinical Psychology, 19, 240-255.

Sullivan, A. (1996). Virtually normal: An argument about homosexuality. New York, NY: Vintage.

Terry, G., \& Braun, V. (2009). "When I was a bastard": Constructions of maturity in men's accounts of masculinity. Journal of Gender Studies, 18, 165-178.

Trumbach, R. (1977). London's sodomites: Homosexual behavior and Western culture in the $18^{\text {th }}$ century. Journal of Social History, 11, 1-33. 
Von Hayek, F. A. (1944). The road to serfdom. New York, NY: Routledge.

Warner, M. (Ed.). (1993). Fear of a queer planet: Queer politics and social theory. Minneapolis, MN: University of Minnesota Press.

Warner, M. (1999). The trouble with normal. Cambridge, MA: Harvard University Press.

Wearing, B. (1996). Gender: The pain and pleasure of difference. Melbourne, AU: Longman Australia.

Weedon, C. (1997). Feminist practice and poststructuralist theory ( ${ }^{\text {nd }}$ ed.). Oxford, UK: Blackwell. Weeks, J. (1985). Sexuality and its discontents: Meanings, myths and modern sexualities. New York, NY: Routledge.

Weeks, J. (1989). Sex, politics and society: The regulation of sexuality since $1800\left(2^{\text {nd }}\right.$ ed. $)$. London, UK: Longman.

Weeks, J. (1990). Coming out: Homosexual politics in Britain from the nineteenth century to the present $\left(2^{\text {nd }}\right.$ ed.). New York, NY: Quartet Books.

Westhaver, R. (2006). Flaunting and empowerment: Thinking about circuit parties, the body, and power. Journal of Contemporary Ethnography, 35, 611-644.

Wetherell, M. (1998). Positioning and interpretive repertoires: Conversation analysis and poststructuralism. Discourse and society, 9, 387-412.

Wetherell, M., \& Edley, N. (1999). Negotiating hegemonic masculinity: Imaginary positions and psycho-discursive practices. Feminism and Psychology, 9, 335-356.

Widdicombe, S. (1995). Identity, Politics and Talk: A case for the mundane and the everyday. In S. Wilkinson \& C. Kitzinger (Eds.), Feminism and Discourse: Psychological Perspectives (pp. 105-127). London, UK: Sage.

Williams, R. (1997). Marxism and literature. Oxford, UK: Oxford University Press. 
Williamson, I. (1999). Why are gay men a high risk group for eating disturbance? European Eating Disorders Review, 7, 1-4.

Williamson, I., \& Hartley, P. (1998). British research into the increased vulnerability of young gay men to eating disturbance and body dissatisfaction. European Eating Disorders Review, 6, 160-170.

Williamson I., \& Spence, K. (2001). Towards an understanding of risk factors for eating disturbance amongst gay men. Health Education, 101, 217-227.

Wood, M. J. (2004). The gay male gaze: Body image disturbance and gender oppression among gay men. Journal of Gay and Lesbian Social Services, 17, 43-62.

Wright, L. K. (1990). The sociology of the urban Bear. Drummer, 140, 53-55.

Yardley, L. (Ed.) (1997). Material discourses of health and illness. London, UK: Routledge.

Yager, J., Kurztman, F., Landsverk, J., \& Wiesmeier, E. (1988). Behaviors and attitudes related to eating disorders in homosexual male college students. American Journal of Psychiatry, $145,495-497$.

Yelland, C., \& Tiggemann, M. (2003). Muscularity and the gay ideal: Body dissatisfaction and disordered eating in homosexual men. Eating Behaviours, 4, 107-116. 


\section{Footnotes}

${ }^{1}$ The notion of a body "ideal" is problematic: many individuals' descriptions of aspirational bodies are "often idiosyncratic and resistant to straightforward dichotomising" (Kane, 2009, p. 30). Ridgeway and Tylka (2005), for instance, warned against generalizing “men's body image by conceptualizing it as one ideal characteristic or type" (p. 219) as that silences individual differences.

${ }^{2} \mathrm{~A}$ gym bunny is a pejorative term of a gay man who spends a lot of his time at the gym. It is viewed negatively, because it suggests that he works out for aesthetic and not health reasons, and that he is vain and body-obsessed.

${ }^{3}$ Bear is a slang term for gay men who are commonly, but not always, overweight and often have hairy bodies and facial hair. Some are also muscular and some project an image of rugged masculinity in their grooming and appearance.

${ }^{4}$ In keeping with this thesis' theoretical and epistemological framework, the deliberate focus on the participants' self-identifications was intended to obviate an authoritative conceptualization of gendered and sexed categories by literally permitting the participants to tell their own stories, drawing on socially accepted (and unconventional) forms of justification to present themselves in a particular manner, which is different from taking the participants' accounts at face value.

${ }^{5}$ Cisgender as a label for individuals who have a match between the gender they were assigned at birth, their bodies, and their personal identity. Cisnormativity means living in a world in which cisgenderism is the norm.

${ }^{6}$ Separate posters, especially for queer men, were deemed important to increasing the likelihood of recruiting queer men/genderqueers. 
${ }^{7}$ Some authors who exemplify this orthodoxy but are not mentioned else in this thesis include, Andersen (1999); French, story, Remafedi, Resnick, and Blum (1996); Gellelman and Thompson (1993); Herzog, Newman, and Warsaw (1991); Russell and Keel (2002); Williamson, Netemeyer, and Greer (2000)' and Yager, Kurtzman, Landsverk, and Wiesmeier (1988).

${ }^{8}$ A gay clone - or, "Castro clone" - is slang for a gay man who appeared (or, appears) in dress and style as an idealized working-classman. The term and image grew out of the heavily gay-populated Castro neighborhood in San Francisco during the late 1970s, when Gay Liberation, sparked by the 1969 Stonewall riots in New York City and the Summer of Love, gave rise to an urban community

${ }^{9}$ Twink is a slang term describing a young or young-looking gay man (16-25 age category) with a slender, ectomorph build, little or no body hair, and no facial hair.

${ }^{10}$ Montreal's Gay Village is located on Saint Catherine Street East.

${ }^{11}$ Wigger is a pejorative slang term for a White person who emulates mannerisms, language, and fashions associated with African-American culture, particularly hip-hop in the United States or the Grime/Garage scene in Britain. The term is a portmanteau of either "wannabe" or "white" and "nigger."

${ }^{12}$ Grindr is a geosocial networking application geared towards gay, bisexual, and bicurious men. It runs on iOS, blackberry OS and Android devices.

${ }^{13}$ Radical faeries are a loosely affiliated, worldwide network and countercultural movement seeking to reject hetero-imitation and redefine queer identity through spirituality. Faeries tend to be fiercely independent, anti-establishment, and community-focused. They embody a wide range of genders, sexual orientations, and identities. 
${ }^{14}$ Genderfuck refers to the conscious effort to mock or "fuck with" traditional notions of gender identity, gender roles, and gender presentation.

${ }^{15}$ Neo-liberalism is an economic policy most commonly found in the Canada, the United States, the United Kingdom, northern Europe, and Australasia. Neo-liberalism developed from the ideas, values, and categories known as Liberalism, which began to cohere into a political theory for capitalist economies in the $17^{\text {th }}$ century. Liberal theorists "provided a set of metaphors, an originating narrative, and a moral apologia for capitalism. They also provided a cartography of the 'proper' regulation of the relations among the state, the economy, and the population" (Duggan, 2003, p. 4). Through master terms (e.g., public versus private) and other rhetorical categories (e.g., the state, the economy, civil society, the family), they presented a totalizing vision of society organized around a particular notion of economic action whereby individual choices ostensibly lead to hypothetical exchanges (Nelson, 1993): they were suspicious of statecontrolled "central planning" and maintained an unwavering belief that an economically "free" system of competition is the only guarantor of individual choice (von Hayek, 1936, 1944, 1945); and they were keen advocates for a capitalist competitive market as the only means to diffuse political power and preserve individual freedom (Freidman, 1962, 1991). Over the centuries, terms like "liberal" and "conservative" merely outlined constantly shifting positions within the overall umbrella of Liberal capitalism. Today's neo-liberalism preserves the key conceits of Liberalism and is a convergence of the new liberal centrism of the 1990s with the conservatism of the 1980s, "advocating learner, meaner government (fewer social services, more 'law and order'), a state-supported but 'privatized' economy, an invigorated and social responsible civil society, and a moralized family with gendered marriage at its center" (Duggan, 2003, p. 10). 
${ }^{16}$ During the $1980 \mathrm{~s}$, standards of living dropped in the Western world and global inequalities expanded; social movements, like Gay Liberation, responded to multiple constraints and pressures "by accommodating to the narrowing horizons of fundraising imperatives, legal constraints, and the vice grip of electoral politics” (Duggan, 2003, p. xviii). Suddenly, singleinterest or single-issue organizations (i.e., civil rights lobbies) developed and multiplied, dedicated to lobbying, litigation, legislation, or public and media education, as parts that replaced the whole. For instance, in the United States, the reproductive freedom movement fragmented, supplanted by the abortion Right Action League; the Civil Rights and Black Power movements and Gay Liberation receded, but not the National Association for the Advancement of Colored People or the Human Rights Campaign. Social movements succumbed to what Duggan (2003) called "liberalism's paltry promise" (p. xviii): they engage in the language and institutional games of established neo-liberal discourse in order to achieve equality, an equality “disarticulated from material life and class politics, to be won by definable 'minority' groups, one at a time" (p. xviii), where "diversity" and "tolerance" are defined in the narrowest terms and entirely within the framework of neo-liberal privatization and personal responsibility.

With regards to homosexuality, early- and mid $-20^{\text {th }}$ century homophile organizations fought to ensure both full access to public life and the publicization of gayhood and full access to privacy (i.e., freedom from state-imposed criminalization and stigma; D’Emilio, 1983). By the 1980s, anti-gay forces began to slowly, unevenly concede the right to privacy, but "attacked gay rhetorical claims for privacy-in-public and for publicizing the private, specifically, and worked to define the private sphere as an isolated, domestic site completely out of range of any public venture" (Duggan, 2003, p. 53). Throughout the 1990s, radical and progressive AIDS activism (i.e., the 1980s analogue to the earlier homophile movement) ebbed as neo-liberal organizations, 
policies, and politicians rose to unprecedented power (Duggan \& Hunter, 1995), inculcating gay moralism.

${ }^{17}$ Gay marriage is often presented to "conservatives" - especially by those seeking its legislative legalization - as a morally conservative institution that encourages "commitment" and "family values" (thus, reforming the promiscuous homosexual). This is the argument favoured by the Prime Minister of the United Kingdom and Leader of the Conservative Party, David Cameron, who does not support gay marriage in spite of being a conservative, but because he is a conservative (Cassidy, 2012). In fact, The Associated Press (2012) noted that recent pro-gay marriage advocacy campaigns in Maine, Maryland, Minnesota, and Washington do not even feature gay persons.

${ }^{18}$ This point that can be readily confirmed with a quick perusal through any of the internet's most popular gay-interest websites - Towleroad, Queerty, Huffington Post: Gay Voices (whose editor-at-large is the gay male body image researcher's favourite, Michelangelo Signorile) - all of which reserve substantial editorial space for Marriage Equality.

${ }^{19}$ Coincidentally, around the time the name for this interpretive repertoire was chosen, NBC placed a series order for a half hour comedy program, titled The New Normal, about a wealthy, White, monogamous gay male couple seeking a surrogate mother to complete their "modern family."

${ }^{20}$ Indeed, moral effeminacy - in particular, the effeminate homosexual - has historically played a useful role in the development of capitalist economies and, by extension, neo-liberalism (Hennen, 2008). Throughout the $19^{\text {th }}$ century, the development of a puritanical, bourgeois consciousness "required that the unwholesome figure of the effeminate homosexual as reviled and stigmatized be kept close at hand" (p. 56): as a "soft" man, given to immoderation or self- 
indulgence, he represented an ever-present threat to the demands of an expanding capitalist system. His lack of productivity and competitiveness, along with the presumptions about his excessive asexual desires, imperilled the idealization of economic pursuits and "the enthronement of self-restraint as a paramount social and sexual virtue" (p. 56). The conflation of sexual and economic values spurred "revulsion toward all forms of pleasure-seeking sexuality, including spending one's semen on 'unproductive' purposes, as in homosexuality" (Lofstrom, 1997, p. 36).

${ }^{21}$ They conveyed either ambivalence - "Um, I would say mixed thoughts about my body, I have comfort in some aspects, but I'm still very aware and conscious of it" (Bruce, 28, gay) or contentment or satisfaction - "I find my body sexy, I'm turned on by my own body, not in a narcissistic way, but I'm very satisfied with how it looks sexually as well as aesthetically" (Bennett, 30, gay/queer). 
Table 1

Socio-Demographic Characteristics

\begin{tabular}{|c|c|c|}
\hline \multirow[t]{2}{*}{ Characteristic } & \multicolumn{2}{|c|}{$\begin{array}{l}\text { Participants } \\
\quad(N=19)\end{array}$} \\
\hline & $M$ & $S D$ \\
\hline$(R=19-32)$ & 26.37 & 3.79 \\
\hline Self-identified gender & $n$ & $(\%)$ \\
\hline Male & 18 & $(94.7)$ \\
\hline Genderqueer & 1 & $(5.3)$ \\
\hline \multicolumn{3}{|l|}{ Self-identified sexual identity } \\
\hline Bisexual & 1 & $(5.3)$ \\
\hline Bisexual/gay & 1 & $(5.3)$ \\
\hline Gay & 9 & $(47.4)$ \\
\hline Gay/queer & 4 & $(21.1)$ \\
\hline Queer & 4 & $(21.1)$ \\
\hline \multicolumn{3}{|c|}{ Self-identified ethno-cultural background } \\
\hline Canadian & 6 & $(31.6)$ \\
\hline Chinese & 1 & $(5.3)$ \\
\hline Italian & 1 & $(5.3)$ \\
\hline Scottish & 1 & $(5.3)$ \\
\hline Turkish & 1 & $(5.3)$ \\
\hline Western European & 1 & $(5.3)$ \\
\hline German-American & 1 & $(5.3)$ \\
\hline Goan-Portuguese & 1 & $(5.3)$ \\
\hline Polish-Danish-Canadian & 1 & $(5.3)$ \\
\hline Scottish-Canadian & 1 & $(5.3)$ \\
\hline Sicilian-Canadian & 1 & $(5.3)$ \\
\hline New Zealander-Irish-French & 1 & $(5.3)$ \\
\hline English-Scottish-Irish-Canadian & 1 & $(5.3)$ \\
\hline Scottish-British-Irish-Italian & 1 & $(5.3)$ \\
\hline \multicolumn{3}{|l|}{ Country of origin } \\
\hline Canada & 14 & $(73.7)$ \\
\hline Hong Kong & 1 & $(5.3)$ \\
\hline Kuwait & 1 & $(5.3)$ \\
\hline New Zealand & 1 & $(5.3)$ \\
\hline Turkey & 1 & $(5.3)$ \\
\hline United States of America & 1 & $(5.3)$ \\
\hline \multicolumn{3}{|l|}{ Self-identified religious affiliation } \\
\hline Agnostic & 1 & $(5.3)$ \\
\hline Anglican & 2 & $(10.5)$ \\
\hline None & 12 & $(63.2)$ \\
\hline Protestant & 1 & $(5.3)$ \\
\hline Spiritual & 3 & (15.8) \\
\hline
\end{tabular}


Education level completed

High school

Some post-secondary

Bachelor's degree

Master's degree

Some doctoral training

(21.1)

(42.1)

(21.1)

(10.5)

Employment

Full-time

Full-time/student

Part-time

Part-time/student

Unemployed

Student

Student/disability

4

2

$(15.8)$

$(15.8)$

(26.3)

$(21.1)$

Self-identified relationship status

Partnered

3

Partnered (monogamous)

Partnered (polyamorous)

Partnered (polyamorous, long-distance)

$(15.8)$

Single

$(10.5)$

$(52.6)$ 
Appendix A

\section{RYERSONUNIVERSITY}

Department of Psychology

\section{Youth and Sexuality Study: Telephone Recruitment Script}

Investigator:

Hello, my name is Alex Vasilovsky and I am a Master's Student in Clinical Psychology at Ryerson University. I am currently recruiting participants for my Master's thesis, which is about body image and sexual identity. Specifically, the purpose of my research is to examine how young gay and queer men feel about their sexual identity and their body image and how these ideas developed in the context of cultural messages.

I received an email from you indicating that you are interested in participating. Before we can schedule an interview, I need to know whether you are eligible to participate in this study.

Do you self-identify in terms of your gender?

Male

\section{Genderqueer}

Other:

Neither

Do you self-identify in terms of your sexuality?

_ Gay

Queer

Other:

Neither

How old are you?

Age:

Do you speak English fluently?

Yes

No 
If prospective participant does not meet inclusion criteria:

Unfortunately, you do not meet the inclusion criteria for this study. I am recruiting men, between the ages of 18 and 30, who self-identify as gay or queer, and speak English fluently. Thank-you very much for your time and interest in this study.

If prospective participant does meet inclusion criteria:

You meet inclusion the inclusion criteria for this study. Now, I would like to provide you with a fuller description of this study. If you decide to participate in this research, you will be asked to read and sign a consent form and complete a one-on-one interview. During the interview, questions about sexual identity and body image will be asked. In order to capture the accuracy of your responses, the interview will be digitally recorded with your permission and I will take some written notes. The interview will last about one-and-a-half to two hours and will take place on the Ryerson campus at the Gender, Sexuality, and Critical Psychology Laboratory, 105 Bond Street.

Your responses in the interviews will be completely confidential. Your name or any other identifying information will not appear on any of the transcribed audiotaped material, written notes or presented findings. You will be given a random, pre-assigned ID number. Recorded responses will be transcribed and these, along with written notes, will be stored separately from the consent forms. All data will be stored in a locked filling cabinet and only I will have access to the data.

To thank you for your participation, your name will be entered into a draw to be eligible to win one of two cash prizes of $\$ \mathbf{1 0 0}$. The draw will take place once all the interviews are completed and the winners will be notified by telephone. You will then be informed about where and when you can receive the prize. If you decide to withdraw from the study at any point or omit some of the questions, you will not lose your eligibility for the draw.

Due to the personal nature of some of the questions asked, you may experience some embarrassment or reflect on unpleasant memories while participating in the interview. If you begin to feel uncomfortable, you can always discontinue participation, or skip any particular questions without incurring a penalty, or losing your eligibility to participate in the cash draw. I will also have a list of counselling referrals, just in case you find you need them.

Given all this information, do you have any questions?

If applicable, answer prospective participant's questions.

Let's schedule a time that is convenient for you to be interviewed for this study.

Schedule interview with prospective participant. Confirm time, date, location, length of interview (oneand-a-half to two hours).

Thank-you for your time. I look forward to meeting you on [date, time, location]. 
Appendix B

RYERSONUNIVERSITY

Department of Psychology

\section{Sexuality and Body Image Study}

You are being asked to participate in a research study. Before you give your consent to be a volunteer, it is important that you read the following information and ask as many questions as necessary to be sure you understand what you will be asked to do.

Investigator: Alex Vasilovsky, H.B.Sc., Department of Psychology, Ryerson University

Supervisor: Maria Gurevich, Ph.D., Department of Psychology, Ryerson University

Purpose of the Study: The purpose of this research is to examine how young gay and queer men feel about their sexual identity and their body image. This project explores the ways in which these ideas develop in the context of available cultural messages. Approximately 20 individuals will agree to participate. If you are a male or genderqueer, between the ages of 18 and 30, self-identify as gay or queer, and speak English fluently, you are eligible to participate.

Description of the Study: If you decide to participate in this research, you will be asked to do the following: complete a one-on-one interview. Questions about sexual identity and body image will be asked. In order to capture the accuracy of your responses, the interview will be audiotaped with your permission (see agreement for audiotaping below), and the interviewer will take some written notes. The interview will last about one and a half to two hours, and will take place on the Ryerson campus (Gender, Sexuality, and Critical Psychology Laboratory - 105 Bond Street).

What is Experimental in this Study: None of the interview questions used in this study are experimental in nature. The only experimental aspect of this study is the gathering of information for the purpose of analysis.

Risks or Discomforts: Due to the personal nature of some of the questions asked, you may experience some embarrassment or reflect on unpleasant memories while participating in the interview. If you begin to feel uncomfortable, you can always discontinue participation, or skip any particular questions without incurring a penalty, or losing your eligibility to participate in the cash draw - you do not need to provide a reason for discontinuing your participation. If you would like to speak to someone about this discomfort, the researcher will provide you with several counselling referrals.

Benefits of the Study: Although we cannot guarantee that you will receive any personal benefits from participating in this study, we anticipate that you may learn more about your own sexual identity and body image. Once we have analyzed the data, you are welcome to view the overall group findings and ask further questions. This research is an important contribution to the study of gay and queer male sexuality and body image.

Confidentiality: Your responses in the interviews will be completely confidential; your name or 
any other identifying information will not appear on any of the transcribed audiotaped material, written notes or presented findings. You will be given a pre-assigned ID number, which will allow us to keep track of your responses without revealing your name or any other identifying information. ID numbers will be randomly selected and assigned prior to your interview. Once your responses are transcribed, they will only be identified by your ID number. In publications and conference presentations, some direct quotes from you may be used for accuracy but these will never be associated with any identifying information, as indicated above. All data will be stored in a locked filling cabinet. Audiotaped responses will be transcribed and these, along with written notes, will be stored separately from the consent forms. All raw data (including transcripts, written notes and audiotapes) will be destroyed within five (5) years of completion of the study. Only the Investigator will have access to the data.

Incentives to Participate: To thank you for your participation, your name will be entered into a draw to be eligible to win one of two cash prizes of $\$ 100$. The draw will take place once all the interviews are completed and the winners will be notified by telephone. You will then be informed about where and when you can receive the prize. If you decide to withdraw from the study at any point or omit some of the questions, you will not lose your eligibility for the draw.

Costs and/or Compensation for Participation: There are no costs associated with participation.

Voluntary Nature of Participation: Participation in this study is voluntary. Your choice of whether or not to participate will not influence your future relations with Ryerson University. If you decide to participate, you are free to withdraw your consent and to stop your participation at any time without penalty or loss of the draw benefits to which you are entitled.

At any particular point in the study, you may refuse to answer any particular question or stop participation altogether.

Questions about the Study: If you have any questions about the research now, please ask. If you have questions later about the research, you may contact:

Alex Vasilovsky

$416-979-5000 \times 2191$

If you have questions regarding your rights as a human subject and participant in this study, you may contact the Ryerson University Research Ethics Board for information.

Research Ethics Board

Office of the Vice President,

Research and Innovation

Ryerson University, 350 Victoria Street

Room YDI 1154 Toronto, Ontario, M5B 2K3

Phone: (416) 979-5000 Ext. 7112

Fax: (416) 979-5336 


\section{Agreement to Participate:}

Your signature below indicates that you have read the information in this agreement and have had a chance to ask any questions you have about the study. Your signature also indicates that you agree to be in the study and have been told that you can change your mind and withdraw your consent to participate at any time, without incurring a penalty or losing your eligibility for the cash draw. You have been given a copy of this agreement.

You have been told that by signing this consent agreement you are not giving up any of your legal rights.

Name of Participant (please print)

Signature of Participant

Date

Signature of Investigator

Date

\section{Agreement for Audiotaping:}

Your signature below indicates that you have agreed to have the interview audio-taped. If you become uncomfortable with the audiotaping at any point, the researcher will turn the taperecorder off and you will not incur a penalty or losing your eligibility for the cash draw.

Name of Participant (please print)

Signature of Participant

Date 
PLEASE PROVIDE YOUR NAME AND TELEPHONE NUMBER BELOW

FOR THE CASH PRIZE DRAW (KEPT SEPARATELY FROM THE CONSENT FORM).

NAME:

TELEPHONE: 


\title{
Appendix C
}

\author{
The Interview Schedule
}

1. Demographics

○ What is your gender?

- How old are you?

- Do you have brothers or sisters? (Number, age, gender)

- What are you living arrangements?

- What was the first language you spoke? (Now speak? When learned English?)

- What is your cultural background?

- Are you religious? (Type?)

- What is your highest level of education?

- How would you describe your employment?

- Are you in a relationship? How would you describe it? (Long-term? Committed?)

- Where you born in Canada? (If not, where were you born and how long have you lived in Canada?)

- Have you lived outside of Canada at any point? (If so, where and for how long?)

2. The body

○ What does the word "body" mean to you? What thoughts, emotions, images, or ideas come to mind?

- Try thinking about your body: What thoughts, emotions, images, or ideas come to mind?

- How does this line up with the body you see in the mirror or touch with your hands?

- When are you aware of your body? When are you not aware of your body? (When do you think about your body?)

- Describe situations (including thoughts and moods)

- How do you feel about your body? What do you like or dislike about your body?

- Do you think about it in terms of "satisfaction" or "dissatisfaction"?

- If so: Are you satisfied? Dissatisfied?

- In either case: Are there specific areas of your body you like more?

- In either case: When do you feel that way about your body?

- Generally, are you concerned about the appearance of your body?

- How much emphasis do you place on appearance?

- When you think about your body, how much are you focused on your physical body (vs. clothes, hairstyle, mannerisms, gait, etc.)?

- Where do your feelings about your body come from? (Friends, media [gay vs. straight], Western culture, etc.)

\section{Remember to ask for specifics (If media, what media? If porn, what porn? If Internet,} what websites?)

3. Identity

○ How would you describe your sexual identity? 
- What does this mean to you?

- How did your sexual identity develop?

- Is your description accurate in all situations/contexts?

- When are you most aware of your sexual identity?

- How is your sexual identity manifested? (Clothing, attitude, behaviour, physicality?)

- What does a "gay identity" mean to you?

- Are there different types of gay identities?

- How are these other identities manifested? (Clothing, attitude, behaviour, physicality?)

- What does the term "queer" mean to you?

- Do you think about this word in a positive or negative manner?

- Do you or have you ever self-identified as queer? If so, what does/did this identification mean for you?

- How would you describe the "gay community"?

- Would you describe yourself as a member of a gay community?

- Do you think of the gay community as unified or as consisting of different sub-groups?

- Do you think a gay body ideal exists?

- If so, what is it? What does it entail?

- Do you think this is (or is not) problematic?

- Do you think it is possible that more than one body ideal exists?

- If so, do hierarchies exist?

- Where do you think these ideas come from?

- Within or without gay culture?

\section{Remember to ask for specifics (If media, what media? If porn, what porn? If Internet,} what websites?)

\section{Embodied identity}

- What does it mean to you to express your sexual identity?

- How comfortable are you doing that?

- What makes that possible? What makes that difficult?

- How does your body fit into how you think about yourself?

- How did that come to be?

- How has that changed over time?

- In what ways do you think your body plays a part in your sexual identity?

- Has it played a role in developing any other aspects of your identity?

- If not your body, your clothing, attitude, behaviour, physicality?

- Do you think that you live in a culture that is heterosexist? (Provide definition if needed [Heterosexism is a system of attitudes, bias, and discrimination in favour of opposite-sex sexuality and relationships])

- In what ways is your sexual identity shaped by heterosexual culture?

- In what ways is your sexual identity shaped by gay and/or queer culture?

- Do you think that you live in a culture that believes there is a proper way to be a "real" man?

- What is the social/cultural ideal of what a man should look like? 
- What does that entail? (Clothing, attitude, behaviour, physicality?)

- Do you think that gay men can fulfill these requirements?

- What does masculinity mean to you?

- Do you think it is possible to have more than one type of masculinity?

- What does a gay masculinity mean to you?

- Have you heard of "straight-acting"? Can you elaborate? How is this the same or different than a "gay masculinity"?

- Do you think society's model of masculinity is too restrictive?

- Do you think society's model of masculinity is heterosexually based?

- What does a muscular male portray?

- What do muscles mean to you?

- What does a muscular gay man portray?

- What does a non-muscular gay man portray (e.g., fat, thin, etc)?

5. Oppression and resistance

- From the previous question: Where do these ideas [what muscles portray, what thinness portrays] come from?

- What effect do they have?

- Do you think gay men with muscles are trying to be more masculine?

- Do you think gay men with muscles are some how influenced by dominant ideals of male beauty and/or masculinity?

- Do you think there are ways in which these men resist dominant ideals of male beauty and/or masculinity?

- Are there situations in which either case might be true?

- Do you think there are certain gay identities that actively resist dominant ideals of male beauty and/or masculinity?

- Who are these people?

- How can they be identified?

- How is this "resistance" displayed? (Through their [bodily practices]?)

- Do you think these acts of resistance are successful?

- Do you think that there are other ways of think about the body instead of just muscles or not, thin or not [hairless of not, Caucasian or not, etc.]?

6. Wrap-up

- Do you think there is anything else I should know about your experiences of sexuality, gender, and your body?

- Is there anything else you want to add that was not discussed today? 